Aus der Abteilung Transfusionsmedizin

(PD Dr. med. J. Riggert)

der Medizinischen Fakultät der Universität Göttingen

\title{
NIEDERMOLEKULARES UND UNFRAKTIONIERTES \\ HEPARIN ALS THERAPEUTIKA DER AKUTEN \\ GRAFT-VERSUS-HOST DISEASE IM MAUSMODELL
}

\author{
INAUGURAL-DISSERTATION \\ zur Erlangung des Doktorgrades \\ der Medizinischen Fakultät der \\ Georg-August-Universität zu Göttingen
}

vorgelegt von

Lena Thieringer

aus

Tübingen

Göttingen 2021 
Dekan:

Referent/in:

Ko-Referent/in:

Drittreferent/in:
Prof. Dr. W. Brück

Prof. Dr. T. J. Legler

Prof. Dr. R. Dressel

Prof. Dr. T. Meyer

Datum der mündlichen Prüfung: 25. November 2021 
Hiermit erkläre ich, die Dissertation mit dem Titel "Niedermolekulares und unfraktioniertes Heparin als Therapeutika der akuten Graft-versus-Host Disease im Mausmodell" eigenständig angefertigt und keine anderen als die von mir angegebenen Quellen und Hilfsmittel verwendet zu haben.

Hannover, den 10.05.2021

(Unterschrift) 
Die Daten, auf denen die vorliegende Arbeit basiert, wurden teilweise publiziert:

Budde H, Thieringer L, Riggert J, Legler TJ (2015): Anti-Inflammatory Effects of Heparin: Do they Influence Murine Acute GvHD? Jacobs J Hemato 2, 023 


\section{Inhaltsverzeichnis}

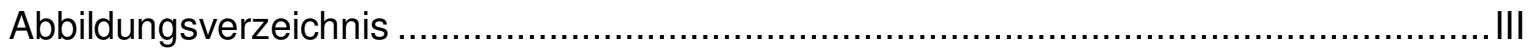

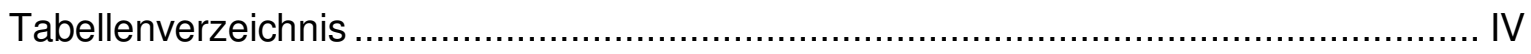

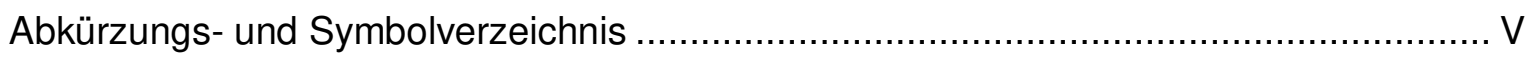

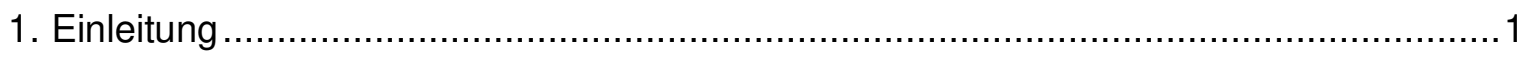

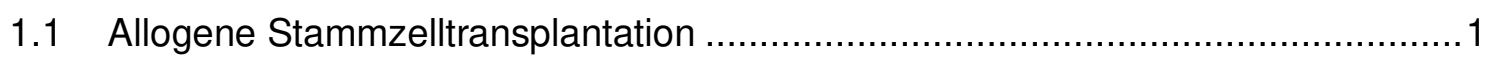

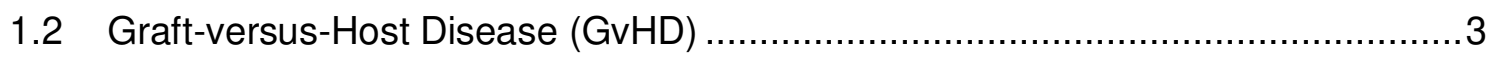

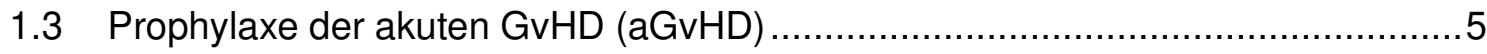

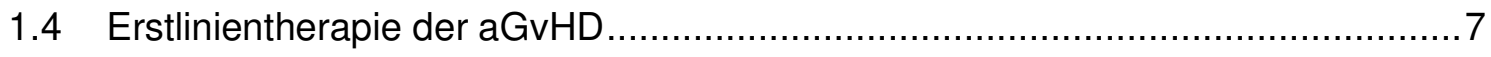

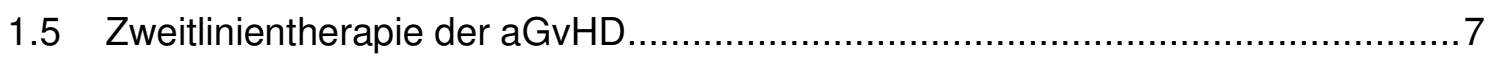

1.6 Graft-versus-Host Disease im Mausmodell .................................................. 8

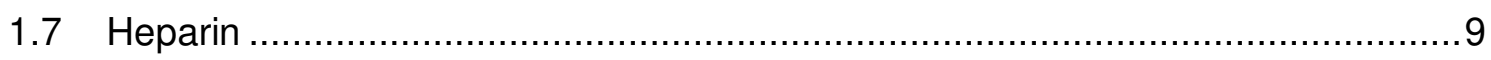

1.8 Niedermolekulares und unfraktioniertes Heparin (NMH und UFH) ..................10

1.9 Antiinflammatorischer Effekt des Heparins ...................................................11

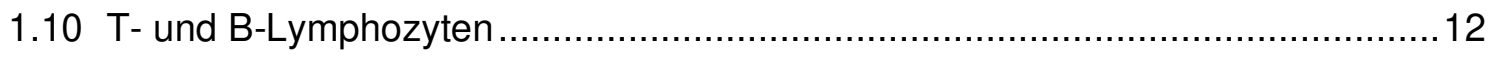

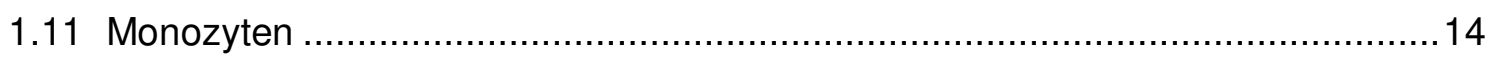

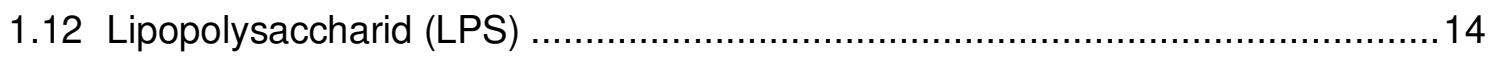

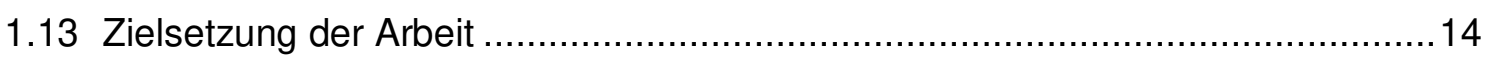

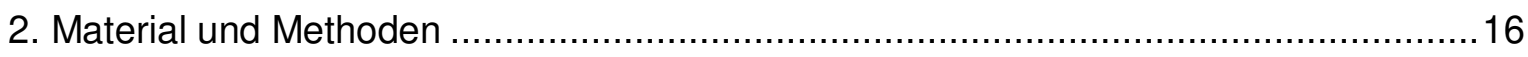

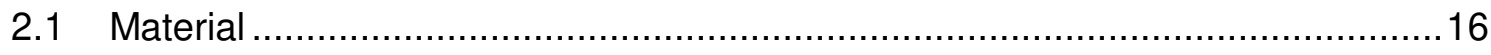

2.1.1 Chemikalien, Medien und Puffer ............................................................16

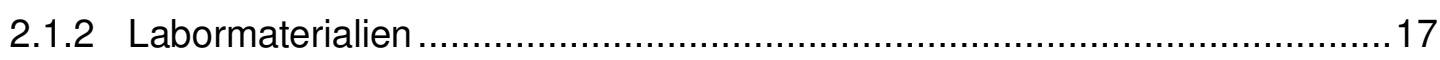

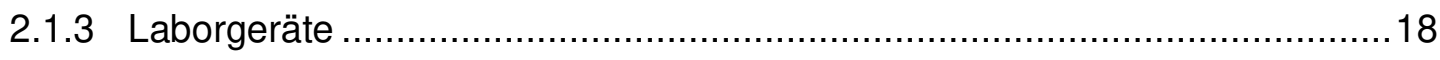

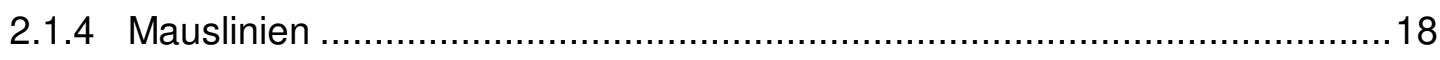

2.1.5 Primärantikörper Anti-Maus ............................................................... 19

2.1.6 Primärantikörper Anti-Human............................................................ 19

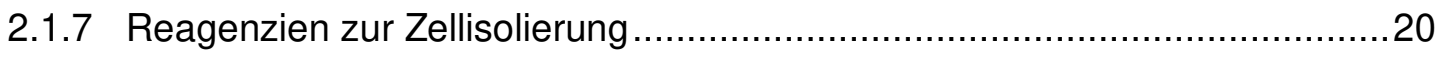

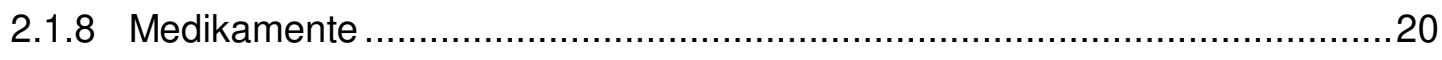

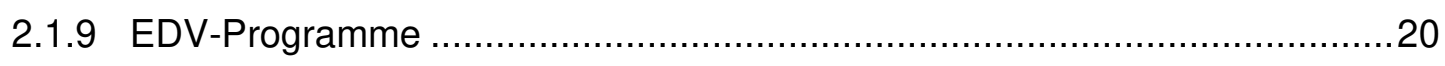

2.1.10 Herstellung gebrauchsfertiger Medien und Lösungen ..............................21

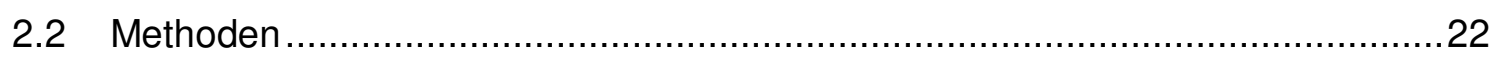

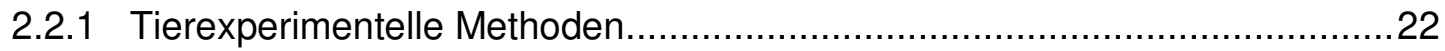

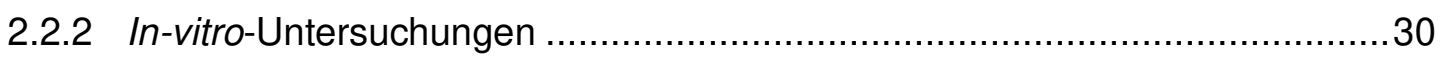

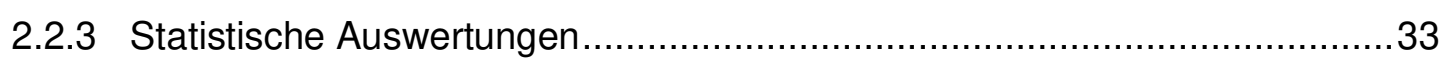




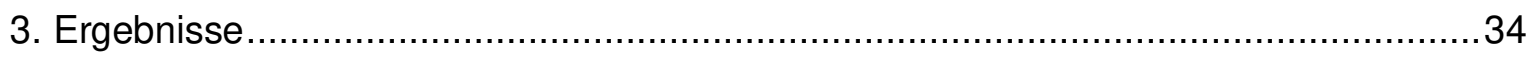

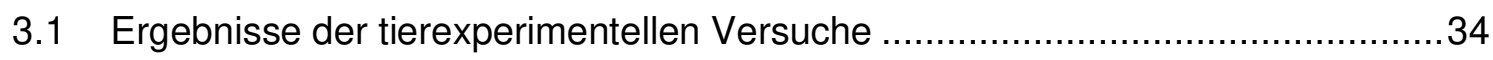

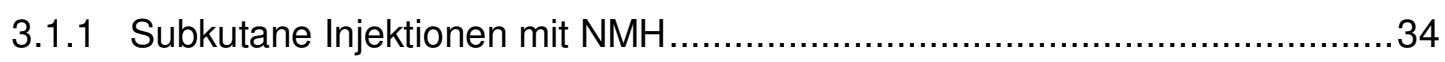

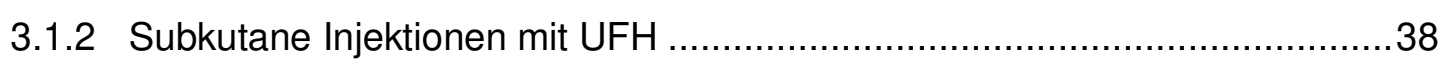

3.1.3 Intravenöse Injektionen mit NMH und UFH ......................................... 42

3.1.4 Tägliche subkutane Injektion mit UFH ............................................... 45

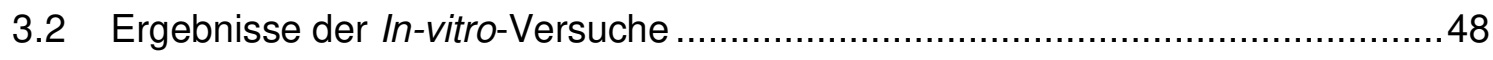

3.2.1 Proliferationsverhalten humaner Leukozyten nach Zugabe von NMH .........49

3.2.2 Proliferationsverhalten humaner Leukozyten nach Zugabe von UFH...........51

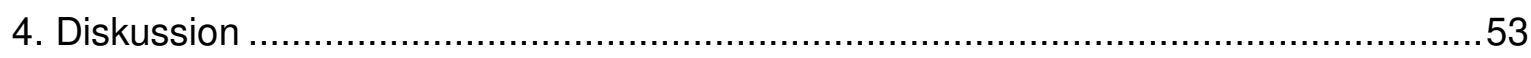

4.1 Vergleich von NMH und UFH als Therapeutika der aGvHD im Mausmodell .......54

4.2 Auswirkungen der s.c. und i.v. Applikation auf den Krankheitsverlauf der aGvHD

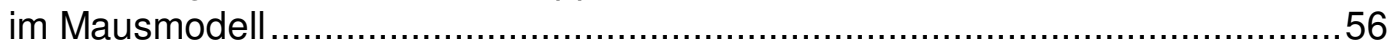

4.3 Einfluss der unterschiedlichen Dosen auf den Krankheitsverlauf der aGvHD im

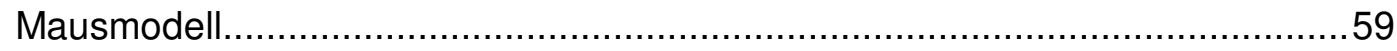

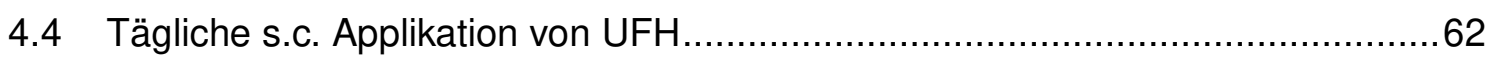

4.5 Beeinflussung der T-Zellpopulation durch Heparin .......................................64

4.6 Beeinflussung des Proliferationsverhaltens humaner Leukozyten durch $\mathrm{NMH}$ und

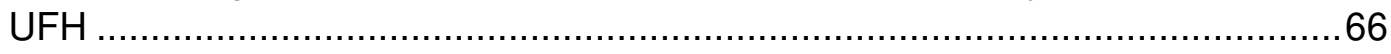

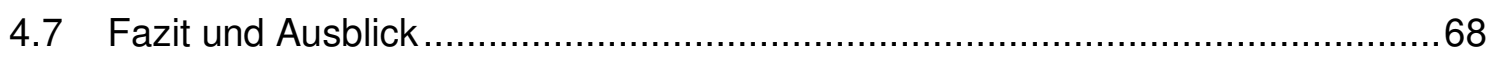

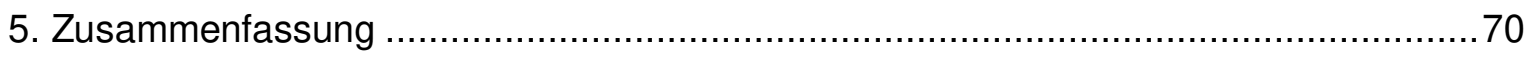

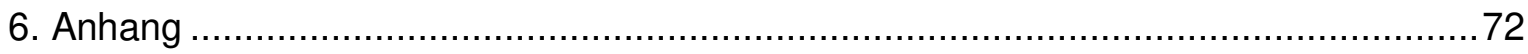

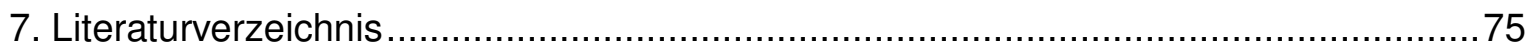




\section{Abbildungsverzeichnis}

Abbildung 1: Verlauf der aGvHD im Mausmodell...............................................

Abbildung 2: Zeitskala der s.c. Injektionen................................................... 28

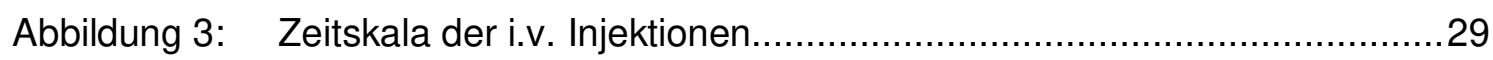

Abbildung 4: Röhrchen mit Buffy-Lösung und Ficoll Paque Plus ${ }^{\mathrm{TM}}$ vor und nach

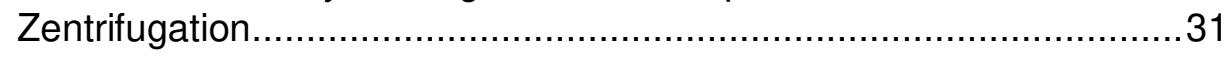

Abbildung 5: Einfluss der s.c. Injektion von NMH auf die murine aGvHD................35

Abbildung 6: Durchflusszytometrische Analyse der $\mathrm{CD}^{+}, \mathrm{CD}^{+}$und $\mathrm{CD}^{+} \mathrm{T}$-Zellen von Lymphknoten und Milz nach s.c. Injektion von $\mathrm{NMH}$..................37

Abbildung 7: Einfluss der s.c. Injektion von UFH auf die murine aGvHD. .................38

Abbildung 8: Durchflusszytometrische Analyse der $\mathrm{CD}^{+}, \mathrm{CD} 4^{+}$und $\mathrm{CD} 8^{+} \mathrm{T}$-Zellen von Lymphknoten und Milz nach s.c. Injektion von UFH ....................41

Abbildung 9: Einfluss der i.v. Injektion von NMH und UFH auf die murine aGvHD...42

Abbildung 10: Durchflusszytometrische Analyse der $\mathrm{CD}^{+}, \mathrm{CD}^{+}$und $\mathrm{CD} 8^{+} \mathrm{T}$-Zellen von Lymphknoten und Milz nach i.v. Injektion von NMH und UFH ......44

Abbildung 11: Einfluss der täglichen s.c. Injektion von UFH auf die murine aGvHD ..45

Abbildung 12: Durchflusszytometrische Analyse der CD3 ${ }^{+}, \mathrm{CD}^{+}$und $\mathrm{CD} 8^{+} \mathrm{T}$-Zellen von Lymphknoten und Milz nach täglicher s.c. Injektion von UFH.......47

Abbildung 13: Durchflusszytometrische Analyse des Proliferationsverhaltens humaner B-Zellen, T-Zellen und Monozyten nach Zugabe von LPS und $\mathrm{NMH}$

Abbildung 14: Durchflusszytometrische Analyse des Proliferationsverhaltens humaner B-Zellen, T-Zellen und Monozyten nach Zugabe von LPS und UFH.

Abbildung A.1: Gating-Strategien in der Durchflusszytometrie zur Identifikation von $\mathrm{CD}^{+}{ }^{-} \mathrm{CD} 4^{+}$und $\mathrm{CD}^{+}{ }^{+} \mathrm{CD} 8^{+} \mathrm{T}$-Zellen aus einer murinen Milz

Abbildung A.2: Gating-Strategien in der Durchflusszytometrie zur Identifikation von $\mathrm{CD}^{+} \mathrm{CD}^{+}$und $\mathrm{CD}^{+} \mathrm{CD}^{+} \mathrm{T}$-Zellen aus murinen Lymphknoten..........73

Abbildung A.3: Gating-Strategie in der Durchflusszytometrie zur Beurteilung des Proliferationsverhaltens humaner T-Zellen . 


\section{Tabellenverzeichnis}

Tabelle 1: Übersicht über die verwendeten Chemikalien, Medien und Puffer ............16

Tabelle 2: Übersicht über die verwendeten Labormaterialien ................................17

Tabelle 3: Übersicht über die verwendeten Laborgeräte.......................................18

Tabelle 4: Übersicht über die verwendeten Mauslinien.........................................18

Tabelle 5: Übersicht über die verwendeten Primärantikörper Anti-Maus....................19

Tabelle 6: Übersicht über die verwendeten Primärantikörper Anti-Human..................19

Tabelle 7: Übersicht über die verwendeten Reagenzien zur Zellisolierung ................20

Tabelle 8: Übersicht über die verwendeten Medikamente ......................................20

Tabelle 9: Übersicht über die verwendeten EDV-Programme................................20

Tabelle 10: Übersicht über die verwendeten Medien und Lösungen...........................21

Tabelle 11: Punktetabelle für das tägliche Monitoring ........................................26

Tabelle 12: Übersicht über alle Serien mit Therapieschemata...................................27

Tabelle 13: Übersicht über die Beimpfung der Zellkulturflaschen. .............................32 


\begin{tabular}{|c|c|}
\hline aGvHD & $\begin{array}{l}\text { acute graft-versus-host disease / akute Transplantat-gegen-Wirt- } \\
\text { Reaktion }\end{array}$ \\
\hline APC & antigen-presenting cell / antigenpräsentierende Zelle \\
\hline aPTT & aktivierte partielle Thromboplastinzeit \\
\hline ATG & Antithymozytenglobulin \\
\hline CPD & Cell Proliferation Dye eFluor ${ }^{\circledR} 450$ \\
\hline CU & Colitis ulcerosa \\
\hline CyA & Cyclosporin A \\
\hline EDTA & Ethylendiamintetraessigsäure \\
\hline FACS & fluorescence activated cell sorting / Durchflusszytometrie \\
\hline FCS & fetal calf serum / fetales Kälberserum \\
\hline GAG & Glykosaminoglykan \\
\hline G-CFS & $\begin{array}{l}\text { granulocyte-colony stimulating factor / Granulozyten-Kolonie- } \\
\text { stimulierender Faktor }\end{array}$ \\
\hline GvL & graft-versus-leukemia / Transplantat-gegen-Tumor \\
\hline HLA & human leukocyte antigen / humanes Leukozytenantigen \\
\hline HSC & hematopoietic stem cell / hämatopoetische Stammzelle \\
\hline HWZ & Halbwertszeit \\
\hline I.E. & Internationale Einheit \\
\hline IL & Interleukin \\
\hline IFNy & Interferon gamma \\
\hline i.v. & intravenös \\
\hline KM & Knochenmark \\
\hline KMT & Knochenmarktransplantation \\
\hline LN & lymphnode / Lymphknoten \\
\hline LPS & Lipopolysaccharid \\
\hline MACS & magnetic cell separation / magnetische Zellseparation \\
\hline $\mathrm{MHC}$ & $\begin{array}{l}\text { major histocompatibility complex / Haupthistokompatibilitätskom- } \\
\text { plex }\end{array}$ \\
\hline $\mathrm{miHA}$ & $\begin{array}{l}\text { minor histocompatibility antigen / Nebenhistokompatibilitätsanti- } \\
\text { gen }\end{array}$ \\
\hline MMF & Mycophenolat Mofetil \\
\hline MTX & Methotrexat \\
\hline
\end{tabular}




$\begin{array}{ll}\mathrm{NaCi} & \text { Natriumcitrat } \\ \text { NF-AT } & \text { nuclear factor of activated T-Cell } \\ \text { NK } & \text { natürliche Killerzellen } \\ \text { NMH } & \text { niedermolekulares bzw. fraktioniertes Heparin } \\ \text { PBS } & \text { phosphate buffered saline / phosphatgepufferte Salzlösung } \\ \text { PBSC } & \text { peripheral blood stem cells / periphere Blutstammzellen } \\ \text { RPMI } & \text { Roswell Park Memorial Institute } \\ \text { S.c. } & \text { subkutan } \\ \text { SP } & \text { Spleen / Milz } \\ \text { TNF } & \text { Tumornekrosefaktor } \\ \text { Tx } & \text { Transplantation } \\ \text { UFH } & \text { unfraktioniertes bzw. hochmolekulares Heparin }\end{array}$




\section{Einleitung}

\subsection{Allogene Stammzelltransplantation}

Eine der ersten erfolgreichen allogenen Stammzelltransplantationen wurde 1968 unter der Leitung von Robert A. Good durchgeführt. Sie erfolgte zwischen einem humanen Leukozytenantigen(HLA)-identischen Geschwisterpaar aufgrund einer schweren Immundefizienz des damals fünf Monate alten Bruders (Gatti et al. 1968). Mittlerweile ist die allogene Stammzelltransplantation ein etabliertes Verfahren zur kurativen Behandlung von vielen hämatoonkologischen Erkrankungen, wie die akute myeloische oder lymphatische Leukämie, aber auch von angeborenen Immundefizienzen und hämatopoetischen Insuffizienzen nicht maligner Genese (Holowiecki 2008). Im Jahr 2014 wurden allein in Europa mehr als 40.000 hämatopoetische Stammzelltransplantationen durchgeführt. Davon waren $43 \%$ allogene Stammzelltransplantationen und $57 \%$ autologe Stammzelltransplantationen. Im Jahr 2000 wurden in Europa 80 \% weniger Stammzelltransplantationen als im Jahr 2014 durchgeführt (Passweg et al. 2016). Diese Zahlen verdeutlichen, welchen wichtigen Stellenwert diese Form der Therapie im klinischen Alltag einnimmt.

Zur Durchführung einer Stammzelltransplantation werden hämatopoetische Stammzellen benötigt. Hämatopoetische Stammzellen (HSC) sind pluripotente Zellen, von welchen die Hämatopoese ausgeht. Das heißt, sie können sich sowohl selbst erneuern, als auch zu verschiedenen Zelllinien des Blutes differenzieren (Shizuru et al. 2005). HSC kommen im Knochenmark, in geringen Mengen im peripheren Blut und im Nabelschnurblut vor (Hatzimichael und Tuthill 2010).

Zur Gewinnung der Stammzellen stehen verschiedene Verfahren zur Verfügung. Die Gewinnung der HSC über eine Knochenmarkpunktion rückt immer weiter in den Hintergrund seit sich das Verfahren der Stammzellapharese etabliert hat (Eapen et al. 2015). Bei diesem Verfahren wird zunächst die Bildung von peripheren Blutstammzellen (PBSC) beim Stammzellspender durch die Gabe des Granulozyten-Kolonie-stimulierenden Faktor (G-CSF) angeregt (Bensinger et al. 1996). Anschließend werden die produzierten PBSC mittels Stammzellapherese herausgefiltert. Studien, wie zum Beispiel von Bensinger et al. (2001), konnten zeigen, dass die Gewinnung der Stammzellen mittels PBSC zu einem schnelleren Anwachsen des Transplantats und somit geringeren Transfusionsraten führten. Jedoch wurde auch ein erhöhtes Risiko für das Auftreten einer Graft-versus-Host Disease (GvHD), besonders einer chronischen GvHD (cGvHD) festgestellt (Flowers et al. 2011; Bittencourt et al. 2009; Cutler et al. 2001). 
Eine Alternative zu den herkömmlichen Stammzellquellen aus Knochenmark und PBSC stellt das Nabelschnurblut dar. Die HSC aus Nabelschnurblut sind immunologisch noch nicht vollständig ausgereift, weshalb bei der Auswahl der Nabelschnurblutspende ein größerer HLA-Unterschied zwischen Spender und Empfänger möglich ist (Bradley und Cairo 2005). Vor allem bei Kindern wurde diese Form des Transplantats erfolgreich angewandt. Sie geht zwar mit einem etwas späteren Einwachsen des Transplantats, gleichzeitig aber auch mit einem geringeren Risiko eine GvHD zu entwickeln und einem geringeren Auftreten von Rezidiven, einher. Bei Erwachsenen zeigten sich insgesamt jedoch schlechtere Resultate nach einer Stammzelltransplantation mit HSC aus dem Nabelschnurblut, als bei einer Stammzelltransplantation mit HSC aus dem Knochenmark. Die Menge der HSC aus dem limitierten Nabelschnurblut reicht hier oft nicht aus (Wang et al. 2010).

Bevor die eigentliche Stammzelltransplantation erfolgt, wird in der Regel zunächst eine Konditionierung des Patienten durchgeführt. Der Patient erhält dabei eine Chemotherapie oder eine Ganzkörperbestrahlung mit oder ohne Chemotherapie. Dieses Vorgehen hat zum Ziel, so viele maligne Zellen wie möglich zu zerstören und über eine Immunsuppression eine mögliche Abstoßungsreaktion des Transplantats durch den Empfänger zu verhindern.

Die Konditionierung wird aktuell in drei Intensitätsstufen eingeteilt: die myeloablative, die nicht myeloablative und die intensitätsreduzierte Konditionierung (Bacigalupo et al. 2009). Diese Abstufung erfolgte auf der Grundlage von Untersuchungen, die bei geringerer beziehungsweise keiner knochenmarkzerstörenden Konditionierung zu weniger toxischen Nebenwirkungen führten. Trotz der reduzierten Konditionierung kam es zu einem Anwachsen des Transplantats und einer Zerstörung der Tumorzellen durch die TZellen des Spenders (Transplantat-gegen-Tumor-Reaktion) (Giralt et al. 1997). Die Wahl des Konditionierungsregimes muss für jeden Patienten individuell evaluiert und entschieden werden. Dabei spielen Faktoren wie Alter, Komorbidität und Rezidivrisiko eine wichtige Rolle (Sorror et al. 2011).

Im Anschluss an die Konditionierung erfolgt die eigentliche Stammzelltransplantation. Bei der autologen Stammzelltransplantation handelt es sich bei Spender und Empfänger um dieselbe Person. Unverträglichkeitsreaktionen, wie die Entwicklung einer GvHD können bei dieser Form der Transplantation nicht auftreten. Dabei besteht jedoch prinzipiell die Gefahr, dass Tumorzellen zurück in den Körper des Patienten gelangen. Diese Form der Transplantation erfolgt vor allem nach Hochdosischemotherapien, um die Erholung des blutbildenden Systems zu beschleunigen (Korbling et al. 1986). Vor Durchführung 
der Hochdosischemotherapie werden die Stammzellen des Patienten durch eine Chemotherapie und/oder die Gabe des G-CFS mobilisiert, entnommen und eingefroren. Nach erfolgter Therapie, durch die der Tumor, aber auch das blutbildende System zerstört wurden, werden die zuvor gesammelten Stammzellen dem Patienten zurückinfundiert (Korbling et al. 1990).

Bei der allogenen Stammzelltransplantation werden HSC von einem Spender auf einen anderen Empfänger übertragen. Bei dem Stammzellspender kann es sich um einen leiblichen Geschwisterteil oder einen freiwilligen nicht verwandten Spender handeln. Voraussetzung für die Spende ist eine möglichst große HLA-Übereinstimmung zwischen Spender und Empfänger (Holowiecki 2008). Ein Vorteil dieser Form der Transplantation besteht in der Induktion der Transplantat-gegen-Tumor-Reaktion/Graft-versus-Leukemia (GvL) (Horowitz et al. 1990). Die Zellen des allogenen Spenders greifen die Leukämie- bzw. Tumorzellen des Empfängers an und zerstören die im Körper verbliebenen malignen Zellen. Die Patienten profitieren von weniger Rezidiven (Horowitz et al. 1990). Einen wichtigen Beitrag zur Erkennung und Zerstörung dieser malignen Zellen leisten dabei die CD4+ und CD8+ T-Zellen sowie die Natürliche Killerzellen (NK) des Spenders (Truitt und Atasoylu 1991; Barrett 1997). Dieser Nutzen geht jedoch gleichzeitig mit dem Risiko für die schwerwiegendste Komplikation einer allogenen Stammzelltransplantation einher: Die Entstehung einer mit hoher Morbidität und Mortalität korrelierenden GvHD (Ferrara und Reddy 2006).

\subsection{Graft-versus-Host Disease (GvHD)}

Eine häufige und gefürchtete Komplikation nach einer Stammzelltransplantation ist die akute Graft-versus-Host Disease (aGvHD). Sie tritt bei bis zu 40-60\% der behandelten Patienten auf (Jagasia et al. 2012). Dabei kommt es zu einer Immunreaktion der CD4+ und CD8 ${ }^{+}$T-Zellen des Spenders gegen das Gewebe des Empfängers (Shlomchik 2007). Die am häufigsten betroffenen Gewebe sind Haut, Gastrointestinaltrakt und Leber. Der Befall der Haut äußert sich dabei durch ein makulopapulöses Exanthem mit Erythrodermie und Juckreiz. Klinische Zeichen einer Darm-GvHD sind neben wässrigen Diarrhoen und Tenesmen, auch Übelkeit, Erbrechen und Gewichtsverlust. Auf eine Beteiligung der Leber weist ein Anstieg des Bilirubins mit klinischem Ikterus hin (Glucksberg et al. 1974). Die aGvHD wird je nach Ausprägung und Anzahl des Befalls der drei Organe in vier Schweregrade (I-IV) eingeteilt. Je höher der Schweregrad, desto schlechter die Prognose des Patienten. So zeigte sich ein Langzeitüberleben von $25 \%$ bei Schweregrad III und ein Überleben von nur $5 \%$ bei Schweregrad IV (Cahn et al. 2005). Von der 
akuten Form der GvHD wird eine chronische Form unterschieden (cGvHD). Bei der cGvHD stehen autoimmune und andere immunologische Störungen im Vordergrund. Dazu zählen Symptome von Krankheiten wie Poikilodermie, Sjögren Syndrom, Bronchiolitis obliterans und chronische Immundefizienz. Die frühere Einteilung nach dem Zeitpunkt des Auftretens der Symptome ist mittlerweile hinfällig. Nach allgemeiner Meinung entscheidet allein die klinische Symptomatik, ob es sich um eine akute oder chronische GvHD handelt. (Filipovich et al. 2005). Diese Arbeit beschäftigt sich mit der akuten Graftversus-Host-Disease.

Um in Zukunft weitere Prophylaxe- und Therapiemöglichkeiten entwickeln zu können, muss die Pathogenese der Krankheit verstanden werden. Verschiedenste Tier-, insbesondere Mausmodelle halfen bisher den Ablauf der Entstehung einer aGvHD besser zu begreifen. Die Pathogenese der aGvHD lässt sich vereinfacht mit Hilfe eines Drei-Stufenschemas nach Ferrara und Kollegen (2009) darstellen.

Die erste Phase ist durch die Aktivierung von antigenpräsentierenden Zellen (APC) gekennzeichnet. Dies geschieht bereits durch die zugrundeliegende, meist maligne, hämatologische Erkrankung und durch die myeloablative Therapie. Das Empfängergewebe schüttet aufgrund des daraus entstandenen Gewebeschadens unter anderem entzündungsfördernde Zytokine, wie Tumornekrosefaktor a (TNFa), Interleukin-6 (IL-6) und Interleukin-1 (IL-1) aus und sorgt so für die Aktivierung der APC (Xun et al. 1994; Hill et al. 1997). Dieser Prozess wird besonders durch geschädigtes Gewebe im gastrointestinalen Trakt gefördert, da hier weitere entzündungsfördernde bakterielle Produkte, wie Lipopolysaccharide freigesetzt werden und einen weiteren inflammatorischen Reiz setzen (Hill und Ferrara 2000).

In der zweiten Phase werden die T-Zellen des Stammzellspenders durch die, auf den Empfänger-APC, präsentierten Antigene aktiviert. Dies führt zu einer Proliferation und Differenzierung der Spender T-Zellen, besonders der $\mathrm{CD}^{+}{ }^{+}$und/oder CD8 ${ }^{+}$T-Zellen. Auch bei HLA-identischer (match) Spender- und Empfängerkombination kann es durch die Präsentation von polymorphen Peptiden, den sogenannten Nebenhistokompatibilitätsantigenen (miHA), die sich trotz HLA-Identität voneinander unterscheiden können, ebenfalls zu einer Präsentation und folglich Aktivierung von T-Zellen kommen (Shlomchik 2007). Diese Kaskade der T-Zell Aktivierung führt zu einer weiteren Freisetzung von proinflammatorischen Zytokinen wie Interferon gamma (INFY), TNFa und IL-1.

In der dritten Phase wird durch zelluläre und entzündungsfördernde Prozesse das Empfängergewebe zerstört. Zytotoxische T-Zellen und natürliche Killerzellen spielen dabei auf zellulärer Ebene die entscheidende Rolle. Sie fördern den Entzündungsprozess 
durch die weitere Ausschüttung von Zytokinen und sorgen für die direkte zytolytische Zerstörung des Effektororgans (Ferrara et al. 2009).

Als wichtigster Risikofaktor für das Auftreten einer aGvHD nach Stammzelltransplantation gilt die Diskrepanz des humanen Leukozytenantigens (HLA) zwischen Spender und Empfänger (Flowers et al. 2011). HLAs werden durch den Major Histocompatibility Complex (MHC) kodiert und sind Glykoproteine des Immunsystems (Ferrara et al. 2009). Ferrara und Kollegen (2009) wiesen darauf hin, dass die Prävalenz der aGvHD direkt mit der Diskrepanz der HLA Proteine korreliert. Liegt eine HLA identische Empfänger/Spenderkombination vor (match), kommt es in 35-45 \% der Fälle zu einer aGvHD. Stimmen Empfänger-/Spenderkombinationen dagegen nicht komplett überein (mismatch), erleiden $60-80 \%$, also knapp doppelt so viele Patienten, eine aGvHD (Jagasia et al. 2012). Auch das Geschlecht des Spenders und Empfängers spielt als Risikofaktor eine Rolle. So haben Stammzellen von Spenderinnen, die für männliche Empfänger bestimmt sind, das höchste Risiko eine aGvHD zu entwickeln, besonders bei vorangegangener Schwangerschaft der Spenderin (Alloimmunisierung) (Gale et al. 1987; Flowers et al. 1990). Das Ausmaß der Konditionierung beeinflusst ebenfalls das Risiko für die Entstehung der Erkrankung. Je ausgeprägter die myeloablative Therapie ausfällt, desto größer ist der verursachte Gewebeschaden des Empfängers. Wie bereits in der Pathogenese (siehe Drei-Stufenschema nach Ferrara und Kollegen, S.4-5) beschrieben, kommt es so zu einer erhöhten Ausschüttung von proinflammatorischen Zytokinen und einer stärkeren Aktivierung von APC (Hill und Ferrara 2000). Weiterhin wurde ein erhöhtes Risiko für das Auftreten einer GvHD bei der HSC-Gewinnung aus PBSC (siehe Kapitel 1.1 „Allogene Stammzelltransplantation") festgestellt (Bittencourt et al. 2009).

\subsection{Prophylaxe der akuten GvHD (aGvHD)}

Die Entwicklung einer aGvHD nach Stammzelltransplantation geht mit einer deutlich reduzierten Überlebensrate der Patienten einher. Ohne Prävention durch Medikamente oder andere Verfahren ist die Inzidenz einer aGvHD deutlich erhöht und liegt in Studien bei bis zu 100 \% (Sullivan et al. 1986). Eine wirkungsvolle Prophylaxe ist daher essenziell. Innerhalb zahlreicher Studien wurde in den letzten Jahrzehnten versucht ein optimales Prophylaxe-Konzept zu entwickeln. Zwar konnte eine Verbesserung hinsichtlich der Inzidenz erzielt werden, dennoch wurde das optimale Verfahren zur sicheren Prävention einer aGvHD noch nicht gefunden (Ruutu et al. 2012). 
Als Standard-Prophylaxe der aGvHD wird in den deutschen Leitlinien zur Diagnostik und Therapie von Blut- und Krebserkrankungen (Onkopedia) aktuell die Gabe einer Kombination aus Cyclosporin A (CyA) oder Tacrolimus mit Methotrexat (MTX) oder Mycophenolat Mofetil (MMF), gegebenenfalls in Kombination mit Antithymozytenglobulin (ATG) empfohlen. Eine individuelle Anpassung der Intensität und Dauer der Prophylaxe gemäß dem Risikoprofil des Patienten soll erfolgen (Onkopedia 2020). Zu den bisher am besten erforschten Substanzen mit der breitesten klinischen Anwendung gehören MTX und CyA (Storb et al. 1986; 1988). Bei MTX handelt es sich um einen Folsäure-Antagonist, der das Enzym Dihydrofolat-Reduktase reversibel hemmt und zu einer Inhibition der Proliferation der Spender T-Lymphozyten führt (Pavletic und Fowler 2012). Allerdings treten bei der Gabe von MTX häufig unerwünschte Nebenwirkungen wie eine Mukositis, ein verzögertes Anwachsen des Transplantats und eine Schädigung von weiteren Organen auf. Eine nebenwirkungsärmere Alternative bietet der Inosinmonophosphat-Dehydrogenase Hemmer MMF. Eine Anwendung in Kombination mit CyA wird bei einer intensitätsreduzierten Konditionierung und bei Transplantationen mit Nabelschnurblut als Standard-Prophylaxe empfohlen (Ruutu et al. 2014). In Studien konnte gezeigt werden, dass die Gabe von MMF zusammen mit CyA deutlich weniger der genannten Nebenwirkungen hervorruft und dabei genauso zuverlässig eine aGvHD verhindert (Niederwieser et al. 2003; Bolwell et al. 2004). CyA ist ein Calcineurin-Inhibitor. Er blockiert über die Hemmung des Calcineurins die Aktivierung des nuclear factor of activated T-Cell (NFAT) und hemmt so die T-Zell-Aktivierung und -Proliferation (Matsuda und Koyasu 2000). Auch Tacrolimus gehört zu der Gruppe der Calcineurin-Inhibitoren. Eine Kombination von Tacrolismus mit MTX wird in ihrer Wirksamkeit in der aGvHD-Prophylaxe als gleichwertig zur Kombination CyA/MTX betrachtet (Nash et al. 2000; Ruutu et al. 2014). Die Empfehlung zum zusätzlichen Einsatz von ATG bei unverwandten Spendern in der Prävention der aGvHD begründet sich aus den Erkenntnissen von verschiedenen Studien. Darin wurde festgestellt, dass die Gabe von ATG nach Stammzelltransplantation zu weniger akuten und chronischen GvHD Erkrankungen führte (Finke et al. 2009; Pidala et al. 2011; Socie et al. 2011). Neben dieser In-vivo-Elimination der T-Zellen, gibt es weitere Ansätze einer T-Zell-Depletion als Prophylaxe der GvHD. Dazu zählt die In-vivo-Elimination mit Alemtuzumab, einem monoklonalen Antikörper gegen das Glykoprotein CD52, das sich auf B- und T-Lymphozyten befindet (Kanda et al. 2011). Aber auch Exvivo-Verfahren wurden und werden weiterhin untersucht und getestet. 


\subsection{Erstlinientherapie der aGvHD}

Als Gold-Standard der Erstlinientherapie gilt die systemische Anwendung von Glukokortikoiden. Glukokortikoide wirken antiinflammatorisch, immunsuppressiv und zeigen einen toxischen Effekt gegenüber Lymphozyten (Martin et al. 2012b). Der genaue Wirkmechanismus während einer aGvHD ist noch nicht genau verstanden. Die Indikation zur Therapie wird anhand des klinischen Schweregrades der aGvHD festgelegt. Liegt ein Schweregrad von II oder mehr vor, sollte mit der systemischen Erstlinientherapie begonnen werden. Eine Dosis von $2 \mathrm{mg} / \mathrm{kg} / \mathrm{KG} / \mathrm{Tag}$ Methylprednisolon für sieben Tage wird empfohlen (Ruutu et al. 2014). Die Gabe einer höheren Dosis (10 mg/kg/KG/Tag) zeigte keinen Vorteil (van Lint et al. 1998). Eine langsame Reduktion der Dosis sollte erst ab Tag 7 und nur bei gleichzeitiger Abnahme der klinischen Symptome erfolgen. Bei milder Grad I GvHD der Haut kann die alleinige Gabe von lokalen Glukokortikoiden ausreichen (Penas et al. 2004). Aufgrund der Vielzahl an möglichen Nebenwirkungen, zu denen unter anderem opportunistische Infektionen, Gastritis, Osteoporose und Diabetes zählen, ist die zeitgleiche Durchführung von supportiven Maßnahmen sehr wichtig (Moghadam-Kia und Werth 2010; Schacke et al. 2002).

Bei Vorliegen einer Darm-GvHD verhindert die zusätzliche Gabe von nicht resorbierbaren oralen Glukokortikoiden wie Budesonid oder Beclomethason das Auftreten eines Rezidivs und weist ein besseres Überleben der Patienten auf (Hockenbery et al. 2007; Bertz et al. 1999). Weitere Studien zur Bestimmung der idealen Dosis und genaueren Differenzierung der beiden Medikamente sind nötig, um diese Form der Therapie besser zu verstehen und weiterhin anwenden zu können (Ibrahim et al. 2009).

Viele verschiedene Studien wurden durchgeführt, um weitere Möglichkeiten einer wirkungsvolleren Erstlinientherapie zu finden. Jedoch ohne vielversprechende Ergebnisse hervorzubringen. Zum Beispiel wurde versucht eine Verbesserung der Erstlinientherapie durch Kombinationen mit anderen immunmodulierenden Medikamenten zu erreichen. Dabei zeigte die Kombination von Glukokortikoiden mit MMF zunächst eine vielversprechende Ansprechrate der Therapie (Alousi et al. 2009). In einer weiteren Studie konnte jedoch keine Verbesserung dieser Kombination gegenüber der alleinigen Glukokortikoidgabe festgestellt werden (Bolaños-Meade et al. 2013).

\subsection{Zweitlinientherapie der aGvHD}

Nur etwa die Hälfte aller Patienten, die eine aGvHD entwickeln, reagieren auf die Erstlinientherapie mit Glukokortikoiden (Martin et al. 1990; MacMillan et al. 2002). Die andere 
Hälfte erweist sich als steroidresistent. Der Beginn der Zweitlinientherapie wird empfohlen, sobald ein Ansprechen des Patienten auf die Erstlinientherapie bis Tag 7 noch nicht erfolgt ist oder sich eine deutliche Verschlechterung des Allgemeinzustandes mit Fortschreiten der aGvHD innerhalb der ersten fünf Tage nach Beginn der Erstlinientherapie zeigt (Ruutu et al. 2014). Aktuell gibt es keine etablierte und standardisierte Zweitlinientherapie (Martin et al. 2012a). Zunächst sind eine optimale supportive Behandlung und die Fortführung der Glukokortikoid- und Calcineurin-Inhibitor-Gabe berechtigte Maßnahmen (Ruutu et al. 2014). Zu den weiteren klinisch häufig angewandten Substanzen und Verfahren zählen MMF, ATG, die extrakorporale Photophorese und monoklonale Antikörper wie TNF-a-Inhibitoren, Basiliximab und Alemtuzumab (Martin et al. 2012b, Wolff et al. 2013). Allerdings zeigte der Vergleich der verschiedenen Therapiekonzepte keine eindeutige Tendenz für eine Substanz bzw. Verfahren. (Martin et al. 2012b). Eine Glukokortikoid-resistente GvHD geht weiterhin mit einer äußert hohen Mortalität von bis zu $90 \%$ einher (Westin et al. 2011). Dementsprechend sind neue und aussichtsreiche Therapieansätze, sowohl zur Prophylaxe als auch zur Erst- und Zweitlinientherapie dringend nötig.

\subsection{Graft-versus-Host Disease im Mausmodell}

Mausmodelle der aGvHD sind essenziell, um die Pathomechanismen der Krankheit besser zu verstehen und bereiten so den Weg für neue und verbesserte Therapiekonzepte. Mittlerweile gibt es viele etablierte Mausmodelle, in denen verschiedene Szenarien simuliert werden können. In dieser Arbeit wurde ein gut fundiertes MHC-Mismatch-Modell zwischen BALB/c und C57BL/6J (B6) Mäusen verwendet. In diesem Mausmodell wird die aGvHD durch CD4 ${ }^{+}$und CD8 ${ }^{+}$T-Zellen verursacht (Schroeder und DiPersio 2011). Es gibt auch Mausmodelle, bei welchen die aGvHD nur durch einen der beiden Zelltypen verursacht wird. Dies war und ist hilfreich, um die genauen Pathomechanismen der unterschiedlichen T-Zellen, die zum Ausbruch der Krankheit führen, im Einzelnen zu verstehen (Sprent et al. 1990). So konnte gezeigt werden, dass CD8 ${ }^{+}$T-Zellen ausschließlich durch Empfänger-APC aktiviert werden können und über die Bindung an MHC IRezeptoren zu einer Ausschüttung von Perforin, Granzymen und der Expression von Fas-Ligand führt (Shlomchik et al. 1999; Maeda et al. 2005; Graubert et al. 1997). CD4+ T-Zellen dagegen können, sowohl durch die Empfänger-, als auch die Spender-APC aktiviert werden und führen über die Bindung an MHC II-Rezeptoren zu einem TNFa-vermittelten zytotoxischen Effekt im Epithel des Empfängers (Anderson et al. 2005; Teshima et al. 2002). 
Die Schwere der aGvHD im Mausmodell wird vor allem durch die Menge der transplantierten T-Zellen und die Stärke der Konditionierung, aber auch durch die genetischen Unterschiede zwischen den Mäusen und den umweltbedingten Abweichungen der Pathogene in den verschiedenen Laboren bestimmt (Schroeder und DiPersio 2011). Die Krankheit verläuft im hier durchgeführten Modell typischerweise in zwei Krankheitswellen. Die erste Krankheitswelle tritt nach etwa acht, die zweite Krankheitswelle nach etwa 21 Tagen im Anschluss an die Stammzelltransplantation auf (siehe Abbildung 1) (Budde et al. 2014).

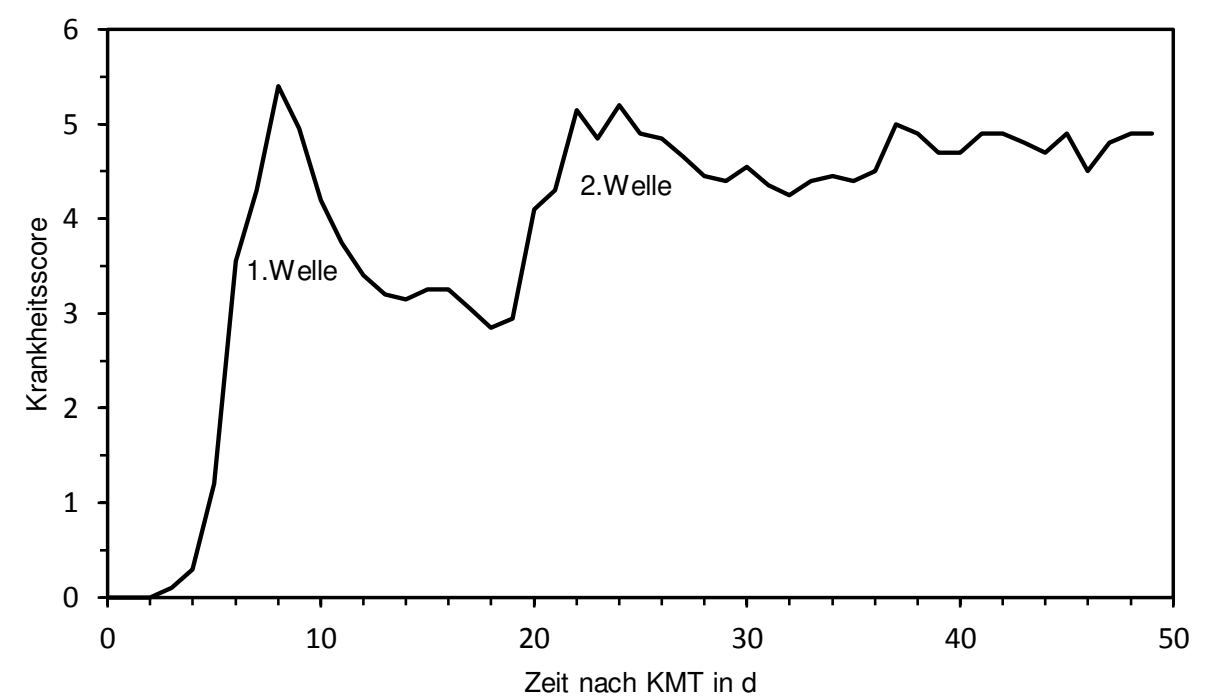

Abbildung 1: Verlauf der aGvHD im Mausmodell. Typischer Verlauf der aGvHD im C57BL/6J $\rightarrow$ BALB/c transplantierten Mausmodell in zwei Krankheitswellen, dargestellt anhand des Krankheitsscores (siehe Tabelle 11). Typischer Zeitpunkt des Auftretens der 1. Krankheitswelle nach etwa acht Tagen und der 2. Krankheitswelle nach etwa 21 Tagen nach KMT. Abbildung basierend auf Budde et al. (2015) mit freundlicher Genehmigung des Autors.

\subsection{Heparin}

Heparin ist eines der ältesten Medikamente, das bis heute weitverbreitete klinische Anwendung als Antikoagulanz findet. Der Medizinstudent Jay McLean extrahierte 1916 zum ersten Mal Heparin aus Hundeleber und zeigte gerinnungshemmende Eigenschaften. Zwei Jahre später beschrieb Howell seine chemische Struktur und nannte es seiner Herkunft entsprechend Heparin (Wardrop und Keeling 2008). Heparine sind Glykosaminoglykane (GAG) und weisen eine Molekülmasse zwischen 4.000-40.000 Da auf. Die GAG-Ketten bestehen aus abwechselnden Disaccharideinheiten, die aus einer Kombination von D-Glucosamin mit einer Uronsäure, entweder D-Glucuronsäure oder L-Iduronsäure, aufgebaut sind. Durch angehängte Sulfatgruppen sind Heparine negativ geladen. Im menschlichen Körper kommt Heparin vor allem in den Mastzellen vor (Page 
2013). Das heutzutage erhältliche und im klinischen Alltag eingesetzte Heparin wird aus der Mukosa des Schweinedarms gewonnen (Fu et al. 2013).

Die antikoagulatorische Wirkung entsteht durch die Bindung von Heparin an Antithrombin, einen Hemmstoff der Blutgerinnung. Antithrombin inaktiviert die Gerinnungsfaktoren Ila (Thrombin), Xa, IXa, Xla und XIla. Dabei werden besonders die Faktoren Ila (Thrombin) und Xa gehemmt. Die Bindung zwischen Heparin und Antithrombin führt zu einer Konformationsänderung des Antithrombins und beschleunigt den gerinnungshemmenden Effekt um das 1.000-fache (Hirsh et al. 2001a). Für die Interaktion der beiden Substanzen ist ein Pentasaccharid des Heparins mit einer bestimmten dreidimensionalen Struktur verantwortlich (Choay et al. 1983; Walenga et al. 1987). Heparin wird aufgrund dieser gerinnungshemmenden Wirkung standardmäßig zur Prophylaxe und Therapie von thromboembolischen Ereignissen, wie einer tiefen Beinvenenthrombose oder Lungenembolie verwendet (Hirsh et al. 2001a). Aufgrund der großen Variabilität zwischen den einzelnen Heparinen hinsichtlich der gerinnungshemmenden Wirkung wird die Dosis als Aktivität in Internationalen Einheiten (I.E.) angegeben (Gray 2012).

\subsection{Niedermolekulares und unfraktioniertes Heparin (NMH und UFH)}

Heparin wird in zwei Formen unterschieden: das fraktionierte oder niedermolekulare Heparin $(\mathrm{NMH})$ und das unfraktionierte oder hochmolekulare Heparin (UFH). UFH haben mit durchschnittlich 15.000 Da und mindestens 18 Sacchariden Kettenlänge eine deutlich größere Molekülmasse als NMH. Letztere werden durch chemische oder enzymatische Depolymerisation aus UFH hergestellt. Sie haben eine deutlich geringere Molekülmasse von durchschnittlich $4500 \mathrm{Da}$ und meist eine Kettenlänge von weniger als 18 Sacchariden. Hieraus lässt sich auch die unterschiedliche Wirkweise der beiden Heparine hinsichtlich ihrer Hemmung der Gerinnungsfaktoren erklären. Zur Inaktivierung von Thrombin muss Heparin gleichzeitig an Antithrombin und Thrombin binden können. Hierfür sind mindestens 18 Saccharide nötig. Folglich inhibiert NMH vor allem Faktor Xa, der unabhängig von der Kettenlänge inaktiviert werden kann und kaum Thrombin. UFH ist es möglich mit seiner größeren Kettenlänge sowohl Faktor Xa, als auch Thrombin zu inhibieren (Weitz 1997; Garcia et al. 2012).

Die Elimination erfolgt bei NMH ausschließlich renal, während UFH durch Endothelzellen und Makrophagen gebunden und renal ausgeschieden werden. Auch hinsichtlich der Bioverfügbarkeit und Halbwertszeit (HWZ) gibt es Unterschiede. UFH weisen eine deutlich höhere Affinität zu Plasmaproteinen auf als NMH. Die Bindung führt zur Aufhebung 
des gerinnungshemmenden Effekts und ist vermutlich für die reduzierte Bioverfügbarkeit der UFH verantwortlich (Hirsh et al. 2001a). NMH haben durch ihre geringe Affinität zu Plasmaproteinen mit fast $100 \%$ eine wesentlich höhere Bioverfügbarkeit. Aus diesem Grund ist auch die HWZ der NMH länger als die dosisabhängige HWZ der UFH, weshalb eine einmal tägliche Gabe zur Thromboseprophylaxe genügt. Insgesamt ist die Bioverfügbarkeit und HWZ der NMH anders als die der UFH von Dosis und Plasmakonzentration unabhängig (Hirsh und Levine 1992). Oral werden beide Substanzen nicht resorbiert, weshalb die Applikation ausschließlich subkutan (s.c.) oder bei UFH auch intravenös (i.v.) erfolgt (Dal Pozzo et al. 1989). Bei einer s.c. Injektion von UFH muss die Dosis höher gewählt werden als bei einer i.v. Gabe, da die s.c. Gabe mit einer geringeren Bioverfügbarkeit verbunden ist (Garcia et al. 2012).

Der Einsatz von Heparin birgt auch Nebenwirkungen. So kann insbesondere die Behandlung mit UFH zu einer Heparin-induzierten Thrombozytopenie oder Osteoporose führen. Außerdem kommt es bei beiden Heparinen zu einer gesteigerten Blutungsneigung (Alban 2012). Der antikoagulatorische Effekt des UFH kann mit der Antidot Protamin aufgehoben werden (Horrow 1985).

\subsection{Antiinflammatorischer Effekt des Heparins}

Neben der antikoagulatorischen Wirkung verfügen Heparine auch über antiinflammatorische Eigenschaften. Wood und Bick (1959) konnten bereits 1959 einen antiinflammatorischen Effekt von Heparin bei allergischen Reaktionen des Auges bei Kaninchen feststellen. Als zugrundeliegender Mechanismus konnte eine Inhibition der Leukozytenadhäsion an das Endothel durch die Hemmung von P- und L-Selektin identifiziert werden (Nelson et al. 1993). L-Selektin ist ein Adhäsionsmolekül, das auf T-Lymphozyten vorkommt. Es ist an der frühen Phase der Leukozytenadhäsion beteiligt und wird durch Heparin gebunden und inhibiert (Koenig et al. 1998). P-Selektin findet sich auf der Zelloberfläche von aktivierten Endothelzellen und Thrombozyten und bindet während der Entzündungsreaktion die entlang rollenden T-Lymphozyten (Springer 1994). Die Bindung von Heparin an die beiden Selektine hängt vermutlich von der Molekülgröße und der Sulfatierung des Heparins ab (Nelson et al. 1993; Koenig et al. 1998). Die Relevanz dieses Mechanismus bezüglich der Entstehung einer aGvHD konnten Lu und Kollegen (2010b) in einer Studie zeigen. Bei Induktion einer aGvHD bei P-Selektin Knock-outMäusen wurde ein verbessertes Überleben und ein milderer klinischer Verlauf der aGvHD beobachtet. In einer weiteren Studie konnte gezeigt werden, dass die Inhibition von L-Selektin und a4-Integrin im Mausmodell zu einem verzögerten Auftreten der aGvHD mit einem verbesserten Überleben der Tiere führte (Li et al. 2001). 
Zudem kann Heparin die Aktivierung einiger proinflammatorischer Zytokine in humanen Monozyten inhibieren (Hochart et al. 2006) sowie die Expression von Th-1, Th-2 und Th17 herunter regulieren (Huang et al. 2014). Diese Ergebnisse gelten sowohl für UFH, als auch für $\mathrm{NMH}$.

Dementsprechend müssten viele entzündlich bedingte Erkrankungen von den antiinflammatorischen Eigenschaften der Heparine profitieren. Eine klinische Studie konnte folglich eine positive Wirkung von inhaliertem Heparin bei Kortikoid-resistenten Patienten mit exazerbierten Asthma demonstrieren (Bendstrup und Jensen 2000). Einige Jahre zuvor konnte bereits in tierexperimentellen Studien eine Verminderung der allergischen Infiltration der Eosinophilen bei inhalativer Anwendung von Heparin gezeigt werden (Seeds et al. 1995). Auch bei der chronisch-entzündlichen Darmerkrankung Colitis Ulcerosa beschrieben mehrere Studien einen günstigen antientzündlichen Effekt von Heparin auf die Erkrankung (Gaffney et al. 1995, Evans et al. 1997, Wang et al. 2013). Ebenfalls wurde in einigen Studien eine positive Wirkung einer Behandlung mit Heparin auf die Mortalität von Sepsis-Patienten festgestellt (Zarychanski et al. 2015; Wang et al. 2014; Jiang et al. 2015). Dabei wiesen die mit Heparin behandelten Patienten kein erhöhtes Blutungsrisiko auf (Wang et al. 2014).

Im Jahr 1993 führten Naparstek et al. (1993) eine Studie zur Wirkung von niedrig dosiertem Heparin bei der aGvHD in Mäusen durch. Dabei wurde durch eine Knochenmarktransplantation die aGvHD in den Versuchstieren induziert. Anschließend wurde die Therapiegruppe für 30 Tage mit UFH s.c. behandelt. Die Ergebnisse zeigten, dass die therapierten Mäuse eine mildere aGvHD entwickelten und eine deutlich geringere Mortalität als die Kontrolltiere aufwiesen. Die Therapie mit Heparin beeinflusste indessen weder den GvL-Effekt, noch das Anwachsen des Transplantats. Dies ist die bislang einzige in der Literatur verfügbare Studie zur Behandlung der aGvHD mit Heparin.

\subsection{T- und B-Lymphozyten}

Lymphozyten gehören zu den Leukozyten und werden im Knochenmark gebildet. Sie sind spezifische Zellen des Immunsystems. Sie werden unter anderem in T- und B-Lymphozyten unterteilt.

T-Lymphozyten sind Träger der zellulären Immunantwort und werden in CD4 ${ }^{+}$und CD8 ${ }^{+}$ T-Lymphozyten unterteilt. Die CD4+ T-Lymphozyten werden auch als T-Helferzellen bezeichnet und in weitere Untergruppen, die TH1-, TH2- und TH17-Zellen sowie die regulatorischen T-Zellen (Treg) gegliedert. Sie erkennen an MHC-Klasse-Il gebundene Anti- 
gene. TH1-Zellen aktivieren Makrophagen, CD8 ${ }^{+}$T-Zellen und andere zytotoxische Zellen und synthetisieren Zytokine wie IL-2 und INF-y. TH2-Zellen aktivieren über die Bildung von Zytokinen B-Lymphozyten und regulieren so die humorale Immunantwort. Th17-Zellen produzieren IL-17 sowie weitere Zytokine und sind bei der Entstehung von Autoimmunkrankheiten und chronischen Entzündungen wie der rheumatoiden Arthritis von Bedeutung. Die regulatorischen T-Zellen bewirken eine Suppression von Autoimmunprozessen und regulieren durch Inhibition der T-Zellen die körpereigene Immuntoleranz (Luckheeram et al. 2012; Larosa und Orange 2008). CD8+ T-Lymphozyten werden auch zytotoxische T-Zellen genannt, da sie infizierte oder als körperfremd erkannte Zellen durch Lyse mittels Perforin, Granzyme und anderen Faktoren direkt zerstören können. CD8 ${ }^{+}$Zellen erkennen an MHC-Klasse-I gebundene Antigene. Das charakteristische Oberflächenprotein aller T-Lymphozyten ist der CD3-Rezeptor, er gilt als Pan-TZellmarker (Larosa und Orange 2008). T-Lymphozyten spielen, wie bereits in Kapitel 1.2 beschrieben, in der Pathogenese der aGvHD eine entscheidende Rolle. Dementsprechend konnte eine Erhöhung der CD8 ${ }^{+}$T-Zellen bei an einer aGvHD erkrankten Patienten noch vor Erscheinen einer klinischen Symptomatik nachgewiesen werden (August et al. 2011).

B-Lymphozyten vermitteln die humorale Immunantwort. Sie exprimieren Immunglobuline, welche als Antigenrezeptoren dienen, können Antigene präsentieren und produzieren Zytokine und Chemokine. Zu den typischen Oberflächenmolekülen der B-Lymphozyten gehören der CD19-, CD20-, CD21- und CD22-Rezeptor. B-Lymphozyten kommt in der Regulierung und Stimulierung von $\mathrm{CD}^{+}$und $\mathrm{CD} 8^{+} \mathrm{T}$-Zellen eine wichtige Bedeutung zu (Shimabukuro-Vornhagen et al. 2009). Sie können zum einen eine Aktivierung und ein Priming zum anderen eine immunologische Toleranz, also eine spezifische Suppression dieser Zellen, bewirken (Croft et al. 1997; Constant et al. 1995). Die exakte Rolle der B-Zellen in der Entstehung und Entwicklung der GvHD ist bisher allerdings nur unvollständig verstanden. Im Mausmodell führte eine B-Zell Depletion zu einem verminderten Auftreten einer aGvHD (Schultz et al. 1995). Eine hohe Zahl an B-Lymphozyten im Stammzellpräparat bei Stammzelltransplantationen ging in einer klinischen Studie wiederum mit einer erhöhten Inzidenz der aGvHD einher (lori et al. 2008). In verschiedenen Studien konnte zudem durch die Anwendung des Anti-CD20-Antikörpers Rituximab eine Linderung der aGvHD erreicht werden (Shimabukuro-Vornhagen et al. 2009). Demgegenüber wurde in anderen Studien eine protektive Wirkung von erhöhten Zahlen an Vorläufer-B-Zellen im Stammzellpräpräparat bezüglich des Auftretens der aGvHD festgestellt (Michonneau et al. 2009). 


\subsection{Monozyten}

Monozyten gehören zu den Leukozyten und werden im Knochenmark gebildet. Sie befinden sich nur kurzzeitig im peripheren Blut und wandern rasch in das Gewebe ab, wo sie sich zu Makrophagen differenzieren. Diese sind wichtiger Bestandteil des mononukleären Phagozytensystems und gehören zu den Antigen-präsentierenden Zellen. Sie erkennen Krankheitserreger, phagozytieren diese und schütten Zytokine und Chemokine aus und sind somit wichtiger Teil der angeborenen Immunantwort. Des Weiteren spielen sie durch die Fähigkeit zur Antigenpräsentation eine wichtige Rolle in der Aktivierung von T-Lymphozyten und somit der spezifischen Immunantwort. Das charakteristische Oberflächenmolekül der Monozyten und Makrophagen ist der CD14-Rezeptor (Ginhoux und Jung 2014).

\subsection{Lipopolysaccharid (LPS)}

Lipopolysaccharide (LPS) kommen in der äußeren Zellmembran gram-negativer Bakterien vor und stimulieren als Endotoxin durch eine Vielzahl an Mechanismen die angeborene Immunantwort. Dies geschieht unter anderem durch die Bindung des LPS an das Lipopolysaccharid-bindende-Protein, welches wiederum an den CD14-Rezeptor auf Monozyten und Makrophagen bindet, diese dadurch aktiviert und zu einer Ausschüttung diverser Zytokine (z. B. TNF- $\alpha$, IL-6, IFN-y) führt. Im Rahmen dieser Reaktion kommt es bei einer Infektion mit gram-negativen Erregern zu Symptomen wie Fieber, Übelkeit und Erbrechen bis hin zum endotoxischen Schock. Des Weiteren verursacht LPS eine Aktivierung und Proliferation von B-Zellen im murinen Organismus (Xu et al. 2008). Verschiedene Studien konnten zudem zeigen, dass bereits eine geringe Menge LPS eine Proliferation muriner und humaner T-Lymphozyten, insbesondere der CD8 ${ }^{+}$T-Zellen, bewirkt (Tough et al. 1997; Mattern et al. 1998). Auch in der Pathogenese der aGvHD spielt LPS eine wichtige Rolle. Das bereits durch die Konditionierung und durch die im Rahmen der GvHD ablaufenden immunlogischen Prozesse geschädigte Gewebe im gastrointestinalen Trakt fördert die Freisetzung von LPS und dessen Aufnahme in den systemischen Kreislauf. Hierdurch wird ein weiterer inflammatorischer Reiz gesetzt, der erheblich zur Entstehung und Entwicklung der aGvHD beiträgt (Hill und Ferrara 2000).

\subsection{Zielsetzung der Arbeit}

Diese Arbeit beschäftigt sich mit dem Einsatz von niedermolekularen und unfraktionierten Heparinen als mögliche Therapeutika in der Behandlung der aGvHD im Mausmodell. 
Das Ziel dieser Arbeit ist es durch die Anwendung von UFH und NMH in einem Mausmodell der aGvHD einen möglichen therapeutischen Einfluss der genannten Substanzen zu erkennen und nachzuweisen. Aufgrund der oben beschriebenen Studien zu dem antiinflammatorischen Potential von Heparin in verschiedenen Erkrankungen (Kapitel 1.9 Antiinflammatorischer Effekt des Heparins) wird angenommen, dass Heparin auch einen positiven Effekt auf das Überleben und den Schweregrad der ebenfalls durch verschiedene entzündliche Mechanismen ausgelösten aGvHD haben könnte. Die bisher einzige in der Literatur verfügbare Studie zeigte bereits einen positiven Effekt von Heparin auf die Ausprägung und Mortalität der Erkrankung im Mausmodell. In dieser Studie erfolgte jedoch weder eine Dosisfindung, noch eine Differenzierung zwischen unfraktioniertem und niedermolekularem Heparin (Naparstek et al. 1993).

Hauptbestandteil dieser Arbeit ist es daher in einem etablierten Mausmodell der aGvHD beide Formen des Heparins hinsichtlich ihrer Wirksamkeit zu testen und möglicherweise die erfolgversprechendere Form abzugrenzen. Zudem wurden verschiedene Applikationsformen miteinander verglichen und untersucht. Konkret führten wir eine Studie zur Dosisfindung mit NMH und UFH mittels s.c. und i.v. Applikation in dem etablierten MHCMismatch-Mausmodell der aGvHD durch.

Zusätzlich wurde in einer In-vitro-Versuchsreihe der mögliche Einfluss von Heparin auf Immunzellen des Menschen untersucht. Hierbei wurde mit Hilfe von Zellkulturen das Proliferationsverhalten humaner Leukozyten mit und ohne Zugabe von Heparin betrachtet. 


\section{Material und Methoden}

Das folgende Kapitel beschäftigt sich mit den verwendeten Materialien und den durchgeführten Methoden. Dabei wird vor allem auf die tierexperimentellen Methoden und die In-vitro-Untersuchungen genauer eingegangen. Zunächst folgt eine Übersicht über die verwendeten Materialien.

\subsection{Material}

\subsubsection{Chemikalien, Medien und Puffer}

Tabelle 1: Übersicht über die verwendeten Chemikalien, Medien und Puffer und deren Bezugsquelle. Geordnet in alphabetischer Reihenfolge.

\begin{tabular}{|c|c|}
\hline Produktname & Hersteller/Bezug \\
\hline Alkopharm 80 Desinfektionsmittel & Brüggemann Alkohol, Heilbronn, DE \\
\hline Ampuwa® Spüllösung Plastipur® & Fresenius, Bad Homburg v. d. H., DE \\
\hline Aqua Spüllösung Ecotainer ${ }^{\circledR}$ & B Braun, Melsungen, DE \\
\hline autoMACS $^{\mathrm{TM}}$ Running Buffer & Miltenyi Biotec, Bergisch Gladbach, DE \\
\hline Dimethylsulfoxid & Sigma-Aldrich, Deisenhofen, DE \\
\hline Ficoll-Paque $^{\mathrm{TM}}$ PLUS & GE Healthcare, Uppsala, SE \\
\hline HI Fetal Calf Serum (FCS) & Thermo Fisher Scientific, Waltham, USA \\
\hline Isotone Natriumchloridlösung $0,9 \%$ & B Braun, Melsungen, DE \\
\hline Lipopolysaccharides E. coli 026:B6 & Sigma-Aldrich, Deisenhofen, DE \\
\hline Penicillin/Streptomycin (10.000 U/ml) & $\begin{array}{l}\text { Gibco® Life Technologies }{ }^{\mathrm{TM}} \text {, Darmstadt, } \\
\text { DE }\end{array}$ \\
\hline PBS pH 7,4 (1X) (-) $\mathrm{CaCl}_{2}(-) \mathrm{MgCl}_{2}$ & $\begin{array}{l}\text { Gibco® Life Technologies }{ }^{\mathrm{TM}} \text {, Darmstadt, } \\
\text { DE }\end{array}$ \\
\hline Red Blood Cell Lysing Buffer & Sigma-Aldrich, Deisenhofen, DE \\
\hline RPMI Medium $1640(1 \mathrm{X})+$ GlutaMAX ${ }^{\mathrm{TM}}$ & $\begin{array}{l}\text { Gibco } ® \text { Life Technologies }{ }^{\mathrm{TM}} \text {, Darmstadt, } \\
\text { DE }\end{array}$ \\
\hline
\end{tabular}




\subsubsection{Labormaterialien}

Tabelle 2: Übersicht über die verwendeten Labormaterialien und deren Bezugsquellen. Geordnet in alphabetischer Reihenfolge.

\begin{tabular}{|c|c|}
\hline Produkt & Hersteller \\
\hline $5 \mathrm{ml}$ Spritzen & BD Discardit ${ }^{\mathrm{TM}}$, Heidelberg, DE \\
\hline $5 \mathrm{ml}$ Polystyrol-Round-Bottom Tube & BD Falcon, Heidelberg, DE \\
\hline $15 \mathrm{ml}$ Clonical Tube & BD Falcon, Heidelberg, DE \\
\hline $50 \mathrm{ml}$ Cellstar ${ }^{\circledR}$ Clonical Tube & Greiner Bio-One, Frickenhausen, DE \\
\hline Dental-Maske mit Ohrenschlaufen & Farstar medical, Barsbüttel, DE \\
\hline Glaspipetten, steril (5-25 ml) & BD Falcon, Heidelberg, DE \\
\hline Hämacytometer Deckgläser & Brand, Wertheim, DE \\
\hline MACS MultiStand & Miltenyi Biotec, Bergisch Gladbach, DE \\
\hline MACS® Seperation Columns & Miltenyi Biotec, Bergisch Gladbach, DE \\
\hline Micro-Fine $^{\mathrm{TM}}+$ Demi U100 Insulinspritzen & BD, Heidelberg, DE \\
\hline Microlance $^{\mathrm{TM}} 3$ Kanülen & BD, Heidelberg, DE \\
\hline Micro tubes 1,5 und $2 \mathrm{ml}$ & Sarstedt, Nürnbrecht, DE \\
\hline MoliNea normal & Hartmann, Heidenheim, DE \\
\hline Neubauer Zählkammer & $\begin{array}{l}\text { Hecht Assistent, Sondheim v. d. Rhön, } \\
\text { DE }\end{array}$ \\
\hline Nitril Next Gen® Handschuhe & Meditrade, Kiefersfelden, DE \\
\hline Pasteurpipetten aus Glas & Brand, Wertheim, DE \\
\hline QuadroMACS Separator & Miltenyi Biotec, Bergisch Gladbach, DE \\
\hline Rad-Sure $^{\mathrm{TM}}$ blood irradiation indicators & Ashland, Convington, USA \\
\hline Safe-Lock Tubes 1,5 und $2 \mathrm{ml}$ & Eppendorf AG, Hamburg, DE \\
\hline Sterican Kanülen Gr. 20 & B Braun, Melsungen, DE \\
\hline Spritze mit Kanüle & BD Plastipak $^{\mathrm{TM}}$, Heidelberg, DE \\
\hline Surgical Hood & $\begin{array}{l}\text { Barrier, Mölnlycke Health Care, Erkrath- } \\
\text { Unterfeldhaus, DE }\end{array}$ \\
\hline TC-Zellkulturflaschen $25 \mathrm{~cm}^{2}$ mit Filter & CytoOne, Hamburg, DE \\
\hline TC-Schalen & Sarstedt, Nürnbrecht, DE \\
\hline $\begin{array}{l}\text { TipOne Pipettenspitzen mit Filter, ver- } \\
\text { schiedene Größen }\end{array}$ & Starlab, Hamburg, DE \\
\hline Tuberkulinspritzen $1 \mathrm{ml}$ Luer & BD Plastipak, Heidelberg, DE \\
\hline Zellkultur Multiwellplatte Cellstar® & Greiner Bio-One, Frickenhausen, DE \\
\hline Zells & \\
\hline
\end{tabular}




\subsubsection{Laborgeräte}

Tabelle 3: Übersicht über die verwendeten Laborgeräte und deren Bezugsquellen. Geordnet in alphabetischer Reihenfolge.

\begin{tabular}{|c|c|c|}
\hline Gerät & Gerätetyp & Hersteller \\
\hline Absaugpumpe & - & KNF Laboport, Freiburg, DE \\
\hline Brutschrank & HERAcell & Heraeus, Hanau, DE \\
\hline Bestrahlungsanlage & Xstrahl RS 225 & $\begin{array}{l}\text { Gulmay Medical Limited, } \\
\text { Surrey, UK }\end{array}$ \\
\hline Durchflusszytometer & FACSCanto II & BD, Heidelberg, DE \\
\hline Eismaschine & - & $\begin{array}{l}\text { Brema Ice Makers, Villa Cor- } \\
\text { tese, IT }\end{array}$ \\
\hline Gefrierschränke $-20^{\circ} \mathrm{C}$ & Premium & $\begin{array}{l}\text { Liebherr, Biberach an der } \\
\text { Riß, DE }\end{array}$ \\
\hline Kühlschränke & Premium/Comfort & $\begin{array}{l}\text { Liebherr, Biberach an der } \\
\text { Riß, DE }\end{array}$ \\
\hline Lichtmikroskop & Axiostar & Zeiss, Oberkochen, DE \\
\hline Lichtmikroskop & Axiovert 25 & Zeiss, Oberkochen, DE \\
\hline $\begin{array}{l}\text { Pipetten, verschiedene } \\
\text { Größen }\end{array}$ & Eppendorf Reference & $\begin{array}{l}\text { Eppendorf AG, Hamburg, } \\
\text { DE }\end{array}$ \\
\hline Pipettierhilfe & Pipetboy acu & $\begin{array}{l}\text { Integra Bioscience, Kon- } \\
\text { stanz, DE }\end{array}$ \\
\hline Präparierbesteck & - & $\begin{array}{l}\text { Fine Science Tools } \AA \text {, Hei- } \\
\text { delberg, DE }\end{array}$ \\
\hline Rotlichtlampe & Sollux 750 & Original Hanau, Hanau, DE \\
\hline Sterilbank & $\begin{array}{l}\text { Microflow Biological Safety } \\
\text { Cabinet }\end{array}$ & $\begin{array}{l}\text { Nalge Nunc International, } \\
\text { Rochster, USA }\end{array}$ \\
\hline Taschenwaage & TEE 150-1 & $\begin{array}{l}\text { Kern, Balingen-Frommern, } \\
\text { DE }\end{array}$ \\
\hline Taumelrollenmischer & TRM 50 & IDL GmbH, Nidderau, DE \\
\hline Vortexer & Vortex-Genie 2 & $\begin{array}{l}\text { Scientific Industries, New } \\
\text { York, USA }\end{array}$ \\
\hline Wasserbad & 3042 & $\begin{array}{l}\text { Köttermann, } \\
\text { Uetze/Hänigsen, DE }\end{array}$ \\
\hline Zentrifugen & Rotanta 46 RS & Hettich, Kirchlengern, DE \\
\hline
\end{tabular}

\subsubsection{Mauslinien}

Tabelle 4: Übersicht über die verwendeten Mauslinien und deren Bezugsquelle. Geordnet in alphabetischer Reihenfolge.

\begin{tabular}{lll} 
Stamm & Hintergrund & Herkunft \\
\hline BALB/c $\left(\mathrm{H}^{\mathrm{d}}{ }^{\mathrm{N}}\right.$ & Inzucht & $\begin{array}{l}\text { Charles River Laborato- } \\
\text { ries, Sulzfeld, DE }\end{array}$ \\
\hline $\mathrm{C} 57 \mathrm{BL} / 6 \mathrm{~J}\left(\mathrm{H}^{\mathrm{b}}\right)$ & Inzucht & $\begin{array}{l}\text { Janvier, St. Berthevin Ce- } \\
\text { dex, FR }\end{array}$
\end{tabular}




\subsubsection{Primärantikörper Anti-Maus}

Tabelle 5: Übersicht über die verwendeten Primärantikörper Anti-Maus mit Klon, Konjugat und Hersteller.

\begin{tabular}{|c|c|c|c|}
\hline Spezifität & Klon & Konjugat & Hersteller \\
\hline CD3 $\varepsilon$ & $145-2 \mathrm{C} 11$ & FITC & $\begin{array}{l}\text { BioLegend, London, } \\
\text { UK }\end{array}$ \\
\hline CD4 & RM4-5 & $\mathrm{PE}$ & $\begin{array}{l}\text { BioLegend, London, } \\
\text { UK }\end{array}$ \\
\hline CD8a & $53-6.7$ & APC & $\begin{array}{l}\text { BioLegend, London, } \\
\text { UK }\end{array}$ \\
\hline CD117 & $3 \mathrm{C} 11$ & APC & $\begin{array}{l}\text { Miltenyi Biotec, Ber- } \\
\text { gisch Gladbach, DE }\end{array}$ \\
\hline $\begin{array}{l}\text { MC CD90.2 T Cell Cock- } \\
\text { tail }\end{array}$ & $30-\mathrm{H} 12$ & $\mathrm{PE}$ & $\begin{array}{l}\text { Miltenyi Biotec, Ber- } \\
\text { gisch Gladbach, DE }\end{array}$ \\
\hline Anti-Biotin & Bio3-18E7 & FITC & $\begin{array}{l}\text { Miltenyi Biotec, Ber- } \\
\text { gisch Gladbach, DE }\end{array}$ \\
\hline $\begin{array}{l}\text { Lineage Cell Detection } \\
\text { Cocktail-Biotin: CD5, } \\
\text { CD11b, CD45R, Anti-7-4, } \\
\text { Anti-Gr-1, Anti-Ter-119 }\end{array}$ & & FITC & $\begin{array}{l}\text { Miltenyi Biotec, Ber- } \\
\text { gisch Gladbach, DE }\end{array}$ \\
\hline
\end{tabular}

\subsubsection{Primärantikörper Anti-Human}

Tabelle 6: Übersicht über die verwendeten Primärantikörper Anti-Human mit Klon, Konjugat und Hersteller.

\begin{tabular}{|c|c|c|c|}
\hline Spezifität & Klon & Konjugat & Hersteller \\
\hline CD3 & HIT3a & FITC & BioLegend, London, UK \\
\hline CD14 & M5E2 & PE & BioLegend, London, UK \\
\hline CD19 & HIB 19 & APC & BioLegend, London, UK \\
\hline $\begin{array}{l}\text { Cell Proliferation Dye } \\
\text { (CPD) eFluor® } 450\end{array}$ & - & $\begin{array}{l}\text { eFluor/Pacific } \\
\text { Blue }\end{array}$ & $\begin{array}{l}\text { eBioscience, Frankfurt, } \\
\text { DE }\end{array}$ \\
\hline $\begin{array}{l}\text { Human } \\
\text { FcX' }\end{array}$ & - & - & BioLegend, London, UK \\
\hline
\end{tabular}




\subsubsection{Reagenzien zur Zellisolierung}

Tabelle 7: Übersicht über die verwendeten Reagenzien zur Zellisolierung und deren Bezugsquelle.

Name

Hersteller

Pan T Cell Biotin-Antibody Cocktail, mouse:

Miltenyi Biotec, Bergisch Glad-

CD11b, CD11c, CD19, CD45R, CD49b, CD105, bach, DE

Anti-MHC class II, Ter-119

Anti-Biotin MicroBeads

Miltenyi Biotec, Bergisch Gladbach, DE

CD90.2 MicroBeads, mouse

Miltenyi Biotec, Bergisch Gladbach, DE

\subsubsection{Medikamente}

Tabelle 8: Übersicht über die verwendeten Medikamente, deren Wirkstoff und Hersteller. Geordnet in alphabetischer Reihenfolge.

\begin{tabular}{lll} 
Name & Wirkstoff & Hersteller \\
\hline Clexane ${ }^{\circledR}$ 20mg & Enoxaparin-Natrium & $\begin{array}{l}\text { Sanofi-Aventis, Frankfurt am } \\
\text { Main, DE }\end{array}$ \\
\hline $\begin{array}{ll}\text { Heparin-Natrium-5000-rati- } \\
\text { opharm }{ }^{8}\end{array}$ & Heparin-Natrium & Ratiopharm, Ulm, DE \\
\hline Metapyrin 500mg/ml & Metamizol-Natrium & $\begin{array}{l}\text { Serumwerk Bernburg AG, } \\
\text { Bernburg, DE }\end{array}$ \\
& & $\begin{array}{l}\text { Sigma-Aldrich, Deisenh- } \\
\text { ofen, DE }\end{array}$ \\
\hline $\begin{array}{l}\text { Neomycin trisulfate salt hyd- } \\
\text { rate }\end{array}$ & Neomycin &
\end{tabular}

\subsubsection{EDV-Programme}

Tabelle 9: Übersicht über die verwendeten EDV-Programme. Geordnet in alphabetischer Reihenfolge.

\begin{tabular}{lll} 
Software & Verwendung & Firma \\
\hline BD FACSDiva V6.1.3 & & BD, Heidelberg, DE \\
& Literaturverwaltung & $\begin{array}{l}\text { Swiss Academic Software } \\
\text { GmbH, Wädenswil, CH }\end{array}$ \\
\hline Citavi 4 & & \\
& & StatSoft, Hamburg, DE
\end{tabular}




\subsubsection{Herstellung gebrauchsfertiger Medien und Lösungen}

Tabelle 10: Übersicht über die verwendeten Medien und Lösungen und deren Zusammensetzung.

\begin{tabular}{ll} 
Name & Zusammensetzung \\
\hline Zellkulturmedium & $\begin{array}{l}\text { Roswell Park Memorial Institute (RPMI) 1640 Medium 1x } \\
+ \text { L-Glutamin } \\
\text { Penicillin/Streptomycin 1\% } \\
\text { Fetal Calf Serum (FCS) } 10 \%\end{array}$ \\
& \\
\hline $\begin{array}{l}\text { Neomycin-Stammlösung } \\
\text { Trinkwasser }\end{array}$ & $\begin{array}{l}250 \mathrm{mg} \mathrm{Neomycin} \text { trisulfat salt hydrat in } \\
1.000 \mathrm{ml} \mathrm{H} \mathrm{O}\end{array}$ \\
\hline $\begin{array}{l}\text { Natriumcitrat(NaCi)- } \\
\text { Stammlösung }\end{array}$ & $\begin{array}{l}73,525 \mathrm{~g} \text { tri-Natrium-Citrat-Dihydrat in } \\
\text { 1.000 ml Aqua dest. }\end{array}$ \\
\hline NaCi-Lösung & $\begin{array}{l}\text { 1 Teil NaCi-Stammlösung } \\
1 \text { Teil PBS ohne Mg, Ca und EDTA }\end{array}$ \\
\hline Buffy-Lösung & 1 Teil NaCi-Lösung \\
& 1 Teil Buffy-Coat
\end{tabular}




\subsection{Methoden}

\subsubsection{Tierexperimentelle Methoden}

Alle tierexperimentellen Methoden wurden unter Einhaltung der gesetzlichen Regelungen und Bestimmungen laut Tierschutzgesetz durchgeführt und sind durch das Niedersächsische Landesamt für Verbraucherschutz und Lebensmittelsicherheit durch die Tierversuchsanträge 33.9-42502-04-12/0943 genehmigt worden. Um das Leiden der Mäuse so gering wie möglich zu halten, wurde das Trinkwasser mit dem Schmerzmittel Metamizol versetzt.

\subsubsection{Haltung der Versuchstiere}

Die Tiere wurden den kompletten Versuchszeitraum in einem IVC-Käfig (individual ventilated cage) mit einer maximalen Anzahl von fünf Mäusen pro Käfig gehalten. Dabei betrug die Temperatur $20^{\circ} \mathrm{C} \pm 2{ }^{\circ} \mathrm{C}$ und die Luftfeuchtigkeit $55 \% \pm 5 \%$. Zur Vermeidung von Kontaminationen wurden die Käfige nur unter einem Abzug geöffnet. Alle Tiere erhielten die gleiche Diät, als Futtermittel dienten Pellets (V1534-0, ssnif R/M-H) und Breifutter (V1530-0, ssnif R/M-H). Das Breifutter wurde erst ab einem Gewicht von unter $20 \mathrm{~g}$ bei mindestens einem Tier im Käfig zusätzlich gefüttert. Bei Breifuttergabe wurden die Käfige täglich gewechselt. Ansonsten erfolgte ein Käfigwechsel am Transplantationstag und an den Therapietagen. Um Infektionen zu vermeiden und Schmerzen zu reduzieren, wurde dem Trinkwasser ab dem Tag der Transplantation das Antibiotikum Neomycin und das Schmerzmittel Metapyrin (Metamizol) zugesetzt. Dafür wurden $100 \mathrm{ml}$ Neomycin-Stammlösung und 2,8 ml Metapyrin mit $900 \mathrm{ml}$ Wasser vermischt. Das Trinkwasser wurde dreimal pro Woche erneuert.

\subsubsection{Mäusemodell zur aGvHD}

Um eine aGvHD im Mäusemodell auslösen zu können, ist das Vorgehen nach einem Transplantationsmodell notwendig (Tischner et al. 2011). Als Empfängertiere dienten immer zwischen zehn und zwölf Wochen alte, männliche BALB/c Mäuse (Charles River Laboratories, Sulzfeld, Deutschland). Die Zellen zur Transplantation wurden bei allen Transplantationen aus männlichen C57BL/6J (B6) Spendertieren (Janvier, St. Berthevin, Frankreich) gewonnen. Bei dieser Kombination handelt es sich um ein MHC-MismatchModell. Zunächst wurden die Empfängertiere mittels Ganzkörperbestrahlung konditioniert. Am darauffolgenden Tag (Tag 0) erfolgte die Gewinnung der zu transplantierenden Zellen und die Transplantation. 


\subsubsection{Bestrahlung der Mäuse}

Zur Konditionierung, vor der Knochenmarktransplantation, erhielten die Mäuse einmalig eine Ganzkörperbestrahlung mit der letalen Dosis von 9,5 Gy (1 Gy/min). Dazu wurden die Mäuse käfigweise in ein Bestrahlungsgefäß gesetzt und durch die Röntgenstrahlanlage Gulmay RS 225 bestrahlt. Die Grayzahl konnte mittels Tischhöhe eingestellt werden. Die Bestrahlung erfolgte immer mit $1 \mathrm{~Gy} / \mathrm{min}$ über 9,5 min. Zur Kontrolle wurde jeweils ein Indikatorstreifen (Rad-Sure ${ }^{\mathrm{TM}}$ blood irradiation indicators, Ashland, Convington, USA) mitbestrahlt. An dem Farbumschlag des Indikatorstreifens konnte die Grayzahl abgeschätzt und so die Bestrahlung verifiziert werden.

\subsubsection{Gewinnung der Zellen}

Um eine akute GvHD sicher induzieren zu können, müssen zunächst ausreichend Spenderzellen aus Knochenmark, Lymphknoten und Milz gewonnen werden. Im durchgeführten Transplantationsmodell wurden pro Empfängertier $10 \times 10^{6}$ Knochenmarkzellen aus Femur und Tibia und $2 \times 10^{6} \mathrm{~T}$-Zellen aus Lymphknoten und Milz für eine sichere Auslösung einer aGvHD benötigt.

Die C57BL/6J Spendertiere wurden dafür mittels $\mathrm{CO}_{2}$ und zervikaler Dislokation abgetötet. Anschließend wurden mit Hilfe von sterilem Präparationsbesteck die inguinalen, zervikalen, axillaren und mesenterialen Lymphknoten sowie die Milz entnommen und in Petrischalen mit eisgekühlter, steriler phosphatgepufferten Salzlösung (PBS) gegeben. Tibia und Femur beider Hinterbeine wurden entfernt und von Geweberesten befreit. Lymphknoten und Milz wurden jeweils unter sterilen Bedingungen mit Hilfe des Stempels einer Spritze durch ein $40 \mu \mathrm{m}$ Zellsieb gedrückt. Dabei wurde mehrfach mit PBS gespült, um alle Zellen aus dem Zellsieb zu entfernen. Die Knochenenden von Tibia und Femur wurden mit einer Schere abgeschnitten und das Knochenmark unter sterilen Bedingungen mit einer Spritze mit Kanüle durch PBS aus dem Knochen in eine Petrischale gespült. Anschließend wurden die separat gewonnenen Zellsuspensionen von Lymphknoten, Milz und Knochenmark jeweils bei $300 g_{0}\left(g_{0}\right.$ ist die Fallbeschleunigung von $\left.9,81 \mathrm{~m} / \mathrm{s}^{2}\right)$ und $4{ }^{\circ} \mathrm{C}$ für 10 min zentrifugiert und dann mit Hilfe einer Neubauer Zählkammer die jeweiligen Zellzahlen bestimmt.

Zur weiteren Separation wurde das Verfahren der Magnetic Cell Seperation (MACS) angewandt.

Bei der Magnetic Cell Seperation werden, mit Hilfe magnetischer MicroBeads und magnetischer Säulen, Zellen markiert und so sortiert. Dabei wird die gewünschte Zellpopulation zunächst in einer Zellsuspension durch Antikörper, die mit den magnetischen 
MicroBeads verbunden sind, markiert. Die Zellsuspension, die nun markierte und unmarkierte Zellen enthält, wird in die MACS-Säule gegeben. Sie befindet sich im MACSSeparator. Der MACS-Separator enthält einen starken Magneten, der ein Magnetfeld erzeugt, wodurch die magnetisch markierten Zellen zurückgehalten werden. Die nicht markierten Zellen können die MACS-Säule ungehindert durchlaufen. Diese aufgefangene Zellsuspension enthält keine markierten Zellen mehr (Depletion). Die in den Säulen verbliebenen markierten Zellen können anschließend bei Bedarf ausgewaschen werden (positive Selektion) (Miltenyi et al. 1990).

Im Einzelnen wurde dabei folgendermaßen vorgegangen:

Die gewünschten Zellzahlen von Knochenmark (KM), Milz (SP) und Lymphknoten (LN) (maximal $6 \times 10^{8}$ Zellen pro Säule) wurden gewaschen und anschließend in dem vorgeschriebenen Volumen PBS aufgenommen.

\subsubsection{Depletion der T-Lymphozyten aus der Knochenmarkzellsuspension}

Die T-Lymphozyten bestimmen die Schwere der aGvHD. Aus diesem Grund wurde die Knochenmarkzellsuspension T-Zell depletiert, um so den Ausprägungsgrad der aGvHD besser steuern zu können. Die T-Zellen wurden aus Milz und Lymphknoten gewonnen. Das Antigen CD90.2 ist auf den T-Lymphozyten der meisten Inzucht-Mauslinien zu finden und kann dazu genutzt werden, diese zu markieren und zu selektieren. Dafür wurde die Knochenmarkzellsuspension mit $167 \mu \mathrm{l}$ CD90.2 MicroBeads gemischt und für 15 min bei $4{ }^{\circ} \mathrm{C}$ inkubiert. Danach erfolgte die Zugabe von $5 \mathrm{ml}$ PBS und eine Zentrifugation bei $300 \mathrm{~g}_{0}$ für $10 \mathrm{~min}$. Das Pellet wurde in $3 \mathrm{ml}$ PBS resuspendiert. 1,5 ml der KM-Suspension wurden in die zuvor mit $3 \mathrm{ml}$ gewaschenen MACS-Säulen gegeben. Nachdem die Zellsuspension die Säulen passiert hatte, wurden die Säulen mit $3 \times 3 \mathrm{ml}$ PBS gespült, um alle nicht markierten Zellen aus den Säulen zu waschen. Das Ganze wurde nochmals genauso mit den verbliebenen 1,5 ml der KM-Suspension wiederholt. Die so gewonnenen und aufgefangenen T-Zell-depletierten Knochenmarkzellen wurden gezählt.

\subsubsection{Gewinnung der T-Zellen}

Die Suspensionen von Lymphknoten und Milz wurden jeweils mit $3 \mu$ Pan T Cell BiotinAntibody Cocktail pro $10^{7}$ Zellen für 10 min inkubiert. Danach wurden sie mit $10 \mu$ PBS pro $10^{7}$ Zellen gemischt und mit 6,5 $\mu \mathrm{l}$ Anti-Biotin Beads pro $10^{7}$ Zellen für 15 min inkubiert. Anschließend erfolgte die Zugabe von je $4 \mathrm{ml}$ PBS und eine Zentrifugation bei $300 \mathrm{~g}_{0}$ für $10 \mathrm{~min}$. Die Pellets wurden in $3 \mathrm{ml}$ PBS resuspendiert. Die zwei Zellsuspensionen wurden analog zum Knochenmark mittels MACS-Säulen separiert und gezählt. 


\subsubsection{Fertigstellung des Stammzelltransplantats}

Pro Tier wurden $10 \times 10^{6} \mathrm{KM}$-Zellen, $1 \times 10^{6} \mathrm{LN}$-Zellen und $1 \times 10^{6} \mathrm{SP}$-Zellen benötigt. Um bei der Injektion ausreichend Transplantat zur Verfügung zu haben, wurde die doppelte Zellzahl angesetzt. Das heißt, bei einer Serie mit 20 Tieren wurde ein Ansatz für 40 Tiere

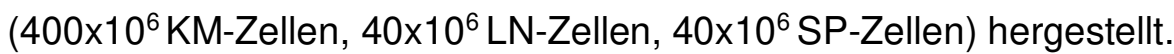

Die benötigten Zellzahlen von Knochenmark, Lymphknoten und Milz wurden in einem $50 \mathrm{ml}$ Röhrchen gesammelt und nochmals bei $300 \mathrm{~g}_{0}$ und $4{ }^{\circ} \mathrm{C}$ für $10 \mathrm{~min}$ zentrifugiert. Das Pellet wurde in PBS (150 $\mu$ l pro Injektion) resuspendiert und in sterile Micro tubes gefüllt. Bis zur Transplantation wurde das Transplantat durchgehend auf Eis gekühlt.

\subsubsection{Stammzelltransplantation (Tag 0)}

Das gewonnene und aufgereinigte Transplantat wurde nun den BALB/c-Empfängertieren injiziert. Die Transplantation der Zellen erfolgte i.v. in die linke oder rechte Schwanzvene. Jedes Tier erhielt ein Injektionsvolumen von $150 \mu$ l. Dafür wurden die Mäuse, insbesondere der Schwanz, unter einer Infrarotlampe angewärmt, um die Schwanzvenen zu erweitern und so die korrekte i.v. Injektion des Transplantats zu erleichtern. In einer speziell angefertigten Halterung wurden die Mäuse fixiert, um so ungehindert in die Schwanzvenen injizieren zu können. Zur Injektion wurden sterile Insulinspritzen verwendet. Anschließend wurde das Ausgangsgewicht der Mäuse ermittelt.

\subsubsection{Färbung der Zellen der Stammzelltransplantation}

Am Tag nach der Transplantation (Tag 1) wurden die Zellen, die für die Knochenmarktransplantation an Tag 0 genutzt wurden, gefärbt und mittels Durchflusszytometrie analysiert. Dafür wurden $1 \times 10^{6}$ Zellen von Knochenmark, Lymphknoten und Milz in jeweils zwei Röhrchen gegeben (eine gefärbte und eine ungefärbte Probe pro Gewebe). Die Röhrchen mit den ungefärbten Proben wurden bis zu der Messung im Durchflusszytometer gekühlt. Die Zellen des Knochenmarks wurde mit $10 \mu$ l Lineage Cell Detection Cocktail Biotin mouse gemischt und für $10 \mathrm{~min}$ bei $4{ }^{\circ} \mathrm{C}$ im Dunkeln inkubiert und anschließend mit $1 \mathrm{ml} \mathrm{PBS}$ gewaschen und bei $350 \mathrm{~g}_{0}$ für 5 min bei $4^{\circ} \mathrm{C}$ zentrifugiert. Das Pellet wurde in $100 \mu \mathrm{l}$ PBS resuspendiert und mit $10 \mu \mathrm{l}$ Anti-Biotin FITC, $10 \mu \mathrm{l}$ CD117 APC und $10 \mu \mathrm{l}$ CD90.2 T-Cell Cocktail durchmischt und erneut für $10 \mathrm{~min}$ bei $4^{\circ} \mathrm{C} \mathrm{im}$ Dunkeln inkubiert. Der Waschschritt wurde wiederholt und das Pellet in $200 \mu$ I PBS resuspendiert. Die Zellen von Lymphknoten und Milz wurden jeweils mit $10 \mu$ l CD90.2 TCell Cocktail für 10 min bei $4{ }^{\circ} \mathrm{C}$ im Dunkeln inkubiert, ebenfalls gewaschen und in $200 \mu \mathrm{l}$ PBS resuspendiert. Die gefärbten und ungefärbten Proben wurden im Anschluss im Durchflusszytometer FACS Canto II, BD gemessen. 


\subsubsection{Monitoring der transplantierten Mäuse}

Die Tiere wurden nach der Transplantation täglich begutachtet und gewogen. Der Krankheitsverlauf wurde mit Hilfe einer Punktetabelle dokumentiert (siehe Tabelle 11). Dabei wurde anhand der Kriterien Fellbeschaffenheit/Hautintegrität, Aktivität, Körperhaltung, Durchfall und Gewichtsverlust der Ausprägungsgrad der GvHD beurteilt. Pro Kriterium konnte eine maximale Punktzahl von zwei Punkten vergeben und so eine Maximalpunktzahl von zehn Punkten erreicht werden. Erreichten die Tiere jedoch einen Gesamtscore von sechs oder mehr Punkten oder einen Gesamtscore von fünf oder mehr Punkten an mehr als drei aufeinanderfolgenden Tagen, wurden die Tiere aus tierschutzrechtlichen Gründen aus dem Versuch genommen und zur weiteren Untersuchung von Lymphknoten und Milz mittels $\mathrm{CO}_{2}$ und zervikaler Dislokation euthanasiert. Bei einem Gewichtsverlust von mehr als $25 \%$ innerhalb von 24 Stunden wurden die Mäuse ebenfalls vorzeitig aus dem Versuch genommen. Nach 49 bzw. 30 Tagen wurde der Versuch beendet und die verbliebenen Tiere wurden zur weiteren Analyse von Lymphknoten und Milz euthanasiert.

Tabelle 11: Punktetabelle für das tägliche Monitoring.

\begin{tabular}{|c|c|c|c|c|}
\hline Kriterium & Score 0 & Score 1 & Score 1,5 & Score 2 \\
\hline $\begin{array}{l}\text { Körperhal- } \\
\text { tung }\end{array}$ & Normal & $\begin{array}{c}\text { Leichtes } \\
\text { Buckeln nur } \\
\text { während des } \\
\text { Sitzens }\end{array}$ & $\begin{array}{l}\text { Deutliches } \\
\text { Buckeln }\end{array}$ & $\begin{array}{l}\text { Starkes Bu- } \\
\text { ckeln, auch } \\
\text { während der } \\
\text { Bewegung }\end{array}$ \\
\hline Aktivität & Normal & $\begin{array}{l}\text { Leicht redu- } \\
\text { ziert }\end{array}$ & $\begin{array}{c}\text { Deutlich redu- } \\
\text { ziert }\end{array}$ & $\begin{array}{l}\text { Bewegungslo- } \\
\text { sigkeit, außer } \\
\text { nach Stimula- } \\
\text { tion }\end{array}$ \\
\hline $\begin{array}{l}\text { Fellbeschaf- } \\
\text { fenheit und } \\
\text { Hautintegrität }\end{array}$ & Normal & $\begin{array}{l}\text { Leicht struppi- } \\
\text { ges Fell oder } \\
\text { schuppige } \\
\text { Haut }\end{array}$ & $\begin{array}{l}\text { Stark struppi- } \\
\text { ges Fell }\end{array}$ & $\begin{array}{l}\text { Stark struppi- } \\
\text { ges Fell und } \\
\text { regionaler Fell- } \\
\text { verlust }\end{array}$ \\
\hline Diarrhoe & Keine & Leicht & Mäßig & Stark \\
\hline $\begin{array}{c}\text { Gewichtsver- } \\
\text { lust }\end{array}$ & $<10 \%$ & $\begin{array}{c}>10 \% \text { bis } \\
<20 \%\end{array}$ & - & $>20 \%$ \\
\hline
\end{tabular}




\subsubsection{Therapie der transplantierten Mäuse}

Um die Einwirkung von UFH und NMH auf die aGvHD im Mausmodell zu untersuchen und die möglichst effektivste Form zu finden, wurden unterschiedliche Dosen beider Substanzen über verschiedenen Applikationswege erprobt. Als NMH wurde EnoxaparinNatrium (Clexane) der Firma Sanofi-Aventis verwendet. Als UFH diente Heparin-Natrium-5000 der Firma Ratiopharm (Heparin). Eine Übersicht über alle durchgeführten Serien mit den jeweiligen Therapieschemata ist in Tabelle 12 dargestellt.

Tabelle 12: Übersicht über alle Serien mit Therapieschemata.

\begin{tabular}{|c|c|c|c|c|c|}
\hline $\begin{array}{l}\text { Serien- } \\
\text { Nummer }\end{array}$ & Tierzahl & $\begin{array}{l}\text { Medika- } \\
\text { ment }\end{array}$ & $\begin{array}{l}\text { Injektions- } \\
\text { art }\end{array}$ & $\begin{array}{l}\text { Dosis pro } \\
\text { Injektion }\end{array}$ & $\begin{array}{l}\text { I.E./kg } \\
\mathrm{KG}\end{array}$ \\
\hline \multirow{2}{*}{ Serie 42} & ב10 Therapietiere & Clexane & \multirow{2}{*}{ s.c. } & 5 I.E. & 200 \\
\hline & 10 Kontrolltiere & $\mathrm{NaCl}$ & & - & - \\
\hline \multirow{3}{*}{ Serie 44} & 8 Therapietiere & Clexane & & 0,5 I.E. & 20 \\
\hline & 8 Therapietiere & Heparin & s.c. & 5 I.E. & 200 \\
\hline & 9 Kontrolltiere & $\mathrm{NaCl}$ & & - & - \\
\hline \multirow{3}{*}{ Serie 46} & 7 Therapietiere & Heparin & & 2,5 I.E. & 100 \\
\hline & 7 Therapietiere & Heparin & s.c. & 1,25 I.E. & 50 \\
\hline & 6 Kontrolltiere & $\mathrm{NaCl}$ & & - & - \\
\hline \multirow{3}{*}{ Serie 48} & 7 Therapietiere & Clexane & & 0,5 I.E. & 20 \\
\hline & 7 Therapietiere & Heparin & i.v. & 2,5 I.E. & 100 \\
\hline & 6 Kontrolltiere & $\mathrm{NaCl}$ & & - & - \\
\hline \multirow{3}{*}{ Serie 50} & 7 Therapietiere & Clexane & & 0,5 I.E. & 20 \\
\hline & 7 Therapietiere & Heparin & i.v. & 2,5 I.E. & 100 \\
\hline & 6 Kontrolltiere & $\mathrm{NaCl}$ & & - & - \\
\hline \multirow{3}{*}{ Serie 52} & 9 Therapietiere & Heparin & & 1,25 I.E. & 50 \\
\hline & 8 Therapietiere & Heparin & s.c. & 0,625 I.E. & 25 \\
\hline & 8 Kontrolltiere & $\mathrm{NaCl}$ & & - & - \\
\hline
\end{tabular}

Als Applikationsformen wurde sowohl die s.c. als auch die i.v. Injektion angewandt. Es wurden Konzentrationen von 20-200 I.E. Heparin oder Clexane pro kg Körpergewicht (KG) appliziert.

Die jeweils gewünschten Konzentrationen an Heparin oder Clexane wurden steril in isotoner Natriumchloridlösung $(\mathrm{NaCl})$ gelöst und pro Injektion wurde ein Volumen von $100 \mu l$, je nach Serie entweder s.c. oder i.v., verabreicht. In allen Serien gab es parallel 
zu den Therapietieren auch eine Gruppe von Kontrolltieren. Diese erhielten auf die gleiche Injektionsart ein Volumen von $100 \mu \mathrm{l} \mathrm{NaCl}$ ohne Zugabe des Therapeutikums. Die Therapie- und Kontrolltiere wurden in allen durchgeführten Serien gemischt gehalten. Zur eindeutigen Identifizierung wurden die Tiere vor Versuchsbeginn mittels Ohrlochung markiert.

Die s.c. Injektionen erfolgten dreimal pro Woche, jeweils Montag, Mittwoch und Freitag, über den kompletten Versuchszeitraum (siehe Abbildung 2). In einer Serie erfolgten die s.c. Injektionen einmal täglich, an sechs Tagen die Woche, über einen Zeitraum von 30 Tagen. Dabei wurde abwechselnd in die Nacken- oder Leistenfalten der Mäuse injiziert, um die Entstehung eines Abszesses durch die häufigen Injektionen vorzubeugen. Zur Injektion in die Nackenfalte wurden die Mäuse mit einer Hand auf dem Käfiggitter fixiert während gleichzeitig mit zwei Fingern die Haut des Nackens etwas angehoben wurde. Mit der anderen Hand wurde die gewünschte Substanz in die angehobene Nackenfalte injiziert. Zur Injektion in die rechte oder linke Leistenfalte wurden die Tiere im Zwangsgriff fixiert. Dazu wird die Maus vorsichtig auf das Käfiggitter gedrückt und mit Daumen und Zeigefinger im Nacken gegriffen. Der Schwanz wird zwischen Ring- und Kleinfinger derselben Hand fixiert. Nun liegen die Leistenfalten frei und mit der anderen Hand kann s.c. injiziert werden. Die Injektion erfolgte mit Sterican Einmalkanülen Gr. 20.

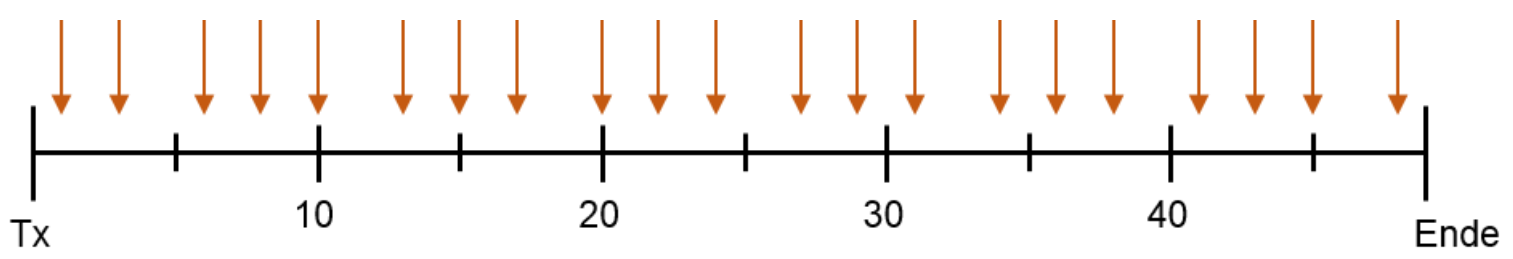

Abbildung 2: Zeitskala der s.c. Injektionen in Tagen, eigene Darstellung. Tx: Transplantation

Die i.v. Injektionen erfolgten ein- bzw. zweimal pro Woche vor den zu erwartenden Krankheitswellen über einen Zeitraum von drei Wochen in die beiden außen liegenden Schwanzvenen (siehe Abbildung 3). Diese Applikationsform wurde nicht über den gesamten Versuchszeitraum angewandt, da die Schwanzvenen der Mäuse durch die aGvHD und die mehrfachen Injektionen stark vernarben und eine korrekte und vollständige Applikation des Medikamentes so nach beiden abgelaufenen Krankheitswellen nicht mehr gewährleistet gewesen wäre. Insgesamt erfolgte die Injektion an fünf verschiedenen Zeitpunkten. Wie auch bei der Transplantation wurden die Mäuse vor der i.v. Injektion, speziell der Schwanz, unter einer Infrarotlampe angewärmt, um die Venen 
zu erweitern. In einer speziell angefertigten Halterung wurden die Mäuse fixiert, so dass ungehindert in die Schwanzvenen injiziert werden konnte. Die Injektion erfolg te analog zur Transplantation mit sterilen Insulinspritzen. Aufgrund der beschriebenen Maßnahmen konnte bei allen durchgeführten i.v. Applikationen die geplante Dosis sicher injiziert werden.

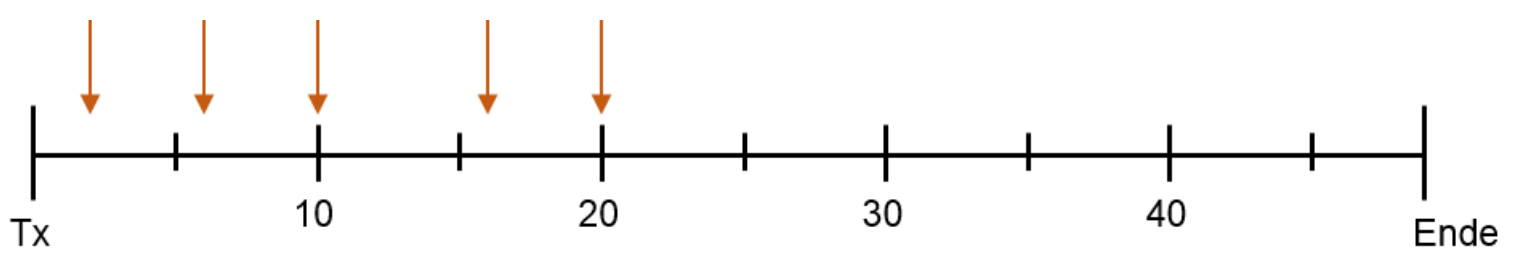

Abbildung 3: Zeitskala der i.v. Injektionen in Tagen, eigene Darstellung.

\subsubsection{Durchflusszytometrische Analyse von Lymphknoten und Milz}

Sobald die Tiere einen Gesamtscore von sechs oder mehr Punkten erreichten oder der Versuch nach 49 bzw. 30 Tagen beendet wurde, ohne dass ein Gesamtscore von sechs oder mehr Punkten erreicht wurde, wurden die Tiere euthanasiert und die Zellen von Lymphknoten und Milz mittels Durchflusszytometrie analysiert. Zwei Beispiele zu den Gating-Strategien in der Durchflusszytometrie sind in den Abbildungen A.1 und A.2 im Anhang dargestellt.

Hierzu wurden den Tieren, nach der Tötung, Lymphknoten und Milz entnommen und jeweils nicht steril durch ein $40 \mu \mathrm{m}$ Zellsieb gedrückt. Das Sieb wurde mehrfach mit PBS gespült, um alle Zellen zu entfernen. Anschließend wurden beide Zellsuspensionen bei $350 g_{0}$ und Raumtemperatur für 5 min zentrifugiert. Das Pellet der Lymphknotensuspension wurde in $300 \mu$ PBS resuspendiert und jeweils $1 \times 10^{6}$ Zellen in zwei Röhrchen gegeben (gefärbte und ungefärbte Probe). Das Pellet der Milzsuspension wurde zur Erythrozytenlyse mit $1 \mathrm{ml}$ Red Blood Cell Lysing Buffer gemischt und für eine Minute auf einem Rollenmischer geschwenkt. Danach wurde der Zellsuspension 20 ml PBS hinzugefügt und bei $400 \mathrm{~g}_{0}$ und Raumtemperatur für 7 min zentrifugiert. Das Pellet wurde in $1 \mathrm{ml}$ PBS resuspendiert und ebenfalls je $1 \times 10^{6}$ Zellen in zwei Röhrchen gegeben.

Die Röhrchen mit den ungefärbten Proben wurden gekühlt aufbewahrt. Die Zellen der verbliebenen Röhrchen wurden jeweils mit $1 \mu \mathrm{l}$ Anti-mouse CD3 FITC $(0,5 \mu \mathrm{g}), 0,7 \mu \mathrm{l}$ Anti-mouse CD4 PE $(0,125 \mu \mathrm{g})$ und 0,7 $\mu$ Anti-mouse CD8 APC $(0,125 \mu \mathrm{g})$ Antikörpern durchmischt und für 10 min im Dunkeln bei Raumtemperatur inkubiert. Anschließend 
wurden $2 \mathrm{ml}$ PBS hinzugefügt und für $5 \mathrm{~min}$ bei $350 \mathrm{~g}_{0}$ zentrifugiert. Das Pellet wurde in $200 \mu$ I PBS resuspendiert und im Durchflusszytometer FACS Canto II, BD gemessen.

\subsubsection{In-vitro-Untersuchungen}

\subsubsection{Zellkultur}

Da der Einfluss von Heparin und Clexane auf die Immunzellen des Menschen im Rahmen des Projekts von großem Interesse war, wurden zusätzlich zu den In-vivo-Untersuchungen auch In-vitro-Untersuchungen durchgeführt. Mit Hilfe von Zellkulturen wurde das Proliferationsverhalten humaner Leukozyten nach Zugabe von Lipopolysaccharid E.coli 026:B6 als Immunstimulans und nach Zugabe von Clexane oder Heparin als möglicher Hemmstoff der Immunzellen untersucht. Die humanen Leukozyten wurden aus Buffy Coats des Blutspendedienstes der Universitätsmedizin Göttingen extrahiert. Die durchgeführten In-vitro-Versuche sind durch die Ethikkommission der Universitätsmedizin Göttingen durch den Ethikantrag „Untersuchung inflammatorischer Parameter humaner mononukleärer Zellen nach Behandlung mit Heparin und Heparin-Derivaten in vitro“ mit der Antragsnummer DOK_287_2015 genehmigt worden.

\subsubsection{Extraktion der Leukozyten}

Um aus dem Buffy-Coat die Leukozyten für die Zellkulturen zu extrahieren, wurde der Buffy-Coat aufgereinigt und von den Thrombozyten freigewaschen. Im Anschluss wurden die Zellen mit dem Fluoreszenzfarbstoff Cell Proliferation Dye (CPD) eFluor ${ }^{\circledR} 450$ gefärbt und für 72 Stunden bei $37^{\circ} \mathrm{C}$ und $5 \% \mathrm{CO}_{2}$ inkubiert. Es wurde in allen Versuchen das unter 2.1.10 „Herstellung gebrauchsfertiger Medien und Lösungen“ dargestellte Nährmedium mit einem Zusatz von RPMI 1640 Medium mit L-Glutamin, 1 \% Penicillin/Streptomycin und $10 \%$ FCS verwendet.

Im Einzelnen wurde dabei folgendermaßen vorgegangen:

Zuerst erfolgte die Herstellung der NaCi- und Buffy-Lösung (siehe Kapitel 2.1.10 „Herstellung gebrauchsfertiger Medien und Lösungen“). Danach wurden 20 ml Ficoll-Paque PLUS in ein $50 \mathrm{ml}$ Röhrchen gegeben und mit $30 \mathrm{ml}$ der Buffy-Lösung vorsichtig überschichtet. Das $50 \mathrm{ml}$ Röhrchen wurde bei $800 \mathrm{~g}_{0}$, Raumtemperatur und ohne Bremse $(R=0)$ für 30 min zentrifugiert. Durch die Zentrifugation bilden sich drei Schichten (siehe Abbildung 4), eine obere Schicht aus Plasma, eine mittlere Schicht aus Leukozyten (und Thrombozyten) und eine untere Schicht aus Erythrozyten. Die obere Plasmaschicht wurde mit einer Glaspipette abgesaugt und verworfen. Da nur die Leukozytenschicht benötigt wurde, wurde diese mit einer $1 \mathrm{ml}$ Pipette aufgenommen und in ein neues $50 \mathrm{ml}$ Röhrchen überführt. Die untere Erythrozytenschicht verblieb im Röhrchen und wurde 
verworfen. Zur Auswaschung der Thrombozyten wurde das Volumen der Leukozytenschicht mit dem dreifachen Volumen NaCi-Lösung gemischt und für 10 min bei $100 \mathrm{~g}_{0}$ und Raumtemperatur zentrifugiert. Das Pellet wurde mit $8 \mathrm{ml} \mathrm{NaCi-Lösung} \mathrm{resuspen-}$ diert und nochmals für 10 min bei $100 \mathrm{~g}_{0}$ und Raumtemperatur zentrifugiert. Darauffolgend wurde dem Pellet $1 \mathrm{ml} \mathrm{NaCi-Lösung} \mathrm{zugegeben} \mathrm{und} \mathrm{die} \mathrm{Leukozyten} \mathrm{mit} \mathrm{Hilfe} \mathrm{einer}$ Neubauer Zählkammer ausgezählt.
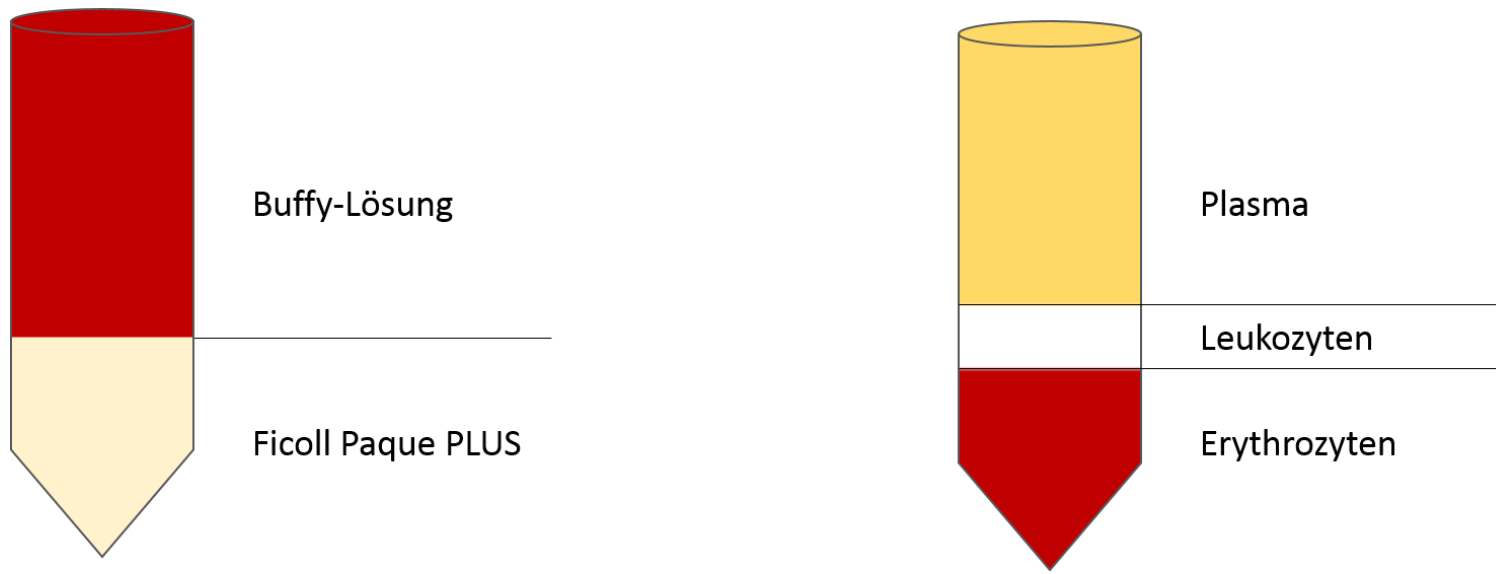

Abbildung 4: Röhrchen mit Buffy-Lösung und Ficoll Paque Plus ${ }^{\mathrm{TM}}$ vor und nach Zentrifugation, basierend auf GE Healthcare (2007).

\subsubsection{Färbung der Leukozyten mit dem Farbstoff CPD eFluor® 450}

Mit Hilfe des CPD eFluor® ist es möglich die Proliferationsrate von Zellen mittels Durchflusszytometrie zu messen. Dafür bindet der Farbstoff an zelluläre Proteine mit primären Aminen und verteilt sich bei einer Zellteilung gleichmäßig auf die entstehenden Tochterzellen. Dabei wird die Fluoreszenzintensität halbiert und dieser Fluoreszenzabfall kann im Durchflusszytometer ermittelt werden. Das heißt, je mehr Zellteilungen stattfinden, desto größer ist der gemessene Fluoreszenzabfall. Der Farbstoff wird bei einer Wellenlänge von $409 \mathrm{~nm}$ maximal angeregt (Thermo Fisher Scientific 2017).

Bevor die Leukozyten mit dem Fluoreszenzfarbstoff CPD eFluor® 450 (eBioscience, Frankfurt, DE) gefärbt wurden, wurde zunächst eine ungefärbte Kontrolle mit $5 \times 10^{6}$ Leukozyten in einer Zellkulturflasche mit $5 \mathrm{ml}$ Medium ausplattiert. Einer Leukozytenzahl von $40 \times 10^{6}$ wurden $2 \mathrm{ml}$ PBS zugegeben und mit $2 \mu \mathrm{l}$ des CPD Farbstoffes vermischt. Die Zellsuspension wurde im Dunkeln bei Raumtemperatur für 20 min inkubiert. Durch die Zugabe des vier- bis fünffachen Volumens des Mediums mit einer Temperatur von ca. $4{ }^{\circ} \mathrm{C}$ wurde der Färbevorgang gestoppt und die Leukozytensuspension wurde für weitere 5 min auf Eis und im Dunkeln inkubiert. Anschließend erfolgte eine Zentrifugation bei $350 \mathrm{~g}_{0}$ und Raumtemperatur für $10 \mathrm{~min}$. Dem Pellet wurden $2 \mathrm{ml}$ PBS zugegeben und die Probe wurde erneut zentrifugiert. 
Die mit CPD gefärbten Leukozyten wurden gezählt und im Anschluss jeweils $5 \times 10^{6}$ Zellen in vier Zellkulturflaschen mit je $5 \mathrm{ml}$ Medium ausplattiert. Die vier Zellkulturflaschen wurden im Anschluss unterschiedlich beimpft. In eine Zellkulturflasche wurde $1 \mu \mathrm{g} / \mathrm{ml}$ des Lipopolysaccharids E.coli 026:B6 (LPS) hinzugegeben, in eine weitere Zellkulturflasche 0,4 I.E./ml Heparin bzw. Clexane und in eine Dritte sowohl LPS als auch Heparin bzw. Clexane. Eine Übersicht über die Beimpfung der Zellkulturflaschen ist in Tabelle 13 dargestellt. Die Zellkulturflaschen wurden für 72 Stunden unter Lichtausschluss bei $37^{\circ} \mathrm{C}$ und $5 \% \mathrm{CO}_{2}$ inkubiert.

Tabelle 13: Übersicht über die Beimpfung der Zellkulturflaschen.

\begin{tabular}{|c|c|c|c|c|}
\hline $\begin{array}{l}\text { Kulturfla- } \\
\text { schenbe- } \\
\text { zeichnung }\end{array}$ & $\begin{array}{l}\text { Zellen + } \\
\text { Medium }\end{array}$ & CPD & $\begin{array}{c}\text { LPS } \\
1 \mu \mathrm{g} / \mathrm{ml}\end{array}$ & $\begin{array}{c}\text { Heparin/ } \\
\text { Clexane } \\
\text { 0,4 I.E./ml }\end{array}$ \\
\hline Kontrolle & $\begin{array}{l}5 \times 10^{6} \text { Zellen in } \\
5 \mathrm{ml} \text { Medium }\end{array}$ & - & - & - \\
\hline CPD & $\begin{array}{l}5 \times 10^{6} \text { Zellen in } \\
5 \mathrm{ml} \text { Medium }\end{array}$ & + & - & - \\
\hline LPS & $\begin{array}{l}5 \times 10^{6} \text { Zellen in } \\
5 \mathrm{ml} \text { Medium }\end{array}$ & + & + & - \\
\hline $\begin{array}{l}\text { Heparin/ } \\
\text { Clexane }\end{array}$ & $\begin{array}{l}5 \times 10^{6} \text { Zellen in } \\
5 \mathrm{ml} \text { Medium }\end{array}$ & + & - & + \\
\hline $\begin{array}{l}\text { LPS + Heparin/ } \\
\text { Clexane }\end{array}$ & $\begin{array}{l}5 \times 10^{6} \text { Zellen in } \\
5 \mathrm{ml} \text { Medium }\end{array}$ & + & + & + \\
\hline
\end{tabular}

\subsubsection{CD3-, CD14-, CD19- Färbung der Leukozyten und durchflusszytometri- sche Analyse}

Nach abgeschlossener Inkubationszeit erfolgte die Färbung der Leukozyten mit drei weiteren humanen Antikörpern (CD3 FITC, CD19 APC und CD14 PE) und die Analyse der Proliferationsrate sowie Zellzahl der $\mathrm{CD}^{+}, \mathrm{CD} 19^{+}$, und CD14+ Zellen im Durchflusszytometer FACS Canto II, BD. Hierbei war stets darauf zu achten, die bereits mit CPD gefärbten Zellen so gut wie möglich vor Lichteinfall zu schützen, da dieser Farbstoff sehr lichtempfindlich ist. Pro Zellkulturflasche wurden eine Millionen Zellen entnommen und in beschriftete Röhrchen gegeben. Alle Röhrchen wurden äquivalent gewaschen und gefärbt. Zunächst wurden die Zellen durch zweimaliges Waschen bei 350 go und Raumtemperatur für 5 min vom Medium gereinigt und anschließend in $200 \mu \mathrm{l}$ PBS resuspendiert. Das Kontroll-Röhrchen mit den ungefärbten Zellen wurde beiseite gestellt. Den übrigen vier Röhrchen wurden $5 \mu$ l Human TruStain FcX zugeben und für 5 min bei 
Raumtemperatur inkubiert. Die Zugabe von Human TruStain FcX (Fc Receptor Blocking Solution) verhindert eine ungewollte, überschießende Färbung. Dabei wird die spezifische und gewollte Antikörperfärbung nicht beeinflusst. Im Anschluss konnte ohne weitere Waschung die Zugabe von 2,5 $\mu$ I Anti-human CD3 FITC, 2,5 $\mu$ I Anti-human CD19 APC und 2,5 $\mu$ I Anti-human CD14 PE Antikörper und die Inkubation für 10 min bei Raumtemperatur im Dunkeln erfolgen. Die Zellen wurden mit $2 \mathrm{ml}$ PBS gewaschen und bei $350 \mathrm{~g}_{0}$ für $5 \mathrm{~min}$ zentrifugiert. Das Pellet wurde in $200 \mu \mathrm{l}$ PBS resuspendiert und im Durchflusszytometer gemessen. In der durchflusszytometrischen Analyse wurde jeweils der Anteil der proliferierenden T-Zellen, B-Zellen oder Monozyten in Bezug auf alle mononukleären Zellen betrachtet. Ein Beispiel zur Gating-Strategie in den In-vitro-Untersuchungen ist in der Abbildung A.3 im Anhang dargestellt.

\subsubsection{Statistische Auswertungen}

Die Überlebensraten wurden mit Hilfe der Kaplan-Meier-Überlebenskurven analysiert und der Log-Rank-Test diente zur Ermittlung der dazugehörigen $p$-Werte. Ein $p$-Wert von $<0,05$ wurde als statistisch signifikant definiert. Die Auswertung der Daten aus den durchflusszytometrischen Analysen erfolgte mit Hilfe des Student's t-Test. In den Balkendiagrammen wurde stets der Mittelwert mit dem Standardfehler dargestellt. 


\section{Ergebnisse}

In dem folgenden Kapitel werden die Ergebnisse der durchgeführten Versuche dargestellt. Dabei werden zunächst die tierexperimentellen Versuche (Abschnitt 3.1) und darauffolgend die In-vitro-Versuchsergebnisse (Abschnitt 3.2) abgebildet und erläutert. Die Durchführung der Versuche und die Gewinnung der Daten erfolgten durch die in Kapitel 2.2 beschriebenen Methoden.

\subsection{Ergebnisse der tierexperimentellen Versuche}

In mehreren Studien konnte bereits die antiinflammatorische Wirkung von Heparin in verschiedenen Erkrankungen nachgewiesen werden. In dieser Arbeit wurde daher angenommen, dass die Gabe von Heparin, die ebenfalls durch entzündliche Mechanismen ausgelöste aGvHD, mildern kann. Um dies zu untermauern, wurden mehrere Versuchsreihen mit unterschiedlichen Applikationsformen und Konzentrationen von UFH und $\mathrm{NMH}$ nach muriner Knochenmarktransplantation und Induktion einer aGvHD durchgeführt. Um einen möglichen therapeutischen Einfluss der genannten Substanzen auf die aGvHD zu erkennen und nachzuweisen, wurden das Überleben, der klinische Ausprägungsgrad der Krankheit und der Gewichtsverlust der Tiere der Therapie- und Kontrollgruppen miteinander verglichen.

Nach Erreichen von einem Gesamtscore von sechs oder mehr Punkten oder nach Beendigung des Versuches nach 49 bzw. 30 Tagen wurden die T-Zellen aus Lymphknoten und Milz der unterschiedlichen Gruppen mittels Durchflusszytometrie analysiert und verglichen. Ein möglicher immunologischer Effekt der Therapie sollte so aufgedeckt werden.

Die Ergebnisse der tierexperimentellen Versuche beziehen sich auf die s.c. Injektionen mit NMH (Abschnitt 3.1.1) und UFH (Abschnitt 3.1.2) sowie die i.v. Injektionen mit NMH und UFH (Abschnitt 3.1.3). Zum Schluss werden noch die Ergebnisse der Versuchsreihen mit einer täglichen s.c. Injektion von UFH (Abschnitt 3.1.4) betrachtet.

\subsubsection{Subkutane Injektionen mit NMH}

Bei der s.c. Applikation von NMH handelt es sich mittlerweile um ein etabliertes Verfahren im Krankenhausalltag, das zum Beispiel zur Thromboseprophylaxe angewendet wird. Dementsprechend wurden zunächst Versuchsreihen durchgeführt, in denen die s.c. Gabe von unterschiedlichen Dosen des NMH Enoxaparin (Clexane) erfolgte. Hierbei wurden Konzentrationen von 200 I.E./kg KG und 20 I.E./kg KG verwendet. In Kapitel 4.3 
„Einfluss der unterschiedlichen Dosen auf den Krankheitsverlauf der aGvHD im Mausmodell“ folgt eine nähere Erläuterung bezüglich der zu Beginn und im Verlauf gewählten Dosen.
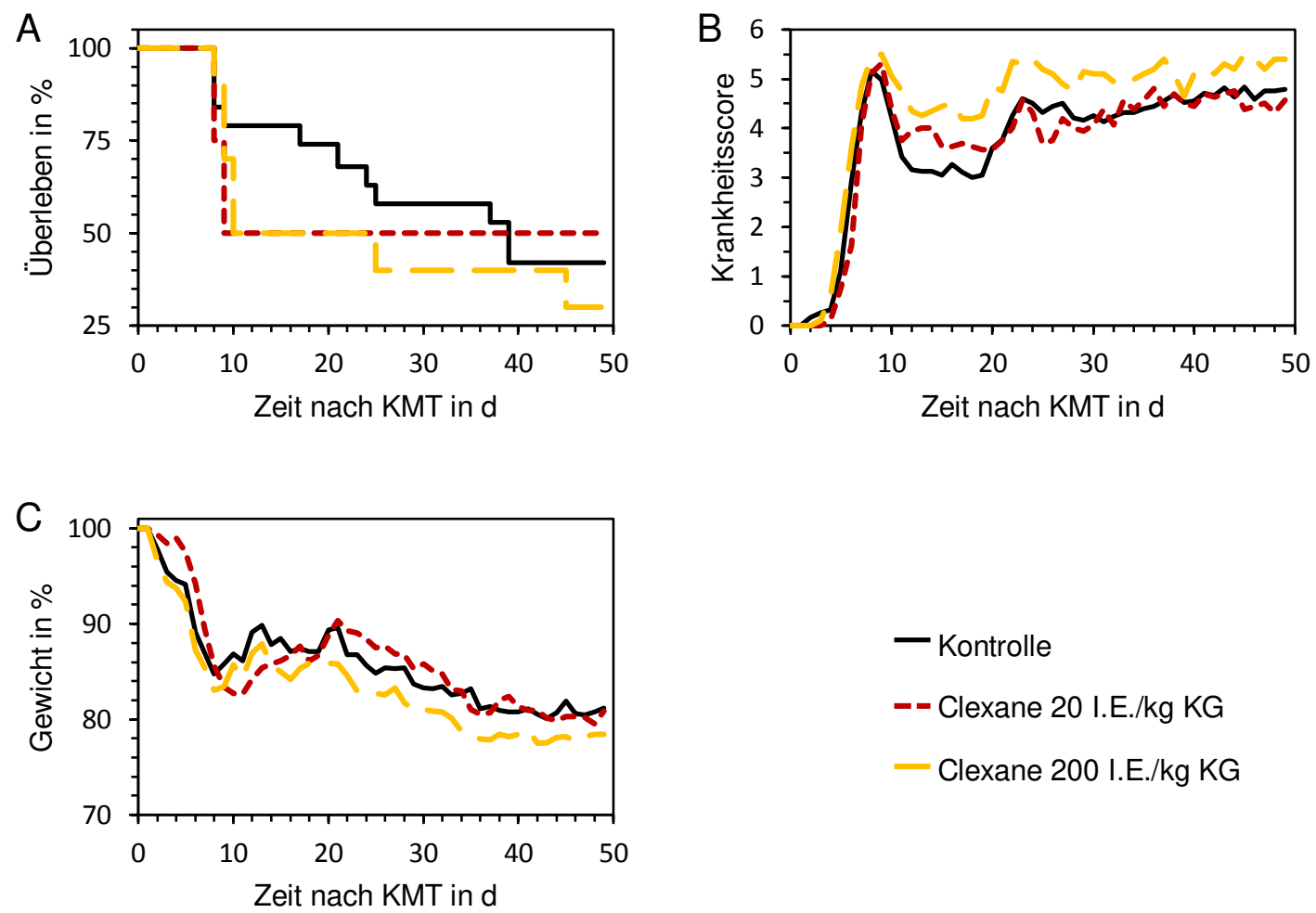

Abbildung 5: Einfluss der s.c. Injektion von NMH (Clexane) auf die murine aGvHD. Zwei Therapiegruppen wurden nach KMT im C57BL/6J $\rightarrow$ BALB/c transplantierten Mausmodell mit einer Clexane-Konzentration von 20 I.E./kg KG $(n=8)$ oder 200 I.E./kg KG $(n=10)$ behandelt und mit einer Kontrollgruppe, die nach simultaner KMT das gleiche Volumen $\mathrm{NaCl}$ erhielt $(n=19)$, verglichen. Der therapeutische Einfluss wurde anhand der Überlebenskurve nach Kaplan-Meier (A), dem klinischen GvHD Krankheitsscore (B) und dem Gewicht (C) ausgewertet und verglichen. Die Daten sind als Mittelwert dargestellt und wurden in zwei voneinander unabhängigen Versuchen durchgeführt. Abbildung A und B basierend auf Budde et al. (2015) mit freundlicher Genehmigung des Autors.

In Abbildung $5 \mathrm{~A}$ ist mit Hilfe der Kaplan-Meier-Kurve das Überleben der Therapie- und Kontrollgruppen während des Versuchszeitraumes von 49 Tagen nach muriner Knochenmarktransplantation dargestellt.

Der Vergleich der Überlebensrate zeigt, dass sowohl die Therapiegruppe, die mit 20 I.E./kg KG behandelt wurde, als auch die Therapiegruppe, die mit 200 I.E./kg KG behandelt wurde, zwischen Tag 9 und 38 ein geringeres Überleben aufwiesen als die Kontrollgruppe. Die Überlebensrate der Kontrolltiere lag an Tag 15 bei $79 \%$, während die Überlebensrate beider Therapiegruppen bei 50 \% lag. Ab Tag 17, zu Beginn der zweiten Krankheitswelle, nahm jedoch auch die Tieranzahl der Kontrollgruppe ab und sank bis 
zum Ende des Versuchszeitraums auf eine Überlebensrate von $42 \%$. Die Therapiegruppe, die 20 I.E./kg KG erhielt, blieb ab Tag 9 konstant bei einer Überlebensrate von $50 \%$. Das heißt, dass kein weiteres Tier dieser Gruppe während des Versuchszeitraums, auch nicht während der zweiten Krankheitswelle, aus dem Versuch genommen werden musste. Die Überlebensrate ist somit höher, allerdings gemäß dem Log-RankTest nicht statistisch signifikant höher, als die der Kontrollgruppe $(p=0,97)$. Die Überlebensrate der dritten Vergleichsgruppe mit einer verabreichten Konzentration von 200 I.E./kg KG NMH sank bis auf $30 \%$ an Tag 49 und wies somit die geringste aber ebenfalls nicht statistisch signifikante Überlebensrate der drei Gruppen auf ( $p=0,48)$. Wird der komplette Versuchszeitraum betrachtet, gibt es keinen statistisch signifikanten Unterschied hinsichtlich der Überlebensrate der drei Versuchsgruppen.

Abbildung $5 \mathrm{~B}$ veranschaulicht den klinischen Ausprägungsgrad der aGvHD während des Versuchszeitraumes von 49 Tagen. Der Krankheitsscore zeigte zwischen der Therapiegruppe, die mit 20 I.E./kg KG NMH behandelt wurde und der Kontrollgruppe keinen wesentlichen und insbesondere keinen statistisch signifikanten Unterschied. Der Verlauf des Krankheitsscores zwischen den zwei Gruppen war annährend gleich. An Tag 6 zeigte sich mit 1,3 Punkten Unterschied die größte Differenz zwischen den beiden Gruppen. Während des restlichen Versuchzeitraumes lag diese Differenz zwischen 0,1 und 0,8 Punkten. Die Therapiegruppe, die eine s.c. Gabe von 200 I.E./kg KG NMH erhielt, hatte im Vergleich zur Kontrollgruppe dagegen durchgehend einen deutlich schwereren klinischen Ausprägungsgrad der aGvHD. Von Tag 11 bis Tag 20 lag der Krankheitsscore der Therapiegruppe, die mit 200 I.E./kg KG behandelt wurde, mindestens einen Punkt höher als der Krankheitsscore der Kontrollgruppe. An Tag 15 zeigte sich zwischen den zwei Gruppen ein statistisch signifikanter Unterschied mit einem Krankheitsscore von 3,05 Punkten in der Kontroll- und einem Krankheitsscore von 4,45 Punkten in der Therapiegruppe ( $p=0,04$ an Tag 15, Abbildung 5 B). Der Verlauf des Krankheitsscores spiegelt erwartungsgemäß die Überlebensrate wider. Die Therapiegruppe mit der geringsten Überlebensrate, die mit 200 I.E./kg KG NMH behandelt wurde, wies den größten Krankheitsscore auf, während die Therapiegruppe mit der zum Versuchsende höchsten Überlebensrate (20 I.E./kg KG NMH) den geringsten Krankheitsscore aufwies.

Abbildung $5 \mathrm{C}$ zeigt den Gewichtsverlust der Tiere während des Versuchszeitraumes von 49 Tagen. Der Verlauf des Gewichtes der Kontrollgruppe und der Therapiegruppe, die mit 20 I.E./kg KG behandelt wurde, verläuft annähernd gleich und lag ab Tag 33 bei $81 \%+/-2 \%$ des Ausgangsgewichts. Die Therapiegruppe, die mit 200 I.E./kg KG therapiert wurde, wies dagegen ab Tag 19 einen 2-3\% größeren Gewichtsverlust im Ver- 
gleich zu den beiden erstgenannten Gruppen auf. An Tag 22 und 23 zeigte sich im Vergleich zur 20 I.E./kg KG Therapiegruppe ein $6 \%$ größerer Gewichtsverlust. Insgesamt ergab sich kein statistisch signifikanter Unterschied zwischen den Gruppen.

Zusammenfassend zeigte sich weder in der Überlebensrate, noch im klinischen Ausprägungsgrad der aGvHD (bis auf eine Ausnahme an Tag 15) oder beim Gewichtsverlust der Tiere ein statistisch signifikanter Unterschied zwischen den Gruppen. Die s.c. Applikation von NMH (Clexane) beeinflusste den Verlauf der Krankheit nicht und zeigte zum Teil die Tendenz, den Krankheitsverlauf ungünstig zu beeinflussen. Insbesondere die gewählte Konzentration von 200 I.E./kg KG beeinflusste die Krankheit negativ. Die Tiere hatten den schwersten Krankheitsverlauf ( $p=0,04$ an Tag 15), den größten Gewichtsverlust und die geringste Überlebensrate.

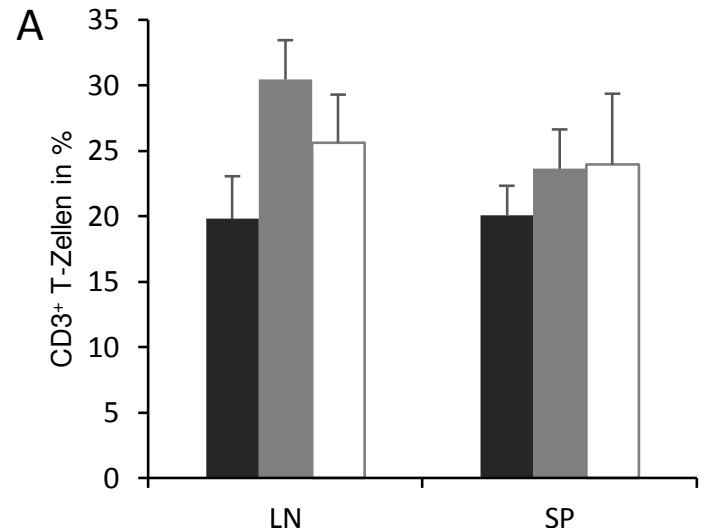

LN

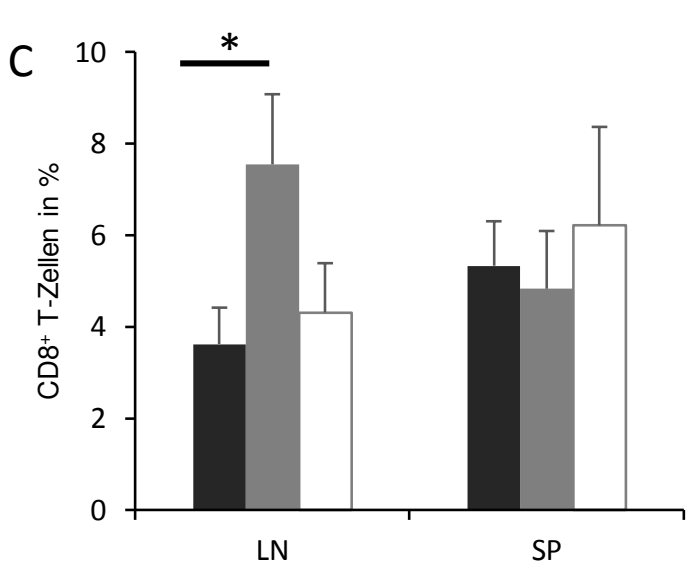

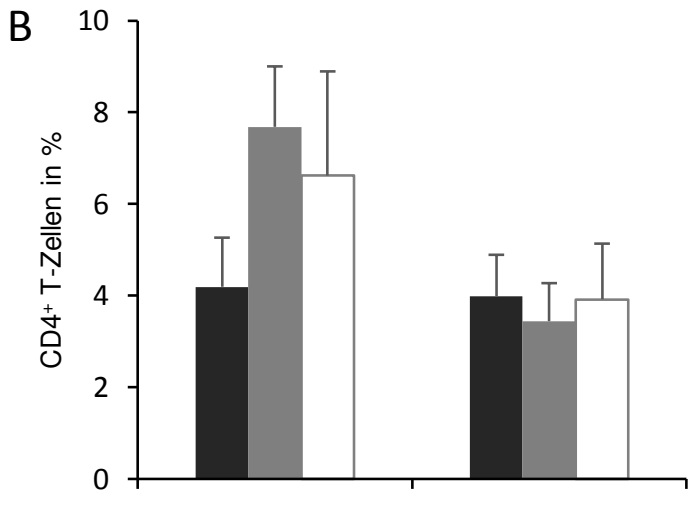

LN

Abbildung 6: Durchflusszytometrische Analyse der $\mathrm{CD3}^{+}, \mathrm{CD}^{+}$und $\mathrm{CD}^{+} \mathrm{T}$-Zellen von Lymphknoten (LN) und Milz (SP) nach s.c. Injektion von NMH (Clexane). Zwei Therapiegruppen der C57BL/6J $\rightarrow$ BALB/c transplantierten Mäuse wurden jeweils mit einer Clexane-Konzentration von 20 I.E./kg KG Clexane $(n=7)$ oder 200 I.E./kg KG $(n=9)$ behandelt, während die simultan transplantierte Kontrollgruppe $(n=19)$ das gleiche Volumen $\mathrm{NaCl}$ erhielt. Die LN und SP der Mäuse wurden analysiert, sobald die Tiere einen Gesamtscore von $\geq 6$ Punkten erreichten oder der Versuch nach 49 Tagen beendet wurde. Der prozentuale Anteil der CD3+ T-Zellen (A), der $\mathrm{CD}^{+}{ }^{+} \mathrm{T}$-Zellen (B) und der CD8 ${ }^{+} \mathrm{T}$-Zellen $(\mathrm{C})$ von $\mathrm{LN}$ und SP wurde mittels durchflusszytometrischer Analyse ausgewertet und verglichen $\left({ }^{*} p<0,05\right)$. Die Daten der Balkendiagramme sind 
als Mittelwert mit Standardfehler dargestellt und wurden in zwei voneinander unabhängigen Versuchen durchgeführt. Abbildung B und C basierend auf Budde et al. (2015) mit freundlicher Genehmigung des Autors.

Die Ergebnisse der T-Zell-Analyse mittels Durchflusszytometrie zeigten in den Lymphknoten einen prozentual erhöhten Anteil der $\mathrm{CD}^{+}, \mathrm{CD}^{+}{ }^{+}$und $\mathrm{CD} 8^{+} \mathrm{T}$-Zellen in beiden Clexane-Gruppen. Dabei zeigte sich bei der mit 20 I.E./kg KG behandelten Therapiegruppe im Vergleich zur Kontrollgruppe eine statistisch signifikante Erhöhung der CD8+ T-Zellen mit einem $p$-Wert von $p=0,03$. Die T-Zell-Analysen der Milz zeigten dagegen keinen statistisch signifikanten Unterschied zwischen den Gruppen. Die Ergebnisse sind in den Abbildungen $6 \mathrm{~A}$ bis $\mathrm{C}$ dargestellt.

\subsubsection{Subkutane Injektionen mit UFH}

Im Anschluss an die Versuchsreihe der s.c. Applikation von NMH (Clexane) wurden weitere s.c. Versuchsreihen mit UFH (Heparin) durchgeführt. Dabei kamen Injektionsdosen von 50, 100 und 200 I.E./kg KG UFH zur Anwendung.

A
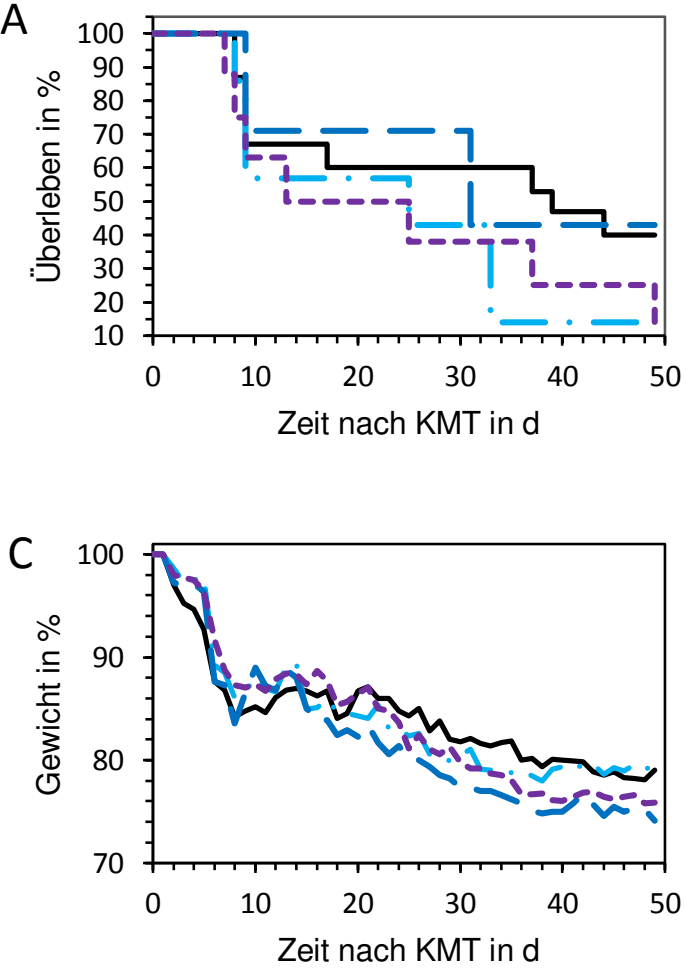

B

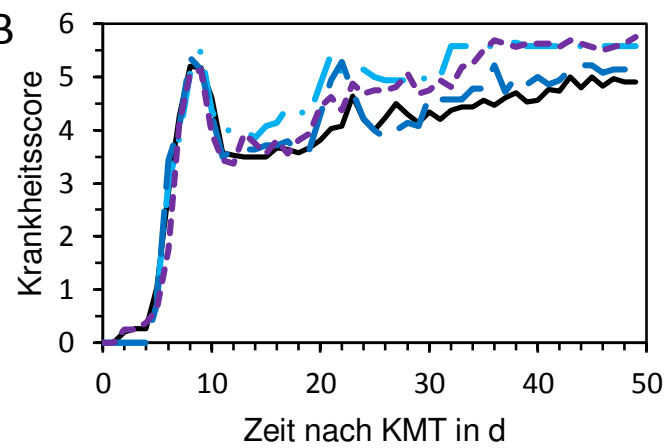

- Kontrolle

- Heparin 50 I.E./kg KG

- Heparin 100 I.E./kg KG

- - Heparin 200 I.E./kg KG

Abbildung 7: Einfluss der s.c. Injektion von UFH (Heparin) auf die murine aGvHD. Drei Therapiegruppen wurden nach KMT im C57BL/6J $\rightarrow$ BALB/c transplantierten Mausmodell mit einer Heparin-Konzentration von 50 I.E./kg KG $(n=7), 100$ I.E./kg KG $(n=7)$ oder 200 I.E./kg KG $(\mathrm{n}=8)$ behandelt und mit einer Kontrollgruppe, die nach simultaner KMT das gleiche Volumen $\mathrm{NaCl}$ erhielt $(n=15)$, verglichen. Der therapeutische Einfluss wurde anhand der Überlebenskurve nach Kaplan-Meier (A), dem klinischen GvHD Krankheitsscore (B) und dem Gewicht (C) ausgewertet und verglichen. Die Daten sind als Mittelwert dargestellt und wurden in zwei voneinander 
unabhängigen Versuchen durchgeführt: Abbildung A und B basierend auf Budde et al. (2015) mit freundlicher Genehmigung des Autors.

Abbildung $7 \mathrm{~A}$ veranschaulicht, mit Hilfe der Kaplan-Meier-Kurve, das Überleben der Kontroll- und der drei verschiedenen Therapiegruppen, die mit UFH behandelt wurden, während eines Versuchszeitraumes von 49 Tagen nach muriner Knochenmarktransplantation. Die Überlebensraten der Therapiegruppen, die mit 200 I.E./kg KG und 50 I.E./kg KG UFH behandelt wurden, lagen von Tag 9 bis Tag 49 konstant unter der Überlebensrate der Kontrollgruppe. Die beiden Therapiegruppen fielen bis zum Versuchsende auf eine Überlebensrate von unter $15 \%$ ab. Dabei verringerte sich das Überleben der Therapiegruppe, die 200 I.E./kg KG UFH erhielt, stetig bis zum Versuchsende. Ein Vergleich dieser Gruppe mit der Kontrollgruppe zeigt einen Abfall der Überlebensrate der Therapiegruppe von Tag 25 bis Tag 37 von $38 \%$ auf $25 \%$, während die Kontrollgruppe von Tag 25 bis 37 konstant eine Überlebensrate von $60 \%$ aufwies und bis zum Versuchsende stufenweise bis auf eine Überlebensrate von $40 \%$ abfiel. Hierbei zeigte sich gemäß dem Log-Rank-Test kein statistisch signifikanter Unterschied $(p=0,18)$. Die mit 50 I.E./kg KG behandelte Therapiegruppe wies ebenfalls ab Tag 9 im Vergleich zur Kontrollgruppe einen kontinuierlichen, stufenweisen Abfall der Überlebensrate auf. Zwischen Tag 25 und 38 fiel die Überlebensrate deutlich von $43 \%$ auf $14 \%$ ab, aber auch hier zeigte sich gemäß dem Log-Rank-Test kein statisch signifikanter Unterschied zwischen der Therapie- und Kontrollgruppe $(p=0,20)$. Insgesamt waren die beiden beschriebenen Therapiegruppen der Kontrollgruppe bezüglich der Überlebensrate tendenziell unterlegen.

Die Therapiegruppe, die mit 100 I.E./kg KG UFH behandelt wurde, wies dagegen von Tag 9 bis Tag 31 mit $71 \%$ eine geringfügig höhere Überlebensrate als die Kontrollgruppe mit $67 \%$ (Tag 9 bis 17) und $60 \%$ (Tag 17 bis 37) auf. Ab Tag 31 fiel die Überlebensrate der Therapiegruppe auf $43 \%$ und somit unter die Überlebensrate der Kontrollgruppe ab. Zum Ende des Versuchszeitraumes näherten sich beide Gruppen mit einer Überlebensrate der Therapiegruppe von weiterhin $43 \%$ und einer Überlebensrate der Kontrollgruppe von $40 \%$ wieder an. Insgesamt betrachtet, gab es keinen statistisch signifikanten Unterschied hinsichtlich der Überlebensraten zwischen den zwei Versuchsgruppen $(p=0,87)$. Jedoch war die Überlebensrate der Kontrollgruppe sowie der Therapiergruppe, die mit 100 I.E./kg KG UFH behandelt wurde am Versuchsende mit $40 \%$ bzw. $43 \%$ deutlich höher als die Überlebensrate der beiden weiteren Therapiergruppen (50 I.E./kg KG und 200 I.E./kg KG), die jeweils unter $15 \%$ lag.

In Abbildung 7 B ist der klinische Ausprägungsgrad der aGvHD während des Versuchszeitraumes von 49 Tagen nach Knochenmarktransplantation dargestellt. Auch hier fiel, besonders gegen Ende des Versuches, auf, dass die Therapiegruppen, die mit 50- und 
200 I.E./kg KG UFH behandelt wurden, einen etwas schwereren klinischen Ausprägungsgrad der Erkrankung aufwiesen. Der Krankheitsscore lag von Tag 35 bis zum Versuchsende auf einem durchschnittlichen Wert von 5,6. Der Krankheitsscore der Kontrollund der 100 I.E./kg KG Therapiegruppe war annähernd gleich und mit einem Wert von durchschnittlich 5,0 geringer als der der anderen zwei Therapiegruppen. Die Ergebnisse des Krankheitsscores zeigten zu keinem Zeitpunkt einen statistisch signifikanten Unterschied bezüglich des Ausprägungsgrad der aGvHD.

Abbildung $7 \mathrm{C}$ bildet den Gewichtsverlust innerhalb des Versuchszeitraumes von 49 Tagen nach Knochenmarktransplantation ab. Der Verlauf des Gewichtsverlustes während des Versuchszeitraumes war zwischen allen vier Versuchsgruppen vergleichbar. Jedoch wies die Therapiegruppe, die mit 100 I.E./kg KG behandelt wurde, den größten Gewichtsverlust von ca. 26 \% zwischen Tag 1 und Tag 49 auf. Die Kontroll- sowie die Therapiegruppe, die 50 I.E./kg KG erhielt, hatten dagegen einen maximalen Gewichtsverlust von $22 \%$. Dies spiegelt nicht die entsprechenden Ergebnisse der Überlebensrate und des Krankheitsscores wider. Die Überlebensrate lag wie oben beschrieben bei der Therapiegruppe, die 100 I.E./kg KG erhielt sowie der Kontrollgruppe höher als die, der beiden weiteren Therapiegruppen (50 I.E./kg KG und 200 I.E./kg KG). Der Krankheitsscore war passend hierzu geringer. Zwischen den Therapiergruppen und der Kontrollgruppe zeigte sich jedoch hinsichtlich des Gewichtsverlustes kein statistisch signifikanter Unterschied.

Werden alle Ergebnisse vergleichend betrachtet, zeigte sich in dieser Versuchsreihe weder im Überleben der Tiere, noch im klinischen Ausprägungsgrad der Krankheit oder beim Gewichtsverlust ein statistisch signifikanter Unterschied zwischen den Gruppen. Eine nicht tägliche s.c. Anwendung von UFH hat keinen Effekt auf den Verlauf der aGvHD im Mausmodell. 

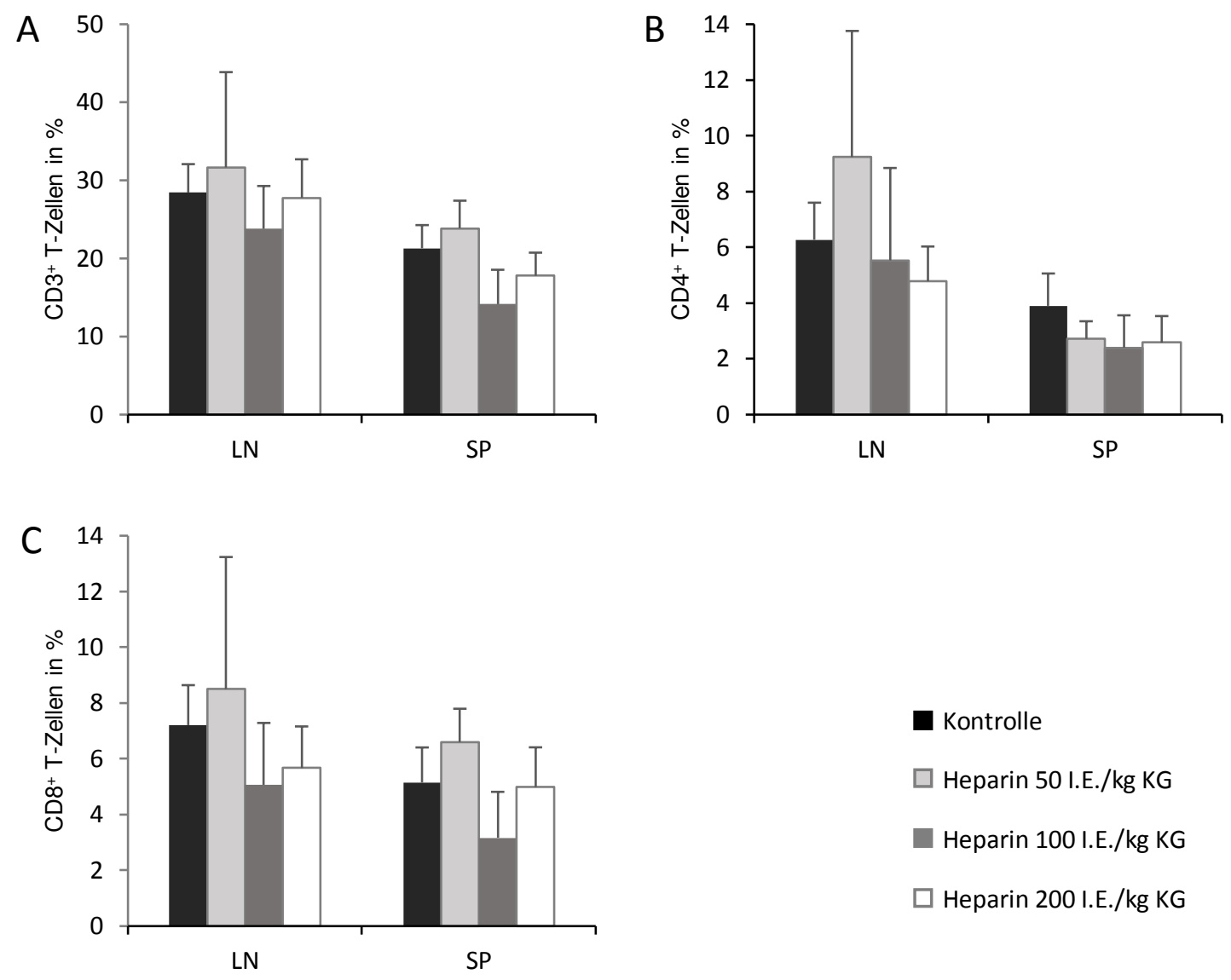

Abbildung 8: Durchflusszytometrische Analyse der $\mathrm{CD}^{+}, \mathrm{CD4}^{+}$und $\mathrm{CD}^{+} \mathrm{T}$-Zellen von Lymphknoten (LN) und Milz (SP) nach s.c. Injektion von UFH (Heparin). Drei Therapiegruppen der C57BL/6J $\rightarrow$ BALB/c transplantierten Mäuse wurden jeweils mit einer Heparin-Konzentration von 50 I.E. $/ \mathrm{kg} \mathrm{KG}(\mathrm{n}=5), 100 \mathrm{I}$.E./kg KG $(\mathrm{n}=6)$ oder $200 \mathrm{I} . \mathrm{E} . / \mathrm{kg} \mathrm{KG}(\mathrm{n}=6)$ behandelt, während die simultan transplantierte Kontrollgruppe $(n=14)$ das gleiche Volumen $\mathrm{NaCl}$ erhielt. Die LN und SP der Mäuse wurden analysiert, sobald die Tiere einen Gesamtscore von $\geq 6$ Punkten erreichten oder der Versuch nach 49 Tagen beendet wurde. Der prozentuale Anteil der $\mathrm{CD}^{+}$ T-Zellen (A), der CD4+ T-Zellen (B) und der $\mathrm{CD}^{+}$T-Zellen (C) von LN und SP wurde mittels durchflusszytometrischer Analyse ausgewertet und verglichen. Die Daten der Balkendiagramme sind als Mittelwert mit Standardfehler dargestellt und wurden in zwei voneinander unabhängigen Versuchen durchgeführt: Abbildung B und C basierend auf Budde et al. (2015) mit freundlicher Genehmigung des Autors.

Die Analyse der $\mathrm{CD}^{+}, \mathrm{CD}^{+}$und $\mathrm{CD}^{+}$T-Zellen von Lymphknoten und Milz mittels Durchflusszytometrie ergaben keinen statistisch signifikanten Unterschied zwischen den Therapie- und Kontrollgruppen (siehe Abbildung $8 \mathrm{~A}$ bis $\mathrm{C}$ ). Es zeigte sich jedoch in den Lymphknoten der Therapiegruppe, die 50 I.E./kg KG UFH erhielt, im Vergleich zur Kontrollgruppe ein prozentual erhöhter Anteil der $\mathrm{CD}^{+}, \mathrm{CD}^{+}{ }^{+}$und $\mathrm{CD} 8^{+} \mathrm{T}$-Zellen. In der Therapiegruppe, die mit 100 I.E./kg KG UFH behandelt wurde, lag der prozentuale Anteil der $\mathrm{CD}^{+}, \mathrm{CD}^{+}$und $\mathrm{CD} 8^{+} \mathrm{T}$-Zellen in Lymphknoten und Milz dagegen immer etwas niedriger als der prozentuale Anteil dieser Zellen in der Kontrollgruppe. 


\subsubsection{Intravenöse Injektionen mit NMH und UFH}

Da die bisher durchgeführten Versuchsreihen der s.c. Applikationsform von NMH und UFH keine deutliche Beeinflussung, insbesondere keinen positiven Effekt auf den Verlauf der aGvHD zeigen konnten, wurde als nächster Schritt die Applikationsform gewechselt. Es wurden einige Versuchsreihen mit einer i.v. Applikation von $\mathrm{NMH}$ und UFH durchgeführt. Dabei wurden Versuchsreihen mit Konzentrationen von 20 I.E./kg KG NMH (Clexane) oder 100 I.E./kg KG UFH (Heparin) durchgeführt, da diese Konzentrationen in den zuvor s.c. durchgeführten Versuchsreihen die am vielversprechendsten Ergebnisse hervorbrachten.
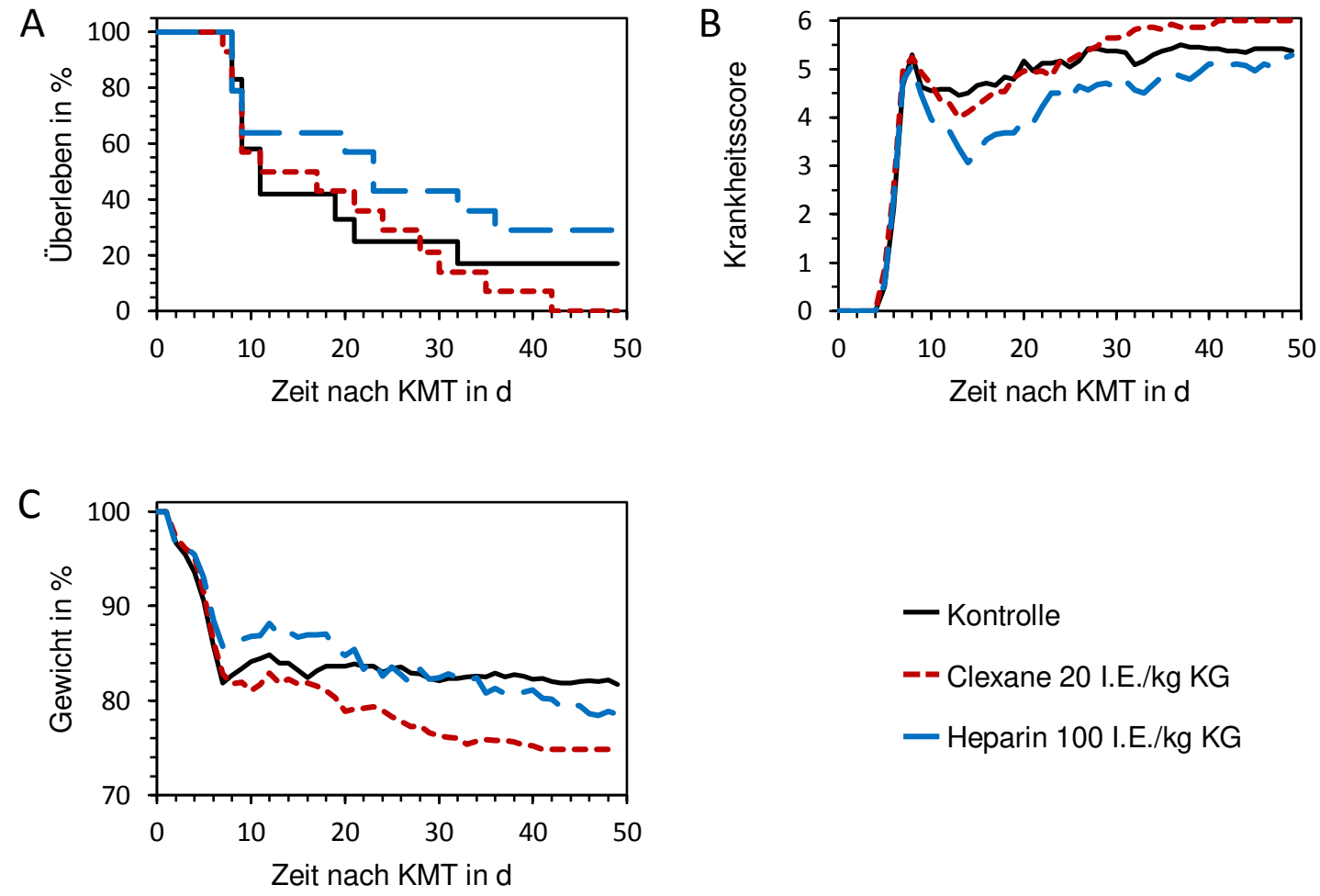

Abbildung 9: Einfluss der i.v. Injektion von NMH (Clexane) und UFH (Heparin) auf die murine aGvHD. Zwei Therapiegruppen wurden nach KMT im C57BL/6J $\rightarrow$ BALB/c transplantierten Mausmodell mit einer Clexane-Konzentration von 20 I.E./kg KG $(n=14)$ oder einer HeparinKonzentration von 100 I.E./kg KG $(n=14)$ behandelt und mit einer Kontrollgruppe, die nach simultaner KMT das gleiche Volumen $\mathrm{NaCl}$ erhielt $(n=12)$, verglichen. Der therapeutische Einfluss wurde anhand der Überlebenskurve nach Kaplan-Meier (A), dem klinischen GvHD Krankheitsscore (B) und dem Gewicht (C) ausgewertet und verglichen. Die Daten sind als Mittelwert dargestellt und wurden in zwei voneinander unabhängigen Versuchen durchgeführt: Abbildung $A$ und B basierend auf Budde et al. (2015) mit freundlicher Genehmigung des Autors.

Abbildung 9 A zeigt mit Hilfe der Kaplan-Meier-Kurve das Überleben der Therapie- und Kontrollgruppen während des Versuchszeitraumes von 49 Tagen nach muriner Knochenmarktransplantation. Die Therapiegruppe, die 20 I.E./kg KG Clexane erhielt, wies bis Tag 35 eine annähernd gleiche Überlebensrate wie die Kontrollgruppe auf. Ab 
Tag 35 fiel die Überlebensrate dieser Therapiegruppe unter die der Kontrollgruppe ab, ab Tag 42 sogar so weit, dass die Gruppe eine Überlebensrate von $0 \%$ aufwies. Die Kontrollgruppe dagegen lag weiterhin konstant bei einer Überlebensrate von $17 \%$. Einen statistisch signifikanten Unterschied gab es zwischen den zwei Gruppen nicht $(p=0,55)$. Die Therapiegruppe, die eine Dosis von 100 I.E./kg KG UFH erhielt, zeigte demgegenüber ab Tag 9 durchweg eine höhere Überlebensrate als die Kontrollgruppe. Ab Tag 11 bis zum Versuchsende an Tag 49 lag die Überlebensrate der 100 I.E./kg KG Therapiegruppe sogar stets $12 \%$ oder mehr über der Überlebensrate der Kontrollgruppe. Von Tag 21 bis Tag 23 zeigte die Therapiegruppe überdies eine $32 \%$ höhere Überlebensrate als die Kontrollgruppe. Am Versuchsende (Tag 49) wies die UFH-Therapiegruppe ein Überleben von $29 \%$ und die Kontrollgruppe ein Überleben von $17 \%$ auf. Insgesamt war dies jedoch gemäß dem Log-Rank-Test mit einem p-Wert von $p=0,34$ nicht statistisch signifikant.

Abbildung $9 \mathrm{~B}$ veranschaulicht den klinischen Ausprägungsgrad der aGvHD während des Versuchzeitraumes von 49 Tagen nach Knochenmarktransplantation. Auch hier zeigte sich zwischen der Therapiegruppe, die 20 I.E./kg KG Clexane erhielt und der Kontrollgruppe kein statistisch signifikanter Unterschied. Bis Tag 28 waren die Punktzahlen beider Gruppen annähernd gleich. Ab Tag 28 bis zum Versuchsende zeigte die Clexanegruppe passend zur Überlebensrate einen im Verlauf zunehmend schwereren klinischen Ausprägungsgrad der Krankheit als die Kontrollgruppe. Die Heparinversuchsgruppe dagegen wies auch hier ab Tag 10 einen deutlich geringeren Krankheitsscore als die Kontrollgruppe auf. An Tag 14 zeigte sich dabei ein statistisch signifikant niedrigerer Krankheitsscore der Heparingruppe mit einem $p$-Wert von $p=0,04$ (HeparinScore: 3,1 Kontroll-Score 4,5 an Tag 14). Zum Versuchsende näherte sich der klinische Ausprägungsgrad der beiden Gruppen wieder an.

In Abbildung $9 \mathrm{C}$ ist der prozentuale Gewichtsverlust der Gruppen innerhalb des Versuchszeitraumes von 49 Tagen nach Knochenmarktransplantation dargestellt. Die Therapiegruppe, die mit 20 I.E./kg KG Clexane therapiert wurde, wies ab Tag 8 einen durchweg größeren und im Verlauf zunehmenden Gewichtsverlust bezogen auf die Kontrollgruppe auf. Am Ende des Versuches zeigte sich ein $7 \%$ größerer Gewichtsverlust dieser Therapiegruppe verglichen mit der Kontrollgruppe. Der Gewichtsverlust zwischen der Heparin- und Kontrollgruppe stellte sich annähernd gleich dar und lag ab Tag 20 bis zum Versuchsende bei beiden Gruppen bei $82 \%+/-3 \%$ des Ausgangsgewichts. Am Versuchsende wies die Therapiegruppe einen $3 \%$ (79 \% des Ausgangsgewichts) höheren Gewichtsverlust als die Kontrollgruppe (82\% des Ausgangsgewichts) auf. Insgesamt zeigte sich kein statistisch signifikanter Unterschied zwischen den Gruppen. 
Der Vergleich der i.v. Veruchsreihen zeigt, dass weder im Überleben, noch im klinischen Ausprägungsgrad der aGvHD oder beim Gewichtsverlust der Tiere ein statistisch signifikanter Unterschied zwischen den Versuchsgruppen auftrat. Die i.v. Applikation von 20 I.E./kg KG NMH (Clexane) beeinflusste den Krankheitsverlauf sogar eher ungünstig. Demgegenüber ließ sich bei der mit 100 I.E./kg KG Heparin behandelten Therapiegruppe ein geringfügiger therapeutischer Effekt feststellen. Es zeigte sich hier sowohl im Überleben als auch beim klinischen Ausprägungsgrad der Krankheit eine günstige Beeinflussung des Krankheitsverlaufs.

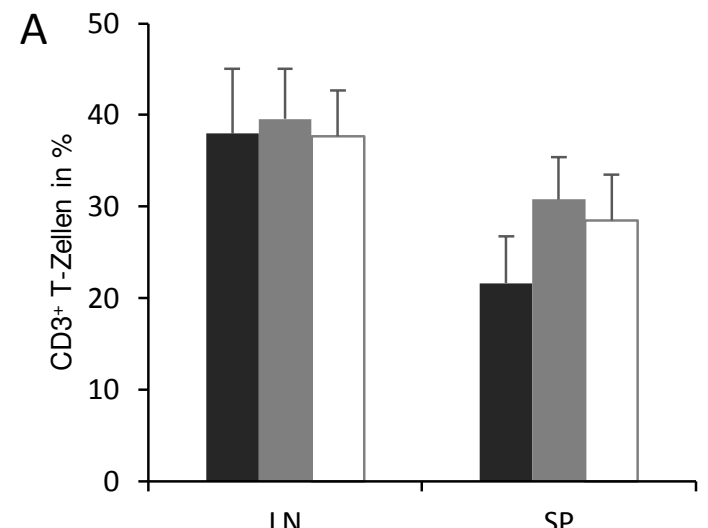

LN

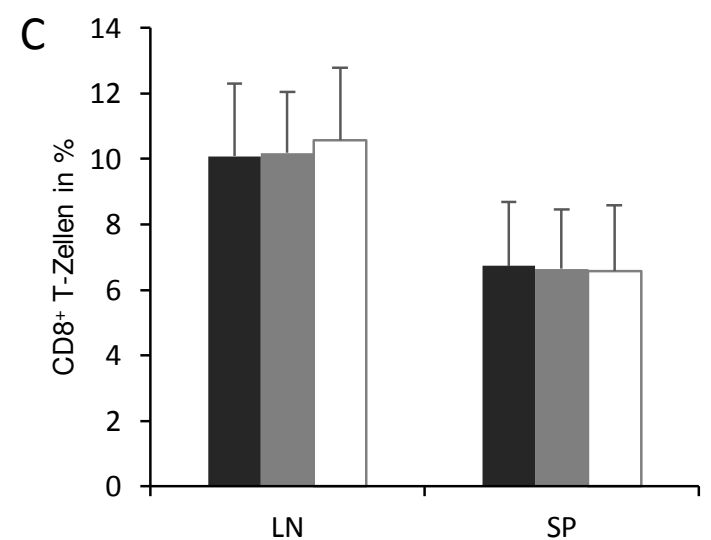

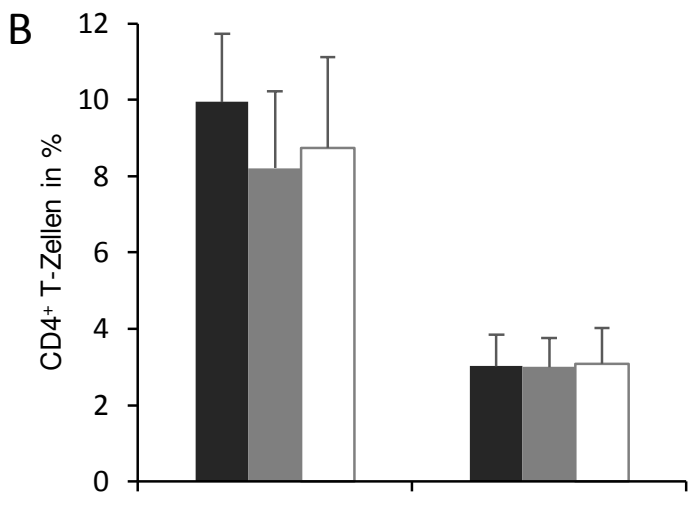

LN

$$
\begin{aligned}
& \text { Kontrolle } \\
& \text { Clexane } 20 \text { I.E./kg KG } \\
& \square \text { Heparin } 100 \text { I.E./kg KG }
\end{aligned}
$$

Abbildung 10: Durchflusszytometrische Analyse der $\mathrm{CD}^{+}, \mathrm{CD}^{+}$und $\mathrm{CD} 8^{+} \mathrm{T}$-Zellen von Lymphknoten (LN) und Milz (SP) nach i.v. Injektion von NMH (Clexane) und UFH (Heparin). Zwei Therapiegruppen der C57BL/6J $\rightarrow$ BALB/c transplantierten Mäuse wurden jeweils mit einer Clexane-Konzentration von 20 I.E./kg KG $(n=11)$ oder einer Heparin-Konzentration von 100 I.E./kg KG $(n=14)$ behandelt, während die simultan transplantierte Kontrollgruppe $(n=9)$ das gleiche Volumen $\mathrm{NaCl}$ erhielt. Die LN und SP der Mäuse wurden analysiert, sobald die Tiere einen Gesamtscore von $\geq 6$ Punkten erreichten oder der Versuch nach 49 Tagen beendet wurde. Der prozentuale Anteil der $\mathrm{CD}^{+} \mathrm{T}$-Zellen (A), der CD4+ $4^{+}$-Zellen (B) und der $\mathrm{CD} 8^{+} \mathrm{T}$-Zellen (C) von LN und SP wurde mittels durchflusszytometrischer Analyse ausgewertet und verglichen. Die Daten der Balkendiagramme sind als Mittelwert mit Standardfehler dargestellt und wurden in zwei voneinander unabhängigen Versuchen durchgeführt: Abbildung $B$ und $C$ basierend auf Budde et al. (2015) mit freundlicher Genehmigung des Autors.

Die Ergebnisse der prozentualen Analyse der $\mathrm{CD}^{+}, \mathrm{CD}^{+}$und $\mathrm{CD} 8^{+} \mathrm{T}$-Zellen mittels Durchfusszytometrie waren sowohl in der Milz als auch in den Lymphknoten zwischen 
den Kontroll- und Therapiegruppen annähernd gleich. Es zeigte sich kein statistisch signifikanter Unterschied. Die Ergebnisse sind in den Abbildungen $10 \mathrm{~A}$ bis $\mathrm{C}$ dargestellt.

\subsubsection{Tägliche subkutane Injektion mit UFH}

Da sich in einigen Versuchsreihen ein zum Teil zwar geringfügiger und noch nicht statistisch signifikanter, aber tendenziell therapeutischer Effekt des UFH auf den Verlauf der aGvHD zeigte, wurde eine erneute Versuchsreihe mit UFH durchgeführt. In dieser Versuchsreihe wurde den Tieren das UFH täglich in s.c. Form appliziert. Der Versuchszeitraum wurde aufgrund des erhöhten Stresslevels für die Tiere durch die tägliche Injektion auf 30 Tage reduziert. Des Weiteren birgt die tägliche Injektion ein höheres Risiko für Infektionen und Abszesse an den Injektionsstellen. Es wurden Konzentrationen von 25 I.E./kg KG und 50 I.E./kg KG zur täglichen s.c. Injektion verwendet.
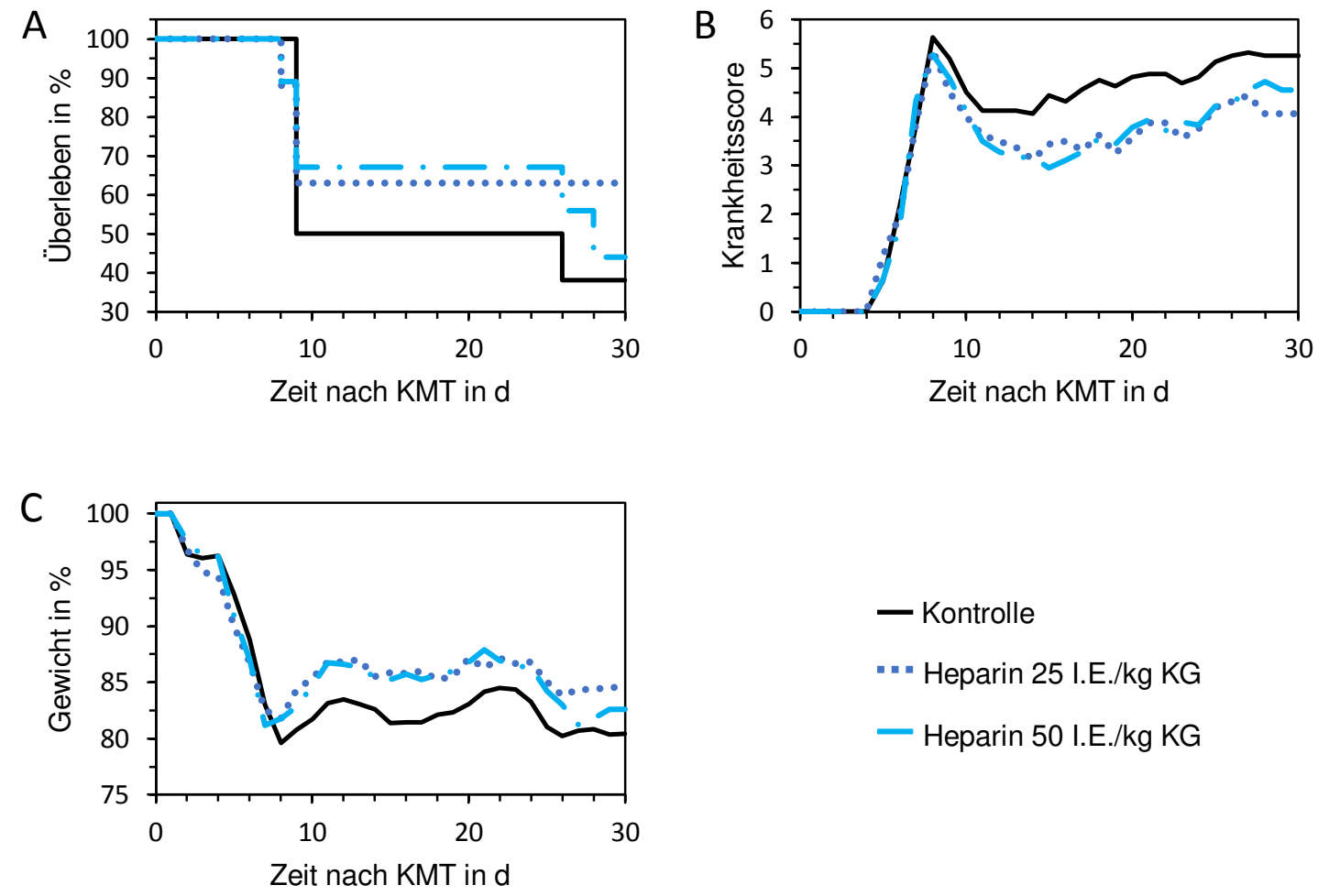

Abbildung 11: Einfluss der täglichen s.c. Injektion von UFH (Heparin) auf die murine aGvHD. Zwei Therapiegruppen wurden nach KMT im C57BL/6J $\rightarrow$ BALB/c transplantierten Mausmodell mit einer Heparin-Konzentration von 25 I.E./kg KG $(n=8)$ oder von 50 I.E./kg KG $(n=9)$ behandelt und mit einer Kontrollgruppe, die nach simultaner KMT das gleiche Volumen $\mathrm{NaCl}$ erhielt $(n=8)$, verglichen. Der therapeutische Einfluss wurde anhand der Überlebenskurve nach Kaplan-Meier (A), dem klinischen GvHD Krankheitsscore (B) und dem Gewicht (C) ausgewertet und verglichen. Die Daten sind als Mittelwert dargestellt und wurden in zwei voneinander unabhängigen Versuchen durchgeführt. 
In Abbildung $11 \mathrm{~A}$ ist mit Hilfe der Kaplan-Meier-Kurve das Überleben der Therapie- und Kontrollgruppen während des Versuchszeitraumes von 30 Tagen nach muriner Knochenmarktransplantation dargestellt. Ab Tag 9 zeigte sich ein durchweg höheres Überleben sowohl der mit 25 I.E./kg KG, als auch der mit 50 I.E./kg KG behandelten Therapiegruppe im Vergleich zur Kontrollgruppe, die von Tag 9 bis Tag 26 ein Überleben von $50 \%$ aufwies. Ab Tag 26 bis zum Versuchsende lag die Überlebensrate der Kontrollgruppe bei $38 \%$. Die Therapiegruppe, die 50 I.E./kg KG Heparin erhielt, zeigte bis Tag 26 ein Überleben von $67 \%$. Ab Tag 26 fiel die Überlebensrate dieser Gruppe bis auf $44 \%$ ab und näherte sich so zum Versuchsende dem Überleben der Kontrollgruppe bis auf $6 \%$ an. Das Überleben der Therapiegruppe, die 25 I.E./kg KG Heparin erhielt, lag ab Tag 9 bis zum Versuchsende konstant bei $63 \%$ und somit zunächst $13 \%$ und zum Schluss sogar $25 \%$ über dem Überleben der Kontrollgruppe. Insgesamt war dies gemäß dem Log-Rank-Test jedoch weder bei der Therapiegruppe, die mit 50 I.E./kg KG UFH $(p=0,80)$ noch bei der Therapiegruppe, die mit 25 I.E./kg KG UFH behandelt wurde $(p=0,48)$ statistisch signifikant.

Abbildung $11 \mathrm{~B}$ veranschaulicht den klinischen Ausprägungsgrad der aGvHD während des Versuchszeitraumes von 30 Tagen nach muriner Knochenmarktransplantation. Auch hier zeigte sich ein deutlich höherer Krankheitsscore der Kontrollgruppe bezogen auf beide Therapiegruppen über den gesamten Versuchszeitraum. Der Krankheitsscore beider Therapiegruppen wies durchgängig einen annähernd gleichen Verlauf auf. Die Differenz des Krankheitsscores der Therapiergruppen und der Kontrollgruppe lag im Schnitt bei 0,8 Punkten und bestätigt den stärkeren Krankheitsverlauf der Kontrollgruppe. Jedoch zeigte sich auch hier zwischen den beiden Therapiegruppen und der Kontrollgruppe kein statistisch signifikanter Unterschied.

Abbildung $11 \mathrm{C}$ zeigt den Gewichtsverlust der Gruppen innerhalb des Versuchszeitraumes von 30 Tagen nach Knochenmarktransplantation. Zwischen beiden Therapiegruppen wies dieser bis zum Versuchsende einen vergleichbaren Verlauf auf. Der Gewichtsverlust der Kontrollgruppe von bis zu $20 \%$ an Tag 30 stellte sich bezogen auf die Therapiegruppen etwas größer dar. Der Gewichtsverlust der Therapiegruppe mit 50 I.E./kg KG Heparin betrug an Tag $3017 \%$ und die Therapiergruppe mit 25 I.E./kg KG hatte nur einen Gewichtsverlust von $16 \%$. Insgesamt zeigte sich jedoch kein statistisch signifikanter Unterschied zwischen den Gruppen.

Alles in allem konnte auch hier weder im Überleben noch im klinischen Ausprägungsgrad der Erkrankung oder beim Gewichtsverlust ein statistisch signifikanter Unterschied zwischen den verschiedenen Gruppen festgestellt werden. Allerdings zeigte sich in allen drei Kategorien tendenziell ein günstiger Effekt der täglichen s.c. Heparininjektionen auf 
den Verlauf der aGvHD der beiden Therapiegruppen. Besonders die Therapiegruppe, die mit einer täglichen Heparindosis von 25 I.E./kg KG behandelt wurde, zeigte konstant bis zum Versuchende eine höhere Überlebensrate, einen geringeren klinischen Ausprägungsgrad und einen schwächeren Gewichtsverlust im Vergleich zur Kontrollgruppe. Bei dieser Therapiegruppe ließ sich zwar kein statistisch signifikanter, aber dafür ein therapeutischer Effekt feststellen, der noch durch weitere Versuchsreihen untersucht werden sollte.
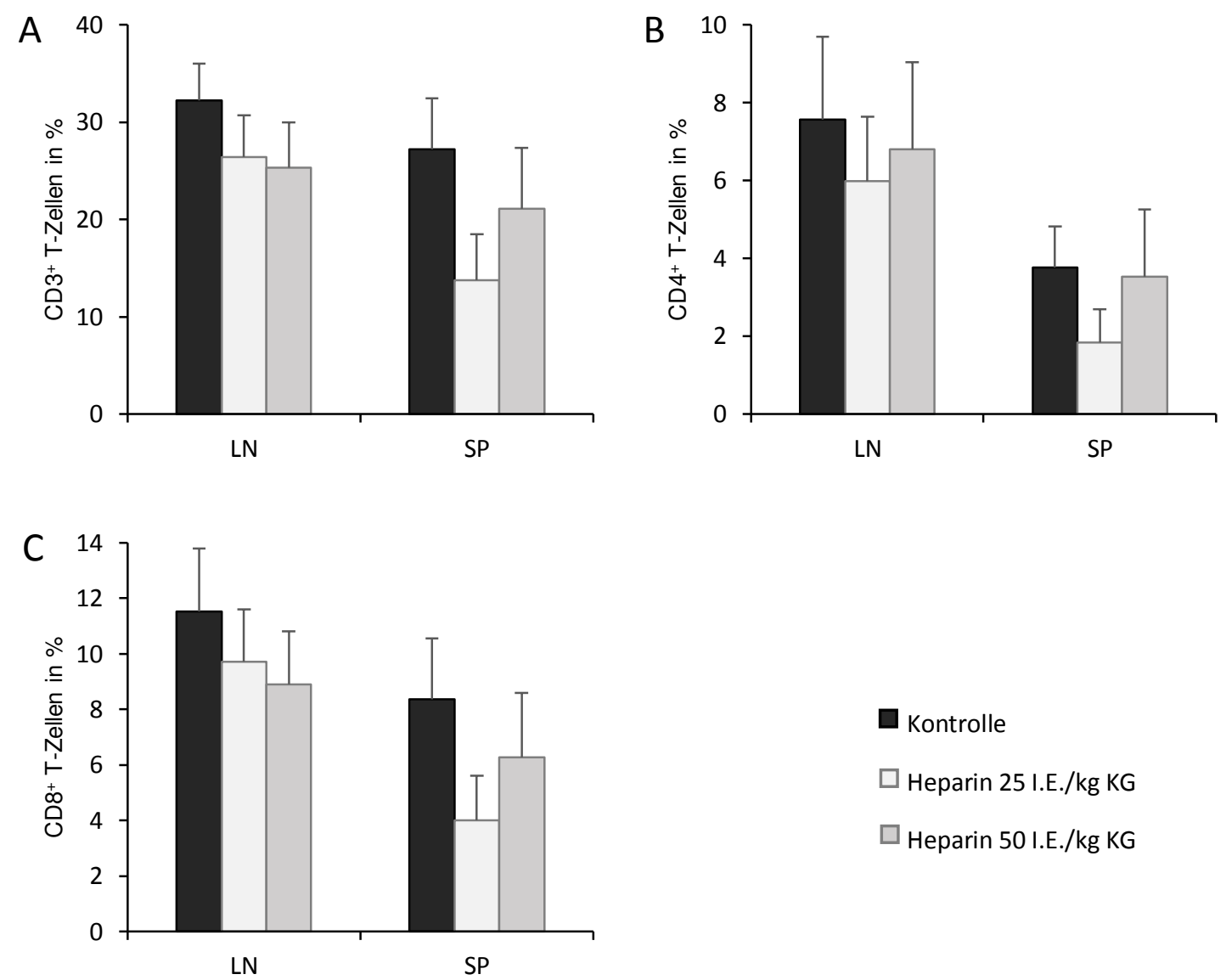

Abbildung 12: Durchflusszytometrische Analyse der $\mathrm{CD}^{+}, \mathrm{CD}^{+}$und $\mathrm{CD} 8^{+} \mathrm{T}$-Zellen von Lymphknoten (LN) und Milz (SP) nach täglicher s.c. Injektion von UFH (Heparin). Zwei Therapiegruppen der $\mathrm{C} 57 \mathrm{BL} / 6 \mathrm{~J} \rightarrow \mathrm{BALB} / \mathrm{c}$ transplantierten Mäuse wurden jeweils mit einer HeparinKonzentration von 25 I.E./kg KG $(n=7)$ oder von 50 I.E./kg KG $(n=9)$ behandelt, während die simultan transplantierte Kontrollgruppe $(n=8)$ das gleiche Volumen $\mathrm{NaCl}$ erhielt. Die LN und SP der Mäuse wurden analysiert, sobald die Tiere einen Gesamtscore von $\geq 6$ Punkten erreichten oder der Versuch nach 49 Tagen beendet wurde. Der prozentuale Anteil der CD3 ${ }^{+}$T-Zellen (A), der CD4 ${ }^{+}$T-Zellen (B) und der CD8 ${ }^{+}$T-Zellen $(C)$ von LN und SP wurde mittels durchflusszytometrischer Analyse ausgewertet und verglichen. Die Daten der Balkendiagramme sind als Mittelwert mit Standardfehler dargestellt und wurden in zwei voneinander unabhängigen Versuchen durchgeführt.

Die Ergebnisse der T-Zell-Analyse mittels Durchflusszytometrie zeigten in den Lymphknoten und der Milz einen prozentual leicht erhöhten Anteil der $\mathrm{CD}^{+}, \mathrm{CD}^{+}$und $\mathrm{CD} 8^{+}$ T-Zellen in allen Kontrollgruppen im Vergleich zu den Therapiegruppen. Dies war kein 
statistisch signifikanter Unterschied. Dabei fällt auf, dass ein geringerer prozentualer TZellanteil in den Gruppen auftrat. In diesem Fall bei den Therapiegruppen, die einen tendenziell günstigeren Krankheitsverlauf aufwiesen. Die T-Zell-Analysen der Milz zeigten zusätzlich einen erhöhten prozentualen Anteil der $\mathrm{CD}^{+}, \mathrm{CD}^{+}$und $\mathrm{CD}^{+} \mathrm{T}$-Zellen der mit 50 I.E./kg KG Heparin behandelten Gruppe gegenüber der mit 25 I.E./kg KG Heparin behandelten Gruppe, jedoch ebenfalls ohne statistische Signifikanz. Die Ergebnisse sind in den Abbildungen $12 \mathrm{~A}$ bis $\mathrm{C}$ dargestellt.

\subsection{Ergebnisse der In-vitro-Versuche}

Neben den tierexperimentellen Versuchen wurde zusätzlich eine In-vitro-Versuchsreihe durchgeführt, um einen möglichen Einfluss von NMH und UFH auf die Immunzellen des Menschen aufzudecken. Dafür wurde mit Hilfe von Zellkulturen das Proliferationsverhalten humaner Leukozyten mit und ohne Zugabe von NMH oder UFH beurteilt. LPS diente dabei als Immunstimulans. Um einen möglichen immunmodulierenden Effekt des Heparins beurteilen zu können, wurde der Anteil an proliferierender Zellen nach alleiniger LPS- oder Heparin- oder nach kombinierter LPS- und Heparin-Zugabe mittels Durchflusszytometrie verglichen. Es erfolgte die Beurteilung des Proliferationsverhaltens der T- (CD3+ Zellen) und B-Zellen (CD19+ Zellen) sowie der Monozyten (CD14+ Zellen) nach Färbung mit dem Cell Proliferation Dye eFluor $\AA^{8} 450$. 


\subsubsection{Proliferationsverhalten humaner Leukozyten nach Zugabe von NMH}
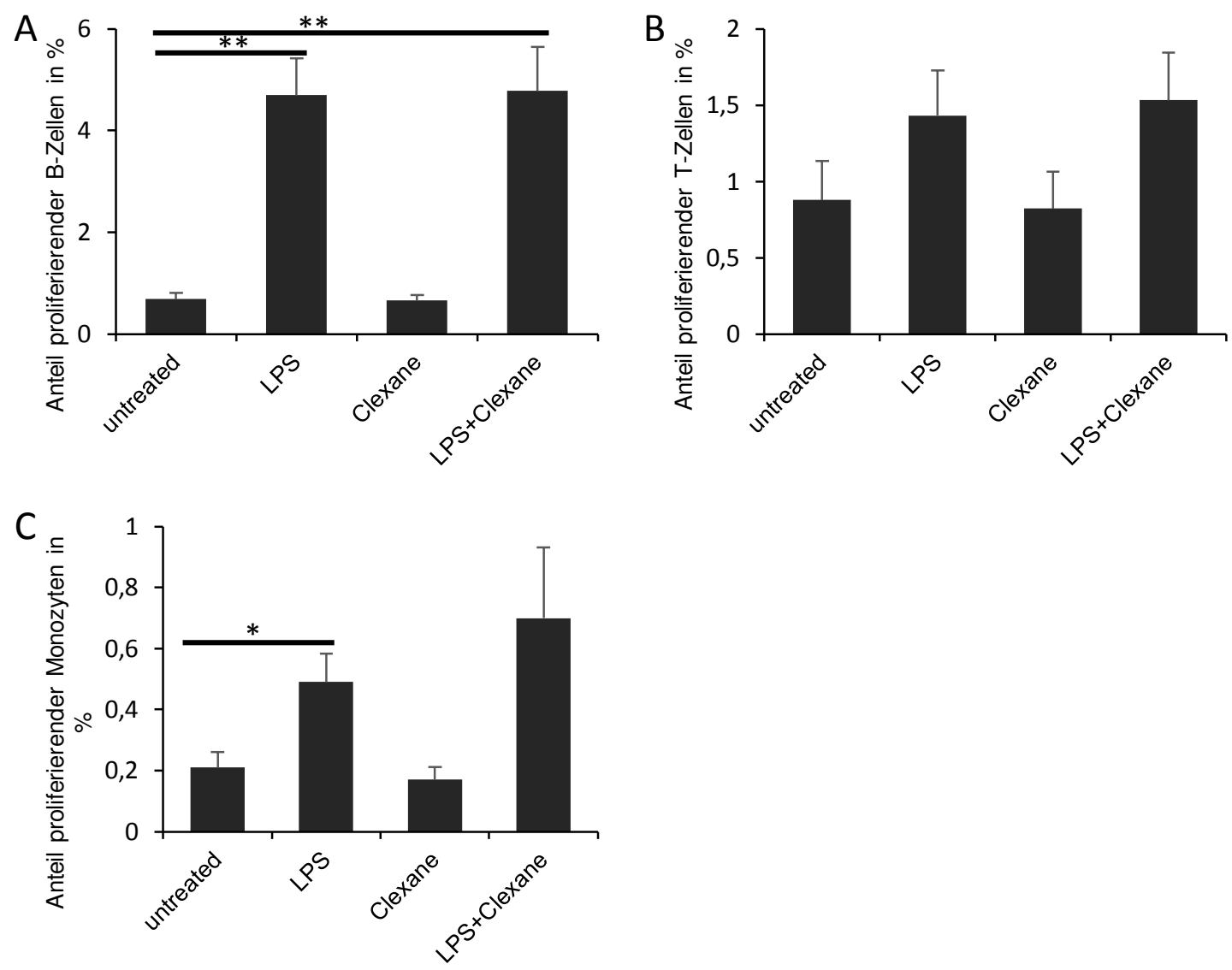

Abbildung 13: Durchflusszytometrische Analyse des Proliferationsverhaltens humaner BZellen, T-Zellen und Monozyten nach Zugabe von LPS und NMH (Clexane). Nach Extraktion und Färbung der Leukozyten aus Buffy-Coats $(n=10)$ wurden diese nach Beimpfung mit LPS, Clexane oder LPS+Clexane für $72 \mathrm{~h}$ in Zellkulturflaschen inkubiert. Der prozentuale Anteil der proliferierenden B-Zellen (A), T-Zellen (B) und Monozyten (C) aus den unterschiedlichen Kulturen wurde mittels durchflusszytometrischer Analyse ausgewertet und verglichen $\left({ }^{*} p<0,05\right.$, $\left.{ }^{* *} p<0,001\right)$. Die Daten der Balkendiagramme sind als Mittelwert mit Standardfehler dargestellt und wurden in mehreren $(n=10)$ voneinander unabhängigen Versuchen durchgeführt.

Abbildungen $13 \mathrm{~A}$ bis $\mathrm{C}$ veranschaulichen das Proliferationsverhalten humaner Leukozyten mit und ohne Zugabe des NMH Clexane. Dabei wurde das Proliferationsverhalten der B- und T-Lymphozyten sowie der Monozyten in Bezug auf alle mononukleären Zellen genauer betrachtet.

Abbildung $13 \mathrm{~A}$ bildet den prozentualen Anteil der proliferierenden B-Zellen an allen mononukleären Zellen ab. Die nur mit CPD behandelte Probe (untreated) wies durchschnittlich einen Anteil von 0,69\% proliferierender B-Zellen auf. Unter alleiniger LPS-Zugabe steigerte sich dieser Anteil statistisch signifikant von 0,69\% auf 4,7\% (LPS) ( $p<0,001)$. Nach Zugabe von Clexane (Clexane) zeigte sich ein prozentualer Anteil von 0,66 \% und somit keine Veränderung des Anteils der proliferierenden B-Zellen im Vergleich zur untreated-Gruppe. Unter der gleichzeitigen Zugabe von LPS und Clexane wiesen die B- 
Zellen weiterhin eine statistisch signifikant gesteigerte Proliferationsrate im Vergleich zur nur mit CPD behandelten Probe von 4,78\% auf $(p<0,001)$. Die Zugabe von Clexane führte somit zu keiner Veränderung, insbesondere zu keiner Verminderung der Proliferationrate der B-Zellen.

Dieses Proliferationsverhalten zeigte sich ebenso in dem in Abbildung $13 \mathrm{~B}$ dargestellten Proliferationsverhalten der T-Zellen. Die untreated-Probe wies hier durchschnittlich einen Anteil von 0,88 \% proliferierender T-Zellen auf. Mit der Zugabe von LPS steigerte sich dieser Anteil auf 1,4\% und unter der Zugabe von Clexane blieb der Anteil der proliferierenden T-Zellen bei 0,82\%. Die gleichzeitige Zugabe von LPS und Clexane wies wie bei der alleinigen Zugabe von LPS eine gesteigerte Proliferationsrate von $1,53 \%$ auf. Die Ergebnisse der T-Zell-Proliferation waren nicht statistisch signifikant.

Abbildung $13 \mathrm{C}$ stellt den prozentualen Anteil der proliferierenden Monozyten dar. Die nur mit CPD behandelte Probe wies durchschnittlich einen Anteil von 0,21\% proliferierender Monozyten auf. Unter alleiniger LPS-Zugabe steigert sich dieser Anteil signifikant von $0,21 \%$ auf $0,49 \%(p<0,05)$. Nach alleiniger Zugabe von Clexane zeigte sich mit einem prozentualen Anteil von $0,17 \%$ keine statistisch signifikante Veränderung des Anteils der proliferierenden Monozyten im Vergleich zur untreated-Gruppe. Unter gleichzeitiger Zugabe von LPS und Clexane wiesen die Monozyten weiterhin im Vergleich zur untreated-Gruppe eine gesteigerte, allerdings nicht signifikante, Proliferationsrate von $0,7 \%$ auf.

Durch die Zugabe von LPS wurde das Proliferationsverhalten aller drei Zellreihen gesteigert, während durch die Zugabe von Clexane das Proliferationsverhalten der Zellreihen nicht, insbesondere nicht statistisch signifikant, beeinflusst wurde. 


\subsubsection{Proliferationsverhalten humaner Leukozyten nach Zugabe von UFH}
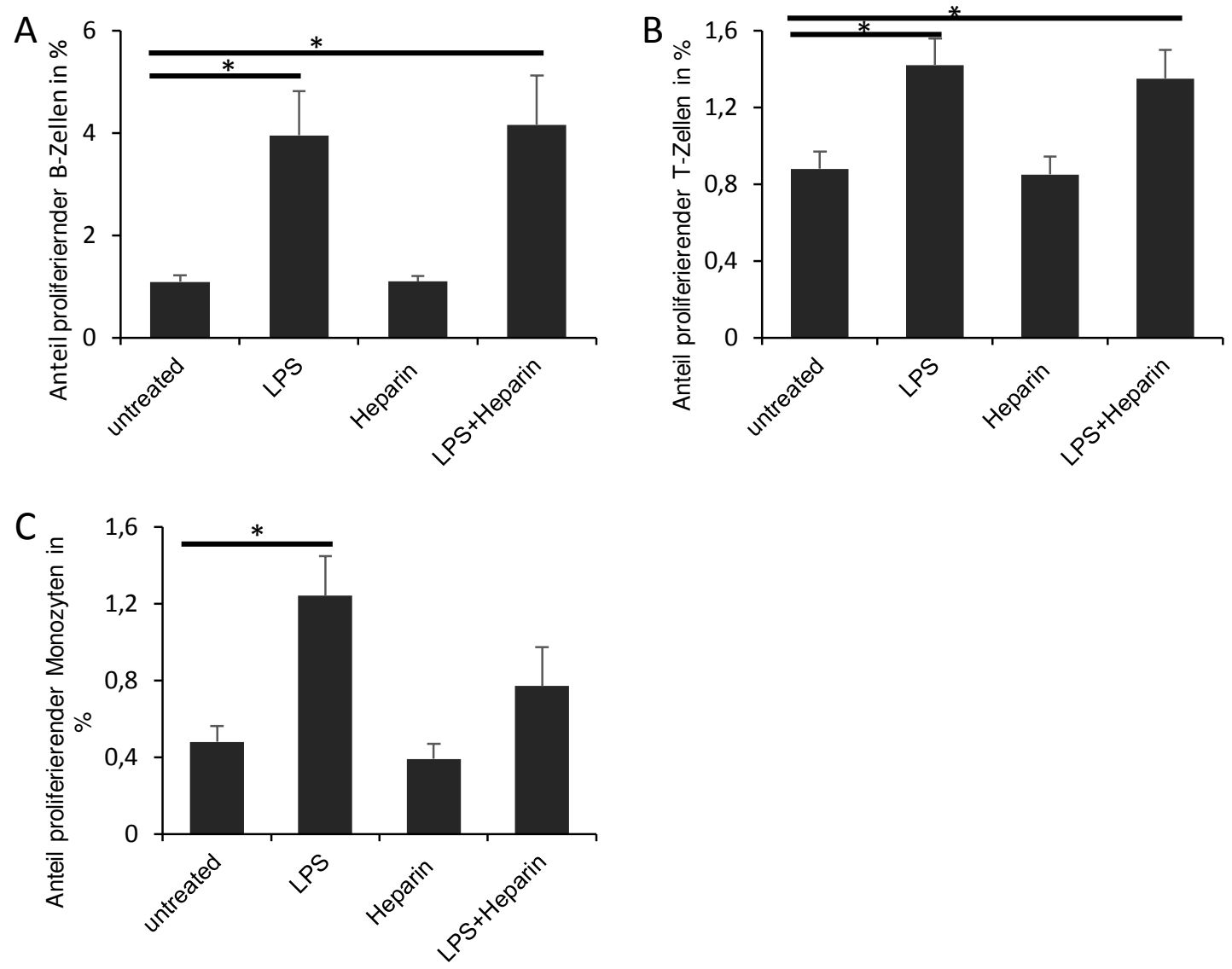

Abbildung 14: Durchflusszytometrische Analyse des Proliferationsverhaltens humaner BZellen, T-Zellen und Monozyten nach Zugabe von LPS und UFH (Heparin). Nach Extraktion und Färbung der Leukozyten aus Buffy-Coats $(n=10)$ wurden diese nach Beimpfung mit LPS, Heparin oder LPS+Heparin für $72 \mathrm{~h}$ in Zellkulturflaschen inkubiert. Der prozentuale Anteil der proliferierenden B-Zellen (A), T-Zellen (B) und Monozyten (C) aus den unterschiedlichen Kulturen wurde mittels durchflusszytometrischer Analyse ausgewertet und verglichen $\left({ }^{*} p<0,05\right)$. Die Daten der Balkendiagramme sind als Mittelwert mit Standardfehler dargestellt und wurden in mehreren $(n=10)$ voneinander unabhängigen Versuchen durchgeführt.

In den Abbildungen $14 \mathrm{~A}$ bis $\mathrm{C}$ ist das Proliferationsverhalten verschiedener humaner Leukozyten mit und ohne Zugabe von UFH dargestellt. Dabei wurde das Proliferationsverhalten der B- und T-Lymphozyten sowie der Monozyten in Bezug auf alle mononukleären Zellen genauer betrachtet.

Abbildung $14 \mathrm{~A}$ bildet den prozentualen Anteil der proliferierenden B-Zellen ab. Die nur mit CPD behandelte Probe (untreated) wies durchschnittlich einen Anteil von 1,09\% proliferierender B-Zellen auf. Unter alleiniger LPS-Zugabe steigerte sich dieser Anteil statistisch signifikant von 1,09\% auf 3,95 \% (LPS) $(p<0,05)$. Nach der Zugabe von UFH (Heparin) zu den mit CPD behandelten Proben kam es mit einem Anteil von 1,1\% proliferiender B-Zellen zu keiner statistisch signifikanten Änderung des Proliferationsverhaltens der B-Zellen. Unter Zugabe von LPS und Heparin wiesen die B-Zellen weiterhin 
eine statistisch signifikant gesteigerte Proliferationsrate von 4,16 \% auf $(p<0,05)$. Die Zugabe von UFH führte somit zu keiner Veränderung, insbesondere zu keiner Verminderung der Proliferationrate der B-Zellen.

Dieses Proliferationsverhalten zeigte sich ebenso in dem in Abbildung 14 B dargestellten Proliferationsverhalten der T-Zellen. Die untreated-Probe wies hier durchschnittlich einen Anteil von 0,88\% proliferierender T-Zellen auf. Mit der Zugabe von LPS steigerte sich dieser Anteil statistisch signifikant auf 1,42\% $(p<0,05)$ und unter der Zugabe von Heparin blieb der durchschnittliche Anteil der proliferierenden T-Zellen bei 0,85\%. Die gleichzeitige Zugabe von sowohl LPS als auch Heparin wies weiterhin eine statistisch signifikant gesteigerte Proliferationsrate von $1,35 \%$ auf $(p<0,05)$.

Abbildung $14 \mathrm{C}$ stellt den prozentualen Anteil der proliferierenden Monozyten dar. Die untreated-Probe wies durchschnittlich einen Anteil von 0,48 \% proliferierender Monozyten auf. Unter alleiniger LPS-Zugabe steigert sich dieser Anteil statistisch signifikant von $0,48 \%$ auf $1,24 \%(p<0,05)$. Nach Zugabe von UFH zeigte sich ein prozentualer Anteil von $0,39 \%$ und somit keine statistisch signifikante Abnahme des Anteils der proliferierenden Monozyten im Vergleich zur untreated-Gruppe. Unter Zugabe von LPS und Heparin wiesen die Monozyten weiterhin eine gesteigerte, aber statistisch nicht signifikante Proliferationsrate von $0,77 \%$ auf.

Durch die Zugabe von LPS wurde das Proliferationsverhalten aller drei Zellreihen gesteigert, während durch die Zugabe von UFH das Proliferationsverhalten der drei Zellreihen statistisch nicht signifikant beeinflusst wurde. 


\section{Diskussion}

Auf dem Gebiet der Stammzelltransplantation und Transfusionsmedizin wird nach wie vor intensiv an neuen Therapiemöglichkeiten und -ansätzen für die häufig nach Stammzelltransplantation auftretende Komplikation der aGvHD geforscht. Zahlreiche veröffentlichte Studien konnten bereits einen antiinflammatorischen Effekt der Heparine und eine daraus resultierende positive Auswirkung auf einige entzündliche Erkrankungen wie Asthma bronchiale oder Colitis ulcerosa aufzeigen (Nelson et al. 1993; Dolowitz und Dougherty 1960; Bendstrup und Jensen 2000; Gaffney et al. 1995). Sowohl UFH, als auch NMH inhibieren die Aktivierung proinflammatorischer Zytokine und anderer Entzündungsparameter (Young 2008; Huang et al. 2014; Hochart et al. 2006). Vor diesem Hintergrund war das Ziel dieser Arbeit, die Auswirkungen einer Applikation von UFH und $\mathrm{NMH}$ auf das Überleben und den Schweregrad der aGvHD im Mausmodell zu untersuchen. Zudem sollten mögliche Erklärungen für die gegebenenfalls entstehenden Auswirkungen auf den Krankheitsverlauf und das Überleben überprüft werden. Im folgenden Kapitel werden die Ergebnisse der durchgeführten Versuche diskutiert. Dabei wird zunächst auf die unterschiedliche Auswirkung der verwendeten Heparinform, Applikationsart und Dosis eingegangen und die möglichen Ursachen erörtert. Zusätzlich werden die Ergebnisse der durchflusszytometrischen Analyse und der In-vitro-Versuchsreihe genauer betrachtet.

Die bereits erwähnte schubweise verlaufende chronisch entzündliche Darmerkrankung Colitis ulcerosa (CU) geht zum Teil mit vergleichbaren Symptomen wie die Darm-GvHD einher. Hierzu zählt die Entzündungsreaktion der Darmmukosa mit wässrigen bis blutigen Diarrhoen in Kombination mit schmerzhaften abdominellen Krämpfen. Aufgrund des beschriebenen antiinflammatorischen Potentials von Heparin gibt es einige Studien zu weiteren Therapiemöglichkeiten der CU mit Heparin. Aufgrund des bestehenden Mangels an vorhandenen Studien zum Einfluss von Heparin auf die aGvHD und somit fehlenden Vergleichsmöglichkeiten werden im Folgenden die Ergebnisse dieser Arbeit den Ergebnissen aus Arbeiten zum Einfluss von Heparin auf die CU und andere entzündliche Erkrankungen gegenübergestellt.

Insgesamt konnte in dieser Arbeit kein statistisch signifikanter therapeutischer Effekt des NM- und UFH auf das Überleben und den Krankheitsverlauf der aGvHD im Mausmodell festgestellt werden. Allerdings konnten gewisse Tendenzen der beiden Substanzen zur günstigen und ungünstigen Beeinflussung der aGvHD beobachtet werden. Dabei war der Einfluss von der Applikationsart, der Dosis und der verwendeten Substanz abhängig. 


\subsection{Vergleich von NMH und UFH als Therapeutika der aGvHD im Mausmodell}

In den letzten Jahrzehnten wurde die Anwendung von UFH im klinischen Alltag durch die Anwendung von $\mathrm{NMH}$ abgelöst. NMH weisen eine höhere Bioverfügbarkeit und eine längere HWZ als UFH auf. Weiterhin liegt ein deutlich günstigeres Nebenwirkungsprofil vor. Die Wahrscheinlichkeit unter der Therapie mit NMH eine heparininduzierte Thrombozytopenie Typ II zu entwickeln ist mit 0,1\% etwa 30 -fach geringer als bei einer Therapie mit UFH. Auch das Osteoporoserisiko bei einer Langzeittherapie mit NMH ist deutlich geringer (Hirsh et al. 2001b; Al-Eidan 2015). Die Ergebnisse einer literarischen Übersichtsarbeit von Costantino und Kollegen (2012) deuten zudem darauf hin, dass die s.c. Anwendung von $\mathrm{NMH}$ in der Behandlung von akuten venösen Thrombembolien zu weniger Blutungskomplikationen als die Anwendung von UFH führt.

Werden diese Eigenschaften berücksichtigt, scheint es naheliegend, dass sich die Anwendung von $\mathrm{NMH}$ in der Therapie der aGvHD insgesamt günstiger und nutzbringender als der Einsatz von UFH auf den Krankheitsverlauf der aGvHD auswirken könnte. Entgegen dieser Vorstellung konnte in den Ergebnissen dieser Arbeit eine gegensätzliche Tendenz nachgewiesen werden. Die Applikation von NMH wies in allen durchgeführten Versuchen keinen oder sogar einen nachteiligen Effekt bezüglich der Überlebensrate und des klinischen Ausprägungsgrades der aGvHD im Vergleich zu den Kontrollgruppen auf. Weder eine niedrige (20 I.E./kg KG), noch eine höher gewählte Dosis (200 I.E./kg KG) führte zu einer Verbesserung der Überlebensrate oder einer Abmilderung des klinischen Ausprägungsgrades der Therapiegruppen. Dabei zeigte sich in der Therapiegruppe, die mit der höher gewählten Therapiedosis (200 I.E./kg KG) des NMH s.c. behandelt wurde, durchgehend ein deutlich schwererer klinischer Verlauf der aGvHD. An Tag 15 ließ sich sogar ein statistisch signifikant höherer Krankheitsscore $(p=0,04)$ als in der Kontrollgruppe nachweisen. Dagegen konnte bei der Anwendung des UFH, insbesondere in den Versuchen zur i.v. Applikation von UFH, ein schwächerer klinischer Ausprägungsgrad und eine höhere Überlebensrate nachgewiesen werden. So wies die Heparinversuchsgruppe ab Tag 10 einen deutlich geringeren Krankheitsscore als die Kontrollgruppe auf. An Tag 14 zeigte sich dabei sogar ein statistisch signifikant niedrigerer Krankheitsscore der Heparingruppe im Vergleich zur Kontrollgruppe $(p=0,04)$.

Passend zu den Ergebnissen dieser Arbeit konnte in einer Studie von Koenig et al. (1998) gezeigt werden, dass NMH deutlich schwächere Inhibitoren der L- und P-Selektine sind und somit einen geringeren immunmodulierenden Effekt als UFH aufweisen. Ursächlich hierfür sind vermutlich die geringere Molekülgröße und die damit veränderte 
Bindungseigenschaft der NMH. Des Weiteren wird ein Verlust der benötigten Bindungsstellen während der chemischen Fraktionierung diskutiert (Koenig et al. 1998; Lu et al. 2010a). Insbesondere das NMH Enoxaparin, das in dieser Arbeit als $\mathrm{NMH}$ verwendet wurde, war in der Studie von Koenig et al. (1998) ein deutlich schwächerer Inhibitor der L- und P-Selektine als das UFH. Für UFH konnte dagegen bereits bei einer 12-50-fach niedrigeren Dosierung, als für die Anwendung zur Antikoagulation empfohlen, eine Inhibition der genannten Selektine nachgewiesen werden.

Die Gabe von Heparinen geht immer mit einem gewissen Blutungsrisiko, insbesondere im Rahmen der aGvHD, die mit dem Auftreten von blutigen Diarrhoen assoziiert ist, einher. Werden die oben beschriebenen Ergebnisse berücksichtigt, scheint es plausibel, dass eine höhere Dosis des NMH benötigt wird, um den gleichen immunsuppressiven Effekt eines UFH zu bewirken. Eine höher gewählte Heparindosis führt wiederum zu einem erhöhten Blutungsrisiko. Das schlechtere Abschneiden der mit NMH behandelten Therapiegruppen kann somit bei der höher gewählten Dosis von 200 I.E./kg KG mit dem vermutlich vermehrten Auftreten von Blutungskomplikationen und bei der geringer gewählten NMH-Dosis von 20 I.E./kg KG mit einem nicht ausreichenden immunsupprimierenden Effekt erklärt werden.

In den bereits erwähnten Studien zur Auswirkung von Heparin auf die chronisch entzündliche Darmerkrankung CU konnte entsprechend sowohl bei der i.v. als auch s.c. Anwendung von UFH ein positiver Effekt auf den Krankheitsverlauf der CU festgestellt werden (Evans et al. 1997; Gaffney et al. 1995; Folwaczny et al. 1999). Die s.c. Applikation von NMH dagegen zeigte keinen Effekt auf den Verlauf der Erkrankung (Chande et al. 2010; Zezos et al. 2006). Insbesondere für das NMH Endoxaparin, das in dieser Arbeit verwendet wurde, konnte in einer Studie von Zezos et al. (2006) kein therapeutischer Nutzen nachgewiesen werden.

Die beschriebenen Ergebnisse unterstützen die Resultate dieser Arbeit. Zusammenfassend konnte durch die Applikation von NMH keine nutzbringende Wirkung hinsichtlich der Überlebensrate oder des Krankheitsverlaufes der aGvHD erzielt werden. Zwar zeigte sich bei der Anwendung von UFH ebenfalls kein statistisch signifikantes Ergebnis, doch konnte insgesamt betrachtet ein vorteilhafterer Verlauf in Bezug auf die Überlebensrate und den klinischen Ausprägungsgrad der aGvHD festgestellt werden. Der therapeutische Effekt hängt dementsprechend von der Form des verwendeten Heparins ab. Gemäß dem Algorithmus des verwendeten Log-Rank-Tests ist es wahrscheinlich, dass weitere Versuchsreihen mit einer größeren Tierzahl zu statistisch signifikanten Ergebnissen führen würden. 


\subsection{Auswirkungen der s.c. und i.v. Applikation auf den Krank- heitsverlauf der aGvHD im Mausmodell}

Injektionen können durch verschiedene Arten einem Organismus zugeführt werden. Zu den häufig angewandten Formen zählen die intravenöse (i.v.), subkutane (s.c.) und intramuskuläre (i.m.) Form (Jin et al. 2015). In dieser Arbeit wurde ausschließlich die i.v. und die s.c. Applikation verwendet. Bei der s.c. Injektion wird der Wirkstoff in die Subkutis appliziert. Dies hat zur Folge, dass sich hier ein Depot bildet und der Wirkstoff nach und nach in den Körper abgegeben wird. Die Wirkung tritt also nicht sofort ein. Bei der s.c. Anwendung von UFH verzögert sich die antikoagulatorische Wirkung um ein bis zwei Stunden (Hirsh et al. 2001b). Des Weiteren können nur geringe Volumina über diesen Applikationsweg verabreicht werden. Bei der i.v. Injektion wird das Medikament direkt in den venösen Kreislauf appliziert. Die Wirkung tritt daher unmittelbar ein und es besteht die Möglichkeit ein größeres Volumen zu verabreichen (Jin et al. 2015).

Im klinischen Alltag werden NMH in der Regel s.c. appliziert. Eine Ausnahme stellt die einmalige i.v. Bolus-Injektion gefolgt von der regelmäßigen s.c. Injektion beim akuten ST-Hebungsinfarkt dar. Hier ist jedoch das Ziel schnellstmöglich eine optimale gerinnungshemmende Aktivität zu erreichen. UFH wird sowohl i.v., als auch s.c. angewendet. Die i.v. Anwendung erfolgt hierbei in der Regel aufgrund der geringeren HWZ kontinuierlich (Hirsh et al. 2001b). Die s.c. Anwendung der UFH wird zur Thromboseprophylaxe angewandt. Da die s.c. Applikation eine geringere Bioverfügbarkeit aufweist, sollte eine ausreichende Anfangsdosis gewählt werden.

In dieser Arbeit wurde die s.c. Applikation, mit Ausnahme einer Versuchsreihe (siehe Kapitel 4.4 „Tägliche s.c. Applikation von UFH“), dreimal pro Woche über den kompletten Versuchszeitraum von 49 Tagen durchgeführt. Die i.v. Gabe erfolgte dagegen nur einbis zweimal pro Woche vor den Krankheitswellen in den ersten drei Wochen des Versuchszeitraumes. Die Versuchsreihen, die eine s.c. Heparinapplikation erhielten, waren den Versuchsreihen der i.v. Heparin Injektion dabei hinsichtlich der Überlebenszeit und des Ausprägungsgrads der aGvHD unterlegen. Insbesondere die Therapiegruppe mit einer i.v. Gabe von UFH zeigte einen geringeren klinischen Ausprägungsgrad und eine höhere Überlebensrate als die Kontrollgruppe und die Therapiegruppen, die UFH s.c. erhielten. Möglicherweise liegt eine der Ursachen in der besseren Bioverfügbarkeit der i.v. Applikation. Dieser positive Effekt wurde zudem ohne einen gleichbleibenden pharmakologischen Medikamentenspiegel des UFH erreicht, denn die i.v. Gabe erfolgte, wie oben beschrieben, nur ein bis zweimal pro Woche. Dies indiziert, dass die immunologischen Eigenschaften des Heparins lang andauernd und mit einer längeren HWZ, als die antikoagulatorischen Eigenschaften, die nur eine HWZ von wenigen Stunden aufweisen, 
einhergehen. In mehreren Studien konnte bereits gezeigt werden, dass der immunmodulierende Effekt der Heparine unabhängig vom antikoagulatorischen Effekt abläuft (Rao et al. 2010; Page 2013). Es liegen allerdings keine Studien bezüglich der HWZ des immunmodulierenden Effektes von Heparin vor.

Evans et al. (1997) sowie Ang und Kollegen (2000) konnten in klinischen Studien zur Therapie der CU mit Heparin zeigen, dass die i.v. Anwendung von UFH die gleiche Wirksamkeit, wie die etablierte Glukokortikoidtherapie aufweist. Hier erfolgte allerdings im Gegensatz zu dieser Arbeit eine kontinuierliche i.v. Gabe. Trotz einer verlängerten aktivierten partiellen Thromboplastinzeit (aPTT) auf das 1,5 bis 2,5-fache kam es dabei zu keiner Zunahme von Blutungskomplikationen. In der klinischen Studie von Ang et al. (2000) führte die i.v. Anwendung von UFH zu einer signifikanten Verbesserung des klinischen Ausprägungsgrades der CU mit deutlicher Reduktion der Stuhlfrequenz sowie endoskopischen und histologischen Rückgang der Krankheit. Eine weitere Studie zur i.v. Anwendung von UFH zeigte dagegen keinen Effekt auf den klinischen Ausprägungsgrad der CU und war mit dem vermehrten Auftreten von Blutungskomplikationen assoziiert. Allerdings wurde in dieser Studie weder die endoskopische noch histologische Verbesserung der CU berücksichtigt (Panés et al. 2000). Insgesamt ist es schwierig die vorhandenen Studien zur Heparintherapie der CU zu vergleichen, da sich diese in den verwendeten Remissionskriterien und der Studiendauern oft stark unterscheiden und somit eine große Heterogenität aufweisen (Shen et al. 2007).

Die s.c. Applikation von NMH weist im Gegensatz zu der von UFH aufgrund der geringeren Molekülgröße eine gute Bioverfügbarkeit auf. Es konnte allerdings gezeigt werden, dass Heparine mit einem niedrigen Molekulargewicht eine geringere Selektin-Inhibition und somit einen geringeren immunsuppressiven Effekt aufweisen (Koenig et al. 1998). Dies bedeutet, dass die Bioverfügbarkeit bei der s.c. Anwendung von NMH zwar gut ist, allerdings gleichzeitig eine geringere immunmodulierende Aktivität im Vergleich zum UFH vorliegt. Bei Berücksichtigung dieser Erkenntnisse ist es plausibel, dass die Therapiegruppen, die i.v. UFH erhielten, bessere Ergebnisse hinsichtlich der Überlebensrate und des klinischen Ausprägungsgrades der aGvHD als die Therapiegruppen, die NMH s.c erhielten, erzielen konnten.

Bei der i.v. Anwendung von NMH konnte weder ein positiver noch ein negativer Effekt auf das Überleben oder den Ausprägungsgrad der aGvHD erkannt werden. Hier spielt vermutlich die sehr gering gewählte Konzentration von 20 I.E./kg KG bei gleichzeitiger geringerer immunmodulierender Aktivität des $\mathrm{NMH}$ eine Rolle. 
Eine zusammenfassende Studie von Chande et al. (2010) zu Heparin in der Therapie der $\mathrm{CU}$ ergab ebenfalls keinen Vorteil von s.c. applizierten NMH hinsichtlich des klinischen Verlaufs der CU gegenüber einer Placebogruppe. In einer Studie von Celasco et al. (2010) konnte allerdings eine Applikation von NMH (Parnaparin sodium) in Form von Tabletten eine Linderung des klinischen Ausprägungsgrades der CU bewirken. Womöglich liegt in dieser Form der Applikation von NMH neues therapeutisches Potential bezüglich entzündlicher Darmerkrankungen, zu welchen die Darm-GvHD zählt, vor. Durch die orale Anwendung ist bei fehlender oraler Bioverfügbarkeit der $\mathrm{NMH}$ eine hochdosierte Gabe ohne erhöhtes Blutungsrisiko möglich (Celasco et al. 2010; Hirsh et al. 2001a). Dieser Effekt würde allerdings auf Kosten einer ebenfalls im Rahmen der aGvHD gewünschten systemischen immunsuppressiven Wirkung gehen, so dass diese Form der Applikation im Rahmen eines supportiven Konzepts der Darm-GvHD in Betracht gezogen werden könnte.

Zusammenfassend betrachtet, hatte die Applikationsform keinen statistisch signifikanten Einfluss auf das klinische Ergebnis. Es konnten jedoch Tendenzen erkannt werden. Die i.v. Applikation von UFH wies dabei in den hier besprochenen Versuchsreihen das vielversprechendste Ergebnis auf. Dies liegt womöglich an der besseren Bioverfügbarkeit der i.v. Applikation. Allerdings scheint dieses Ergebnis, wie bereits im vorherigen Kapitel beschrieben, insbesondere von der verwendeten Heparinform, in diesem Fall dem UFH, abzuhängen. Weder durch die i.v., noch die s.c. Gabe von NMH konnte ein positiver Einfluss auf den Verlauf der aGvHD erkannt werden. In Studien zur Verwendung von Heparin als Therapeutikum der CU wurde in vielen Fällen bei der Verwendung von UFH zunächst mit einer i.v. Anwendung begonnen, die im Verlauf auf eine s.c. Applikation umgestellt wurde (Ang et al. 2000; Folwaczny et al. 1999). Möglicherweise liegt in dieser praktikableren Kombination der Injektionsformen eine weitere Möglichkeit das therapeutische Potential des Heparins in der aGvHD im Mausmodell aufzudecken. Hierfür sind weitere Studien mit größeren Tierzahlen von Nöten. Des Weiteren liegt in der oralen Applikation von Heparin eventuell weiteres therapeutisches Potential, auch hinsichtlich einer Anwendung von NMH. Hierfür sind ebenfalls weiterführende Versuche und Studien notwendig. 


\subsection{Einfluss der unterschiedlichen Dosen auf den Krankheits- verlauf der aGvHD im Mausmodell}

$\mathrm{NMH}$ und UFH werden im klinischen Alltag unter anderem routinemäßig in der Therapie und Prophylaxe von tiefen Beinvenenthrombosen angewandt (Hirsh et al. 2001a). Hierbei wird die Dosis zur Thromboseprophylaxe des NMH Enoxaparin (Clexane) anhand des Risikoprofils des Patienten mit Beachtung des Körpergewichts bestimmt. Das heißt, es erfolgt eine zusätzliche Anpassung der Dosis bei besonders adipösen oder kachektischen Patienten. In der Regel werden einmal täglich je nach Risikoprofil 2.000 bzw. 4.000 I.E. s.c. injiziert. Bei einem Körpergewicht von $70 \mathrm{~kg}$ entspricht dies einer Dosis von 29 bzw. 57 I.E./kg KG täglich. Zur Therapie von venösen Thrombembolien wird von dem NMH Clexane zweimal täglich eine Dosis von 100 I.E./kg KG, das heißt eine Tagesdosis von 200 I.E./kg KG verabreicht (Sanofi-Aventis Deutschland GmbH 2015). UFH wird zur Vollantikoagulation bei tiefen Beinvenenthrombosen zunächst als Bolus mit einer absoluten Dosis von 5.000 I.E. (entspricht etwa einer Dosis von 70 I.E./kg KG bei einem Körpergewicht von $70 \mathrm{~kg}$ ) und anschließend kontinuierlich mittels Perfusorsystem in einer Tagesdosis von durchschnittlich 350 I.E./kg KG verabreicht. Zur Thromboseprophylaxe wird UFH zweimal täglich in einer absoluten Dosis von 7.500 I.E. s.c. injiziert. Bei einem Körpergewicht von $70 \mathrm{~kg}$ entspricht dies einer Dosis von 214 I.E./kg KG täglich (ratiopharm GmbH 2017). Eine Internationale Einheit (I.E.) beschreibt die blutgerinnungshemmende Wirkung von Heparin. Dabei wird die Gerinnung von Schafsplasma bei $37^{\circ} \mathrm{C}$ unter Zugabe von Heparin untersucht und mit einer Standardzubereitung verglichen (Hänsel und Sticher 2006). Dies bedeutet, dass sich die hier verwendete Angabe der I.E. streng genommen nur auf den gerinnungshemmenden und nicht auf den in dieser Arbeit untersuchten und gewünschten antientzündlichen Effekt des Heparins bezieht. Dieser Wert ist also nicht zwangsläufig gleichbedeutend mit der antiinflammatorischen Wirkung der Substanz, gibt jedoch eine Vorstellung der injizierten Dosis. Zudem sollte bei der Dosisfindung auch der mögliche gerinnungshemmende Einfluss und die folgenden Komplikationen berücksichtigt werden. Bezüglich der antiinflammatorischen Wirkung gibt es bisher noch kein sicheres und messbares Korrelat, da dieser Mechanismus bisher nur ansatzweise verstanden und geklärt ist. Es gibt jedoch in vielen Studien Hinweise darauf, dass dieser Effekt unabhängig von den antikoagulatorischen Eigenschaften stattfindet (Koenig et al. 1998; Nelson et al. 1993).

In dieser Arbeit wurde zunächst mit der auch im klinischen Alltag zur Thromboseprophylaxe verwendeten s.c. Dosis des UFH von 200 I.E./kg KG begonnen. Zu Vergleichszwecken wurde ebenfalls eine Versuchsreihe, in der dieselbe Dosis NMH verabreicht wurde, durchgeführt. Die genannte Dosis wurde den Tieren dreimal pro Woche s.c. injiziert. Es 
zeigten sich in beiden Therapiegruppen eine tendenziell geringere Überlebensrate, ein schwererer klinischer Ausprägungsgrad und ein größerer Gewichtsverlust als in den Kontrollgruppen. An Tag 15 ergab sich bei der mit 200 I.E./kg KG NMH behandelten Gruppe sogar ein signifikant höherer Krankheitsscore im Vergleich zur Kontrollgruppe. Diese Ergebnisse indizieren, dass die zunächst gewählte Dosis von 200 I.E./kg KG zu hoch bemessen war und dies mutmaßlich zu einer Überdosierung mit einem erhöhten Auftreten von Komplikationen wie beispielsweise vermehrten inneren Blutungen und damit zu einer Verschlechterung des klinischen Krankheitsverlaufs und einem früheren Versterben führte. Eine Reduktion der s.c. Dosis des NMH auf 20 I.E./kg KG, d.h. ein Zehntel der vorherigen Dosis und auf eine Dosis, die unter der zur Thromboseprophylaxe verwendeten Dosis liegt, hatte wiederum keinen therapeutischen Effekt auf das Überleben, den Krankheitsscore und das Gewicht der Tiere im Vergleich zu Kontrollgruppe. Im Umkehrschluss zeigte sich bei dieser Dosis auch keine Verschlechterung des Krankheitsverlaufes, wie es bei der mit 200 I.E./kg KG NMH behandelten Therapiegruppe beobachtet werden konnte. Offenbar war diese Dosis des NMH in der s.c. Applikationsform zu gering gewählt, so dass eine ausreichende antientzündliche Wirkung nicht stattfinden konnte bzw. komplett ausblieb. Diese Annahme bestätigt sich auch bei einer zu Enoxaparin als Therapeutikum der CU durchgeführten Studie, bei der eine höhere und tägliche s.c. Injektion von 100 I.E./kg KG keinen therapeutischen Effekt erzielen konnte. Gleichzeitig wurde diese Dosis gut vertragen und es kam nicht zu vermehrten Blutungskomplikationen (Zezos et al. 2006). Hier spielt vermutlich abermals die bereits dargestellte schwächere Inhibition der L- und P-Selektine und die somit geringere immunmodulierende Aktivität des NMH Enoxaparin eine Rolle (Koenig et al. 1998). Demzufolge ist, um den gleichen immunmodulierenden Effekt wie UFH zu erreichen, bei der Anwendung von NMH eine höhere Dosis nötig, die wiederum mit einer erhöhten Gefahr für das Auftreten von Komplikationen verbunden ist.

Da es bei der hohen Dosis (200 I.E./kg KG) des UFH ebenfalls zu einem tendenziell schlechteren Verlauf der aGvHD kam, wurden auch hier Versuche mit einer reduzierten s.c. Dosis von 50 I.E./kg KG und 100 I.E./kg KG durchgeführt. Hier ergab sich für die Dosis von 50 I.E./kg KG tendenziell ebenfalls eine geringere Überlebensrate und ein höherer klinischer Ausprägungsgrad der aGvHD. Dieses Resultat ist erstaunlicherweise mit dem bereits beschriebenen Ergebnis der Gruppe, die mit 200 I.E./kg KG UFH behandelt wurde vergleichbar und schlechter als das Ergebnis der Kontrollgruppe. Womöglich war die Dosis von 50 I.E./kg KG zu gering gewählt, allerdings wäre in diesem Fall ein mit der Kontrollgruppe vergleichbares Ergebnis zu erwarten gewesen. Werden die bisherigen 
und folgenden Ergebnisse berücksichtigt, liegt es nahe, dass es in dieser Versuchskonstellation zu einem einmaligen unerwartet verschärften Krankheitsverlauf der aGvHD kam. Ferner besteht kein statistisch signifikanter Unterschied.

Für die s.c. Dosis von 100 I.E./kg KG UFH zeigte sich bis Tag 31, das heißt über die erste und zweite Krankheitswelle hinaus, tendenziell eine höhere Überlebensrate als in der Kontrollgruppe. Zum Ende des Versuchszeitraumes näherten sich beide Gruppen an. Auch eine in dieser Dosis durchgeführte i.v. Versuchsreihe ergab nach der ersten Krankheitswelle eine höhere Überlebensrate als die Kontrollgruppe. Jedoch waren diese Versuchsreihen ebenfalls statistisch nicht signifikant. Auch der klinische Ausprägungsgrad und der Gewichtsverlust der Therapiegruppe verliefen milder. An Tag 14 zeigte sich ein statistisch signifikant niedrigerer Krankheitsscore der Gruppe, die mit 100 I.E./kg KG UFH behandelt wurde (mit einem $\mathrm{p}$-Wert von 0,04 ). Von den bisher besprochenen Dosen wies die verwendete Dosis von 100 I.E./kg KG demnach das vielversprechendste Ergebnis auf. Möglichweise konnte mit dieser Dosis ein immunmodulierender Effekt ohne ein Auftreten von vermehrten Blutungskomplikationen erreicht werden. Diese Hypothese wird durch eine Studie von Attal et al. (1992) zur Prävention von hepatisch venookklusiven Erkrankungen nach Knochenmarktransplantation verstärkt. Hier konnte gezeigt werden, dass eine kontinuierliche prophylaktische Gabe von 100 I.E./kg KG UFH pro Tag zu keinem erhöhten Blutungsrisiko und zu keiner Verlängerung der PTT führte. Dieses Ergebnis ist allerdings an die verwendete Heparinform, in diesem Fall an das UFH gebunden. Wie bereits beschrieben, konnte eine Dosis von 100 I.E./kg KG bei der Verwendung von NMH im Rahmen einer Studie zur CU keinen therapeutischen Effekt erzielen (Zezos et al. 2006). Zusätzlich muss bei der Bestimmung und Angabe der Dosis in der Einheit I.E./kg KG berücksichtigt werden, dass bei der Berechnung der Dosis von einem durchschnittlichen Körpergewicht der Maus von $25 \mathrm{~g}$ ausgegangen wurde. Im Verlauf der Versuche kam es jedoch, bedingt durch die Erkrankung der aGvHD, zu einem progredienten Gewichtsverlust. Die zu Beginn bestimmte absolute Dosis wurde beibehalten. Das bedeutet, dass es während des Versuchsverlaufs automatisch zu einer leichten Steigerung der relativen Dosis (I.E./kg KG) kam.

Zusammenfassend ergaben sowohl die s.c. als auch die i.v.Versuchsreihen, in welchen eine Dosis von 100 I.E./kg KG UFH verwendet wurde, das vielversprechendste Ergebnis. Hier zeigten sich tendenziell eine bessere Überlebensrate und ein schwächerer klinischer Ausprägungsgrad der aGvHD, jedoch ohne statistische Signifikanz. Die Ergebnisse waren abhängig von der verwendeten Heparinform (NMH oder UFH). Da es bezüglich der Halbwertszeit der antiinflammatorischen Wirkung des Heparins bisher noch kein sicher messbares Korrelat gibt, hängt der therapeutische Erfolg womöglich nicht nur 
von der Dosis, sondern auch von der Häufigkeit der Applikation ab. Weitere Studien mit größeren Tierzahlen und unterschiedlichen Injektionsfrequenzen und Dosen sind notwendig, um das mögliche therapeutische Potential des Heparins in der aGvHD im Mausmodell aufzudecken.

\subsection{Tägliche s.c. Applikation von UFH}

Bereits 1993 wurde von Naparstek et al. (1993) eine Studie zur Wirkung von Heparin als Therapeutikum der aGvHD im Mausmodell durchgeführt. In dieser Studie erfolgte eine tägliche s.c. Injektion von UFH an sechs Tagen die Woche über einen Zeitraum von 30 Tagen. Der Krankheitsverlauf und die Überlebensrate der Mäuse konnten dabei in einer abgeschwächten Form der aGvHD statistisch signifikant verbessert werden. Dies ist bis heute die einzige in der Literatur verfügbare Studie zur Behandlung der aGvHD mit Heparin im Mausmodell.

Angelehnt an die oben beschriebene Studie wurde in dieser Arbeit zusätzlich eine Versuchsreihe mit einer täglichen s.c. Injektion von UFH durchgeführt. Im klinischen Alltag stellt die praktische Ausführung einer täglichen s.c. Applikation beim Patienten kein Problem dar. Im Mausmodell birgt eine tägliche Injektion für die Tiere allerdings ein deutlich höheres Stresslevel und ein erhöhtes Risiko für das Auftreten von Infektionen und Abszessen an den Injektionsstellen. Aus diesen Gründen wurde die Versuchsdauer dieser Versuchsreihe auf 30 Tage reduziert. Eine tägliche i.v. Applikation ist durch die starke Vernarbung, der für die Injektion benötigten Schwanzvenen, bei regelmäßiger Injektion und gleichzeitiger aGvHD nicht praktikabel, da so eine korrekte und vollständige Applikation des Medikamentes nicht mehr gewährleistet ist. Auf die Durchführung einer analogen Versuchsreihe mit einer täglichen i.v. Gabe wurde dementsprechend, trotz tendenziell vielversprechenderen Ergebnissen der i.v. Applikation in den bisher durchgeführten Versuchen, verzichtet.

In dieser Versuchsreihe erfolgten die s.c. Injektionen einmal täglich, an sechs Tagen pro Woche, über einen Zeitraum von 30 Tagen. Es wurden zwei verschiedene Konzentrationen (25 I.E./kg KG und 50 I.E./kg KG) getestet. Sowohl in der Therapiegruppe, in der eine Dosis von 25 I.E./kg KG UFH appliziert wurde, als auch in der Therapiegruppe, die täglich 50 I.E./kg KG UFH erhielt, zeigten sich über den kompletten Versuchszeitraum ein zwar nicht statistisch signifikanter, aber tendenziell schwächerer klinischer Ausprägungsgrad und eine höhere Überlebensrate der Tiere als in der Kontrollgruppe. Insbesondere die Gruppe, die 25 I.E./kg KG UFH erhielt, wies ab Tag 9 mit einer Überlebensrate von $63 \%$ eine konstant höhere Überlebensrate als die Tiere der Kontrollgruppe 
(Überlebensrate von $50 \%$ bis Tag 25 und $38 \%$ ab Tag 26 bis zum Versuchsende) auf. Die Ergebnisse deuten darauf hin, dass eine tägliche s.c. Applikation tendenziell einen vorteilhafteren Verlauf der aGvHD, insbesondere im Vergleich zu einer nicht täglichen s.c. Applikation, zu begünstigen scheint. Diese Annahme wird durch Studien zur Heparintherapie in der CU verstärkt. So führte in einer klinischen Studie von Gaffney et al. (1995) eine zwei Mal tägliche s.c. UFH-Gabe zu einer statistisch signifikanten Remission der CU. Ebenso konnte in einer Studie von Ang et al. (2000) eine tägliche s.c. Injektion von UFH im Verlauf ein gleichwertiges Ergebnis wie die Anwendung von Cortison in der Therapie der CU erzielen. Da die Halbwertszeit der antiinflammatorischen Wirkung nicht bekannt ist, konnte vermutlich durch die tägliche s.c. Applikation eine bessere und nachhaltigere Inhibition der Selektine als durch eine nicht tägliche s.c. Injektion erreicht werden. Möglicherweise wird aber auch bzw. additional durch die tägliche s.c. Anwendung des UFH der Nachteil der geringeren Bioverfügbarkeit der s.c. Anwendung kompensiert und so eine effektivere antientzündliche Wirkung erzielt. Ferner muss auch hier berücksichtigt werden, dass die antiinflammatorische Wirkung von Heparin nicht zwangsläufig mit der in I.E. angegebenen antikoagulatorischen Wirkung korreliert. Durch die hier sehr gering gewählte Konzentration (25 I.E./kg KG und 50 I.E./kg KG) kam es vermutlich zu einer klinisch nicht relevanten gerinnungshemmenden Wirkung bei weiterhin hinreichender Inhibition der Selektine und somit antientzündlichen Effekt. Diese Annahme wird durch die Erkenntnis verstärkt, dass die Bindung von P- und L-Selektin an für die Leukozytenadhäsion benötigte Selektinliganden bereits durch 12 bis 50 -fach geringere Konzentrationen von UFH als für eine effektive Antikoagulation empfohlen, gehemmt wird (Koenig et al. 1998).

Weiterhin konnte in Studien zur Verminderung einer Metastasenbildung durch Heparin im Mausmodell, welche ebenfalls auf eine Hemmung der P- und L-Selektine beruht, gezeigt werden, dass eine s.c. Applikation von UFH unabhängig von der antikoagulatorischen Wirkung zu einer Verminderung der Metastasenbildung führte (Stevenson et al. 2005; Simonis et al. 2007; Ludwig 2004). In diesen Studien wurde zudem gezielt der Einfluss der verschiedenen Heparinarten auf die Inhibition der Selektine untersucht. Simonis et al. (2007) konnten beispielsweise zeigen, dass UFH eine höhere Bindungsaffinität an die P- und L-Selektine als das NMH Endoxaparin, das in dieser Arbeit verwendet wurde, aufweist und im Umkehrschluss über eine größere antimetastatische und antientzündliche Wirkung verfügen.

Zusammenfassend führte die tägliche s.c. Injektion zu einem statistisch nicht signifikanten, aber vorteilhafteren Verlauf der aGvHD im Mausmodell als eine nicht tägliche s.c. Applikation. Dies könnte zum einen an der hierdurch verbesserten antiinflammatorischen 
Wirkung bei gleichzeitig minimalem antikoagulatorischen Nebenwirkungsprofil bei niedrig gewählter Dosis, zum anderen aber auch an der verwendeten Heparinart (UFH) liegen. In den in dieser Arbeit durchgeführten und diskutierten Versuchen konnte durch die Anwendung von UFH durchweg ein vielversprechenderes Ergebnis als durch die Injektion von NMH festgestellt werden. Zugleich zeigte eine tägliche s.c. Gabe von NMH in verschiedenen klinischen Studien zur CU keinen Effekt auf den Krankheitsverlauf (Bloom et al. 2004; Zezos et al. 2006; Bièvre et al. 2007) Eine tägliche s.c. Gabe von $\mathrm{NMH}$ wäre deshalb vermutlich der täglichen s.c. Applikation von UFH unterlegen gewesen.

Weitere Studien mit unterschiedlichen Dosen und höheren Tierzahlen sind notwendig um das mögliche, therapeutische Potential von Heparin in der aGvHD im Mausmodell zu erfassen. Ergänzend sollte, insbesondere unter Berücksichtigung der bisher analysierten und diskutierten Ergebnisse, eine Kombination der i.v. und täglichen s.c. Applikationsform in Betracht gezogen werden. So wäre womöglich eine tägliche s.c. Heparinanwendung, die durch i.v. Injektionen vor den Krankheitswellen ergänzt wird, ein optimales und im Mausmodell gut praktikables Therapieregime.

\subsection{Beeinflussung der T-Zellpopulation durch Heparin}

Die verschiedenen T-Zellen spielen in der Pathogenese der aGvHD eine entscheidende Rolle. Ein Anstieg des Anteils der $\mathrm{CD}^{+}, \mathrm{CD}^{+}$, und $\mathrm{CD}^{+}$T-Zellen nach $\mathrm{KMT}$ im Blut geht mit der Entwicklung einer aGvHD einher (Brinkman et al. 2007). Aus diesem Grund wurden in dieser Arbeit die $\mathrm{CD}^{+}, \mathrm{CD}^{+}$und $\mathrm{CD} 8^{+} \mathrm{T}$-Lymphozyten aus Lymphknoten und Milz, der an der aGvHD erkrankten Mäuse, isoliert und mittels durchflusszytometrischer Analyse untersucht. Besonderes Interesse galt hierbei der Auswirkung der Heparingabe auf die T-Zellpopulation in Abhängigkeit vom Krankheitsverlauf.

Bereits 1986 kam mit dem murinen monoklonalen Antikörper Muromonab-CD3 ein Antikörper gegen den CD3-Rezeptor der T-Lymphozyten auf den Markt. In verschiedenen Studien konnte gezeigt werden, dass die Anwendung eines CD3-Rezeptor-Antikörpers zu einer Verminderung der $\mathrm{CD}^{+} \mathrm{T}$-Zellen und Milderung des klinischen Ausprägungsgrads der aGvHD führte (Anasetti et al. 1992; Benekli et al. 2006; Martin et al. 1988). Eine verminderte Anzahl an $\mathrm{CD}^{+} \mathrm{T}$-Zellen geht hiernach mit einem schwächeren Ausprägungsgrad der aGvHD einher. Entgegen dieser Erkenntnisse konnte in dieser Arbeit weder ein statistisch signifikanter Unterschied zwischen den unterschiedlichen Krankheitsverläufen noch generell zwischen den Kontroll- und Therapiegruppen bezüglich der Anteile $\mathrm{CD}^{+}$T-Zellen festgestellt werden. Lediglich in einer Versuchsreihe konnte ein, 
allerdings statistisch nicht signifikant, verminderter Anteil CD3 ${ }^{+} \mathrm{T}$-Zellen mit einem tendenziell günstigeren Krankheitsverlauf in Zusammenhang gebracht werden. Dieses Ergebnis deckt sich mit den Resultaten einer Studie von Budde et al. (2014), diese zeigte ebenfalls keinen Unterschied bezüglich des Anteils der $\mathrm{CD}^{+} \mathrm{T}$-Zellen bei transplantierten Mäusen mit aGvHD und transplantierten Mäusen ohne aGvHD. In dieser Studie von Budde et al. (2014) wurde ebenfalls nachgewiesen, dass die an einer aGvHD erkrankten Tiere im Vergleich zur Kontrollgruppe eine signifikant verminderte Zahl an CD4+ T-Lymphozyten aufwiesen. Huang und Kollegen (2014) konnten im Rahmen eines Tiermodells zu allergischen Atemwegserkrankungen zeigen, dass eine intranasale Verabreichung von UFH und $\mathrm{NMH}$ im Mausmodell zu einer Abnahme der $\mathrm{CD}^{+}$Zellen führte. Folglich wäre in dieser Arbeit eine verminderte Zahl an CD4+ T-Zellen bei den mit Heparin behandelten und an einer schweren aGvHD erkrankten Tieren zu erwarten gewesen. Im Gegensatz hierzu zeigte sich kein statistisch signifikanter Unterschied zwischen den Kontroll- und Therapiegruppen in Bezug auf die Veränderungen der CD4+ T-Zellen, auch waren keine einheitlichen Tendenzen erkennbar. Lediglich in einer Versuchsreihe konnte ein, allerdings nicht statistisch signifikant, verminderter Anteil CD4+ T-Zellen mit einem günstigeren Krankheitsverlauf in Zusammenhang gebracht werden. Ferner konnte diesbezüglich kein Unterschied zwischen den Tieren erkannt werden, die den Versuch überlebten und den Tieren, die frühzeitig aufgrund des Schweregrades der Erkrankung aus dem Versuch genommen werden mussten. Dieses Ergebnis bildete sich ebenfalls in einer Studie zur Therapie der GvHD mittels extrakorporaler Photopherese im Mausmodell ab. Hier konnte kongruent kein Unterschied hinsichtlich der Entwicklung der CD4+ Zellen zwischen den Kontroll- und Therapietieren sowie zwischen den unterschiedlichen Krankheitsverläufen erkannt werden (Papert 2016). Allerdings wurde sowohl in der letztgenannten Studie als auch in dieser Arbeit der prozentuale Anteil der CD4+ T-Zellen ausschließlich zwischen Tiergruppen verglichen, die an einer aGvHD litten und lediglich unterschiedlich therapiert wurden. In der Studie von Budde et al. (2014) demgegenüber erfolgte der Vergleich des Anteils der CD4+ $\mathrm{T}$-Zellen zwischen transplantierten Mäusen mit einer aGvHD und transplantierten Mäusen ohne eine aGvHD.

August et al. (2011) konnten bereits zeigen, dass es zu einem Anstieg der CD8+ Zellen in einem an aGvHD erkrankten Patienten kommt. Im Rahmen dieser Arbeit konnte passend zu den Erkenntnissen von August et al. (2011) bei der Therapiegruppe, die mit 20 I.E./kg KG NMH behandelt wurde, im Vergleich zur Kontrollgruppe eine statistisch signifikante Erhöhung der CD8 ${ }^{+}$T-Zellen in den Lymphknoten $(p=0,03)$ festgestellt werden. Die beschriebene Therapiegruppe wies hierbei im Vergleich zur Kontrollgruppe einen ausgeprägteren Krankheitsverlauf auf. Allerdings konnte in keiner weiteren Ver- 
suchsreihe ein statistisch signifikanter Unterschied bezüglich der CD8 ${ }^{+}$T-Zellen festgestellt werden. Lediglich in einer weiteren Versuchsreihe in dieser Arbeit konnte ein, allerdings nicht statistisch signifikant, verminderter Anteil CD8 ${ }^{+}$T-Zellen mit einem tendenziell günstigeren Krankheitsverlauf assoziiert werden.

Inwieweit und ob Heparin die T-Zellpopulationen, insbesondere im Rahmen einer aGvHD beeinflusst, konnte durch diese Arbeit nicht geklärt werden. Des Weiteren konnten insgesamt keine in sich geschlossenen Tendenzen der Veränderung der T-Zellpopulation in Bezug auf die Schwere der Erkrankung erkannt werden. Möglicherweise liegt in der komplexen Plastizität und Vielschichtigkeit der T-Zellen, die sich unter anderem durch die Ausschüttung diverser Zytokine und anderer Faktoren und damit direkter sowie indirekter Beeinflussung weiterer Zellen manifestieren, eine Erklärung für die uneinheitlichen Ergebnisse. Die exakte Funktion und Beteiligung der T-Zellen in der Pathogenese der aGvHD ist bisher nur unvollständig verstanden und geklärt. Folgendermaßen ist es denkbar, dass die ausgeprägte Dynamik der T-Zellpopulation zu einer stetigen Veränderung der Zellzusammensetzung führt und mit den hier dargestellten Ergebnissen nur eine Momentaufnahme vorliegt, die diesen dynamischen Prozess nicht widerspiegelt (Coghill et al. 2011). Zudem wurde die durchflusszytometrische Analyse stets am Ende der Versuche bzw. nach Erreichen von einem Gesamtscore von sechs oder mehr Punkten vorgenommen. Eine Querschnittsuntersuchung zu einem früheren Zeitpunkt hätte möglicherweise ein anderes Bild ergeben. Zusammenfassend sind weitere detailliertere und umfassendere Studien notwendig, um den Einfluss von Heparin auf die aGvHD und die beteiligten Zellpopulationen abschließend beurteilen zu können.

\subsection{Beeinflussung des Proliferationsverhaltens humaner Leu- kozyten durch NMH und UFH}

Eine durch LPS induzierte Proliferation humaner T-Lymphozyten und Monozyten konnte in der Vergangenheit bereits in mehreren Studien nachgewiesen werden (Mattern et al. 1994; Ulmer et al. 2000). Humane B-Lymphozyten werden im Gegensatz zu murinen BLymphozyten nicht allein durch LPS zur Proliferation stimuliert. Hier kommt es durch das Zusammenspiel zwischen T- und B-Lymphozyten zu einer Proliferation letzterer (Zubler et al. 1987). In dieser Arbeit wurde das Proliferationsverhalten aller drei Zellreihen durch die Zugabe von LPS sowie der Einfluss von NM- und UFH auf dieses Proliferationsverhalten untersucht. Ziel war es Hinweise auf mögliche immunmodulatorische Wirkmechanismen im humanen Organismus zu erhalten. 
Im Rahmen dieser In-vitro-Versuchsreihe konnte durchweg eine Steigerung der Proliferation aller drei Zellreihen durch die Zugabe von LPS nachgewiesen werden, so dass von einer prinzipiell effizienten Versuchsdurchführung ausgegangen werden kann. Allerdings konnten mehrere Studien aufzeigen, dass humane B-Zellen aufgrund der fehlenden Expression des Toll-like-Rezeptors 4, der ein wesentlicher Faktor für die Zellaktivierung durch LPS darstellt, nicht mit einer Proliferation nach LPS-Stimulation reagieren. Murine B-Lymphozyten sowie Monozyten und T-Lymphozyten reagieren dagegen mit einer Proliferation auf LPS (Vaure und Liu 2014; van Belle et al. 2016). Indessen erbrachten andere Untersuchungen den Nachweis, dass eine B-Zell-Proliferation durch LPS nach einer Aktivierung der Zellen durch bestimmte Zytokine möglich ist. Insgesamt ist der exakte Einfluss von LPS auf humane B-Lymphozyten nicht abschließend geklärt (Dumont et al. 2009). Da in dieser Arbeit die B-Lymphozyten nicht separat, sondern ein Zellgemisch aus allen Leukozyten mit LPS beimpft und inkubiert wurden, führte womöglich diese Kokultivierung mit anderen Immunzellen zu der in dieser Arbeit nachgewiesenen Steigerung der Proliferation der B-Zellen.

Durch die alleinige Zugabe von NMH oder UFH konnte in keiner der drei untersuchten Zellreihen eine Veränderung des Proliferationsverhaltens erreicht werden. Unter der simultanen Zugabe von LPS und Heparin kam es weiterhin zu einer gesteigerten Proliferationsrate aller drei Zellreihen. Weder die Zugabe von NMH noch von UFH zu den LPSstimulierten Zellen führte zu einer Beeinflussung derselben. Eine In-vitro-Studie von Hochart et al. (2006) beschreibt den Einfluss von NMH und UFH auf die Ausschüttung proinflammatorischer Zytokine in LPS-stimulierten humanen Monozyten. Die alleinige Heparinzugabe zu den Monozyten ohne LPS-Stimulation beeinflusste in Übereinstimmung mit den Ergebnissen dieser Arbeit nicht die Zytokinabgabe. Durch die Zugabe sowohl von NMH als auch UFH und gleichzeitiger LPS-Stimulation konnte jedoch eine signifikante Inhibition der Zytokinausschüttung nachgewiesen werden. Hier wurde zum Teil sogar mit einer geringeren Heparindosis $(0,1$ I.E. $/ \mathrm{ml}$ vs.0,4 I.E. $/ \mathrm{ml})$ als in dieser Arbeit gearbeitet, so dass eine zu gering gewählte Dosis als Ursache der fehlenden Beeinflussung von Heparin auf das Proliferationsverhalten unwahrscheinlich erscheint. Allerdings wurde zugleich eine 1.000-fach geringere LPS-Dosis verwendet. Weiterhin erfolgte die Impfung der Zellen zunächst mit Heparin und erst im Anschluss wurde LPS hinzugegeben (Hochart et al. 2006). Beide beschriebenen Aspekte könnten möglichweise einen wesentlichen Einfluss auf die Wirkung des Heparins und folglich auf die ungleichen Resultate haben. Zwar wurde in der Arbeit von Hochart et al. (2006) nicht der Effekt auf die Proliferation der Zellen, sondern die Wirkung auf die Zytokinausschüttung betrachtet, doch führt eine vermehrte Zytokinausschüttung der untersuchten Zytokine wiederum zu einer gesteigerten Proliferation der immunmodulatorischen Zellen. 
Des Weiteren beruht ein wichtiger Teil der antiinflammatorischen Wirkung von Heparin auf die Inhibition der Leukozytenadhäsion an das Endothel durch die Hemmung von Pund L-Selektin (Nelson et al. 1993). Folglich schließt die in dieser Arbeit festgestellte fehlende Hemmung der Proliferation der mononukleären Zellen durch Heparin den immunmodulierenden Effekt von Heparin nicht aus, sondern kam hier möglicherweise einfach nicht zur Darstellung.

Zusammenfassend hatte die alleinige Heparinbehandlung keine Wirkung auf die Proliferationsrate bzw. die Zytokinausschüttung der untersuchten Zellen. Durch die gleichzeitige Hinzugabe von LPS und Heparin zeigte sich zwar ein deutlich gesteigertes Proliferationsverhalten der Zellen, allerdings konnte eine Inhibition durch Heparin nicht erkannt werden. Wie bereits im In-vivo-Teil dieser Arbeit diskutiert, ist womöglich der Zeitpunkt der Heparingabe ein entscheidender Faktor in Bezug auf die mögliche immunmodualtorische Wirkung. Diese Annahme wird durch die Ergebnisse der beschriebenen Studie von Hochart et al. (2006), in welcher eine Beimpfung der Zellen mit Heparin vor der Zugabe von LPS zu einer Hemmung der Zytokinausschüttung führte, ebenfalls unterstützt. Insbesondere um die Einflussnahme des richtigen Zeitpunkts der Heparinapplikation auf den immunmodulatorischen Effekt aufzudecken, sind weitere Studien nötig, in welchen neben dem Proliferationsverhalten ergänzend andere wichtige Marker, wie beispielsweise die Zytokinausschüttung oder die Selektine, betrachtet werden sollten.

\subsection{Fazit und Ausblick}

Das Hauptziel dieser Arbeit war es den möglichen therapeutischen Einfluss von $\mathrm{NMH}$ und UFH in der Behandlung der akuten GvHD im Mausmodell zu identifizieren. In den Ergebnissen der In-vivo-Versuchsreihen konnte dabei kein statistisch signifikanter therapeutischer Effekt festgestellt werden. Die Aussagekraft in Hinblick auf künftige mögliche therapeutische Optionen in der Behandlung der aGvHD ist daher begrenzt. Es konnten allerdings richtungsweisende Resultate gewonnen werden.

Zusammenfassend konnte durch die Applikation von NMH durchweg keine nutzbringende Wirkung hinsichtlich der Überlebensrate oder des Krankheitsverlaufes der aGvHD beobachtet werden. Die Applikation von UFH führte hingegen zu einem günstigeren Krankheitsverlauf und einer höheren Überlebensrate und war damit einer Gabe von $\mathrm{NMH}$ grundsätzlich überlegen. In weiteren Studien sollte daher die Anwendung von UFH bevorzugt werden. Inwieweit sich die Verwendung anderer NMH (z. B. Dalteparin) auf den Verlauf der aGvHD im Mausmodell auswirkt, muss in weiteren Studien geklärt werden. 
Die verwendete Dosis von 100 I.E./kg KG wies das vielversprechendste Ergebnis auf. Dies war allerdings erwartungsgemäß abhängig von der verwendeten Heparinform. Bezüglich der Applikationsform konnte das aussichtsreichste Ergebnis dieser Arbeit durch die tägliche s.c. Applikation von UFH erreicht werden.

Diese Arbeit gibt Hinweise darauf, dass sowohl die Dosis als auch die Häufigkeit und Form der Applikation eine wesentliche Rolle auf die immunmodulierende Wirkung des Heparins hat. Weitere Studien mit deutlich größeren Tierzahlen und unterschiedlichen Injektionsfrequenzen und Dosen sind nötig, um das mögliche therapeutische Potential von Heparin in der Behandlung der aGvHD im Mausmodell aufzudecken. Gemäß dem Algorithmus des verwendeten Log-Rank-Tests ist es wahrscheinlich, dass weitere Versuchsreihen mit einer größeren Tierzahl zu statistisch signifikanten Ergebnissen führen würden. Insbesondere die Kombination der s.c. und i.v. Applikation äquivalent zu den vielversprechendsten Versuchsreihen, gegebenenfalls unter Hinzunahme einer oralen Verabreichung, könnte erfolgsversprechende Wege aufzeigen. Darüber hinaus sind vermutlich der Applikationszeitpunkt und somit der Beginn der Therapie von großer Bedeutung. Der Nutzen einer Heparingabe schon vor möglichem Krankheitsausbruch, also bereits vor der Knochenmarktransplantation sollte ebenfalls durch weitere Versuche geklärt werden. 


\section{Zusammenfassung}

Die akute Graft-versus-Host Disease (aGvHD) ist eine häufige und gefürchtete Komplikation nach Stammzelltransplantationen. Sie resultiert aus einer Immunreaktion der $\mathrm{CD}^{+}$und CD8+ T-Zellen des Spenders gegen das Gewebe des Empfängers. Bislang gilt die systemische Anwendung von Glukokortikoiden als Gold-Standard der Erstlinientherapie. Etwa die Hälfte der Patienten erweist sich jedoch als steroidresistent. Eine etablierte und standardisierte Zweitlinientherapie gibt es aktuell nicht. Heparin verfügt neben seinen antikoagulatorischen auch über antiinflammatorische Eigenschaften und kann in verschiedenen entzündlichen Erkrankungen einen günstigen antientzündlichen Effekt bewirken.

Ziel dieser Arbeit war es den möglichen therapeutischen Einfluss von niedermolekularen Heparin (NMH) und unfraktionierten Heparin (UFH) auf die aGvHD im Mausmodell nachzuweisen. Konkret wurde eine Studie zur Dosisfindung mit unfraktionierten und niedermolekularen Heparin mittels subkutaner (s.c.) und intravenöser (i.v.) Applikation in einem etablierten Mausmodell der aGvHD (C57BL/6 -> BALB/c) durchgeführt. Anhand des klinischen Krankheitsscores und der Überlebensrate wurde der therapeutische Effekt ermittelt und anschließend beurteilt. Der Anteil der T-Zellen wurde am Versuchsende mittels Durchflusszytometrie analysiert. Zusätzlich wurde in einer In-vitro-Versuchsreihe der mögliche Einfluss von Heparin auf humane Immunzellen untersucht.

Die Anwendung von UFH hatte im Gegensatz zu NMH einen günstigeren aber nicht statistisch signifikanten Effekt auf die Schwere der Erkrankung und die Überlebensrate. Hierbei wies die i.v. sowie die tägliche s.c. Anwendung von UFH das vielversprechendste Ergebnis auf. Eine tägliche s.c. Injektion war einer nicht täglichen s.c. Applikation überlegen. Die Versuchsreihen mit den verwendeten Dosen von 25, 50 und 100 I.E./kg KG zeigten in Abhängigkeit von der Applikationsform die mildesten Krankheitsverläufe. Eine signifikante Beeinflussung der T-Zellpopulationen konnte weder durch die Gabe von NMH noch durch die Applikation von UFH festgestellt werden. In den durchgeführten In-vitro-Untersuchungen war durch eine Heparinbehandlung keine Wirkung auf die Proliferationsrate der Immunzellen zu beobachten.

Zusammengefasst konnte zwar kein statistisch signifikantes Ergebnis beobachtet werden, dennoch weisen die Ergebnisse auf einen immunmodulierenden Einfluss von Heparin in der aGvHD hin. Um eine abschließende Aussage treffen zu können, besteht jedoch weiterer Untersuchungsbedarf. Weitere Studien mit größeren Tierzahlen und einer Anpassung der Applikationswege und Zeitpunkte könnten erfolgsversprechende 
Herangehensweisen aufzeigen und möglicherweise die vollständige antientzündliche Bedeutung von Heparin in der aGvHD aufdecken. 


\section{Anhang}
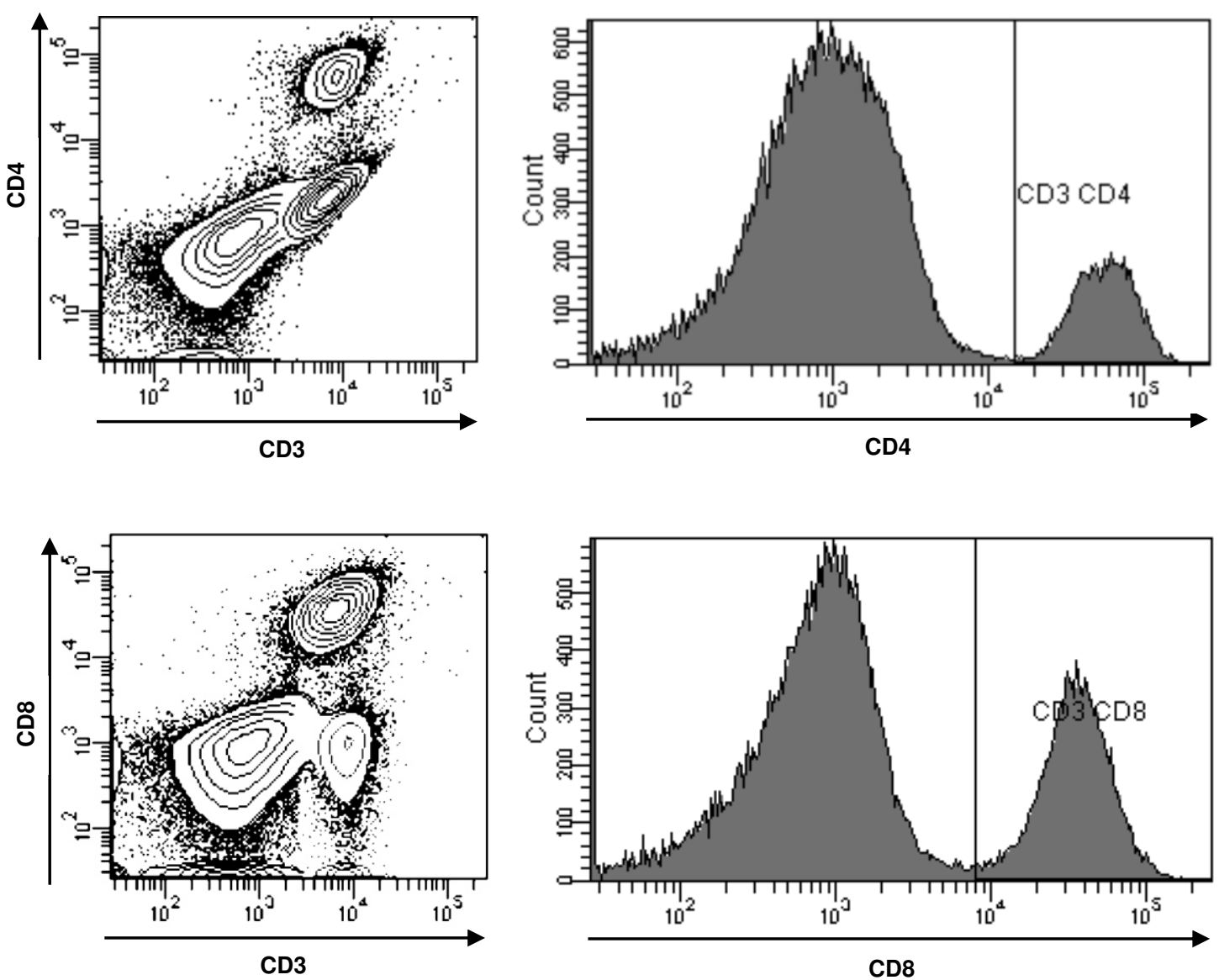

Abbildung A.1: Gating-Strategien in der Durchflusszytometrie zur Identifikation von CD3 $^{+}$ $\mathrm{CD4}^{+}$und $\mathrm{CD}^{+}{ }^{+} \mathrm{CD} 8^{+} \mathrm{T}-$-Zellen aus einer murinen Milz. 

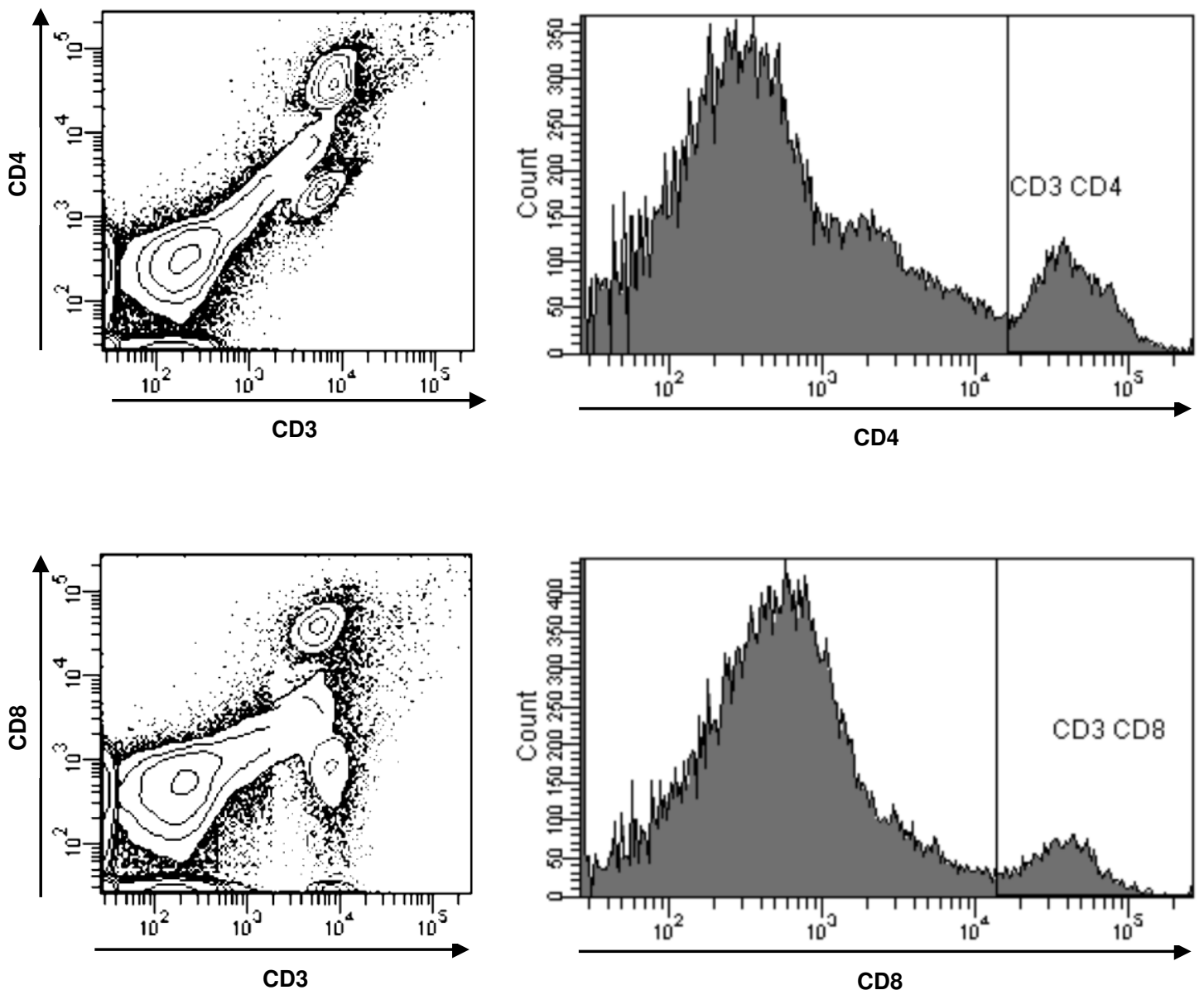

Abbildung A.2: Gating-Strategien in der Durchflusszytometrie zur Identifikation von CD3 ${ }^{+}$ $\mathrm{CD4}^{+}$und $\mathrm{CD}^{+}{ }^{+} \mathrm{CD} 8^{+} \mathrm{T}-$ Zellen aus murinen Lymphknoten. 

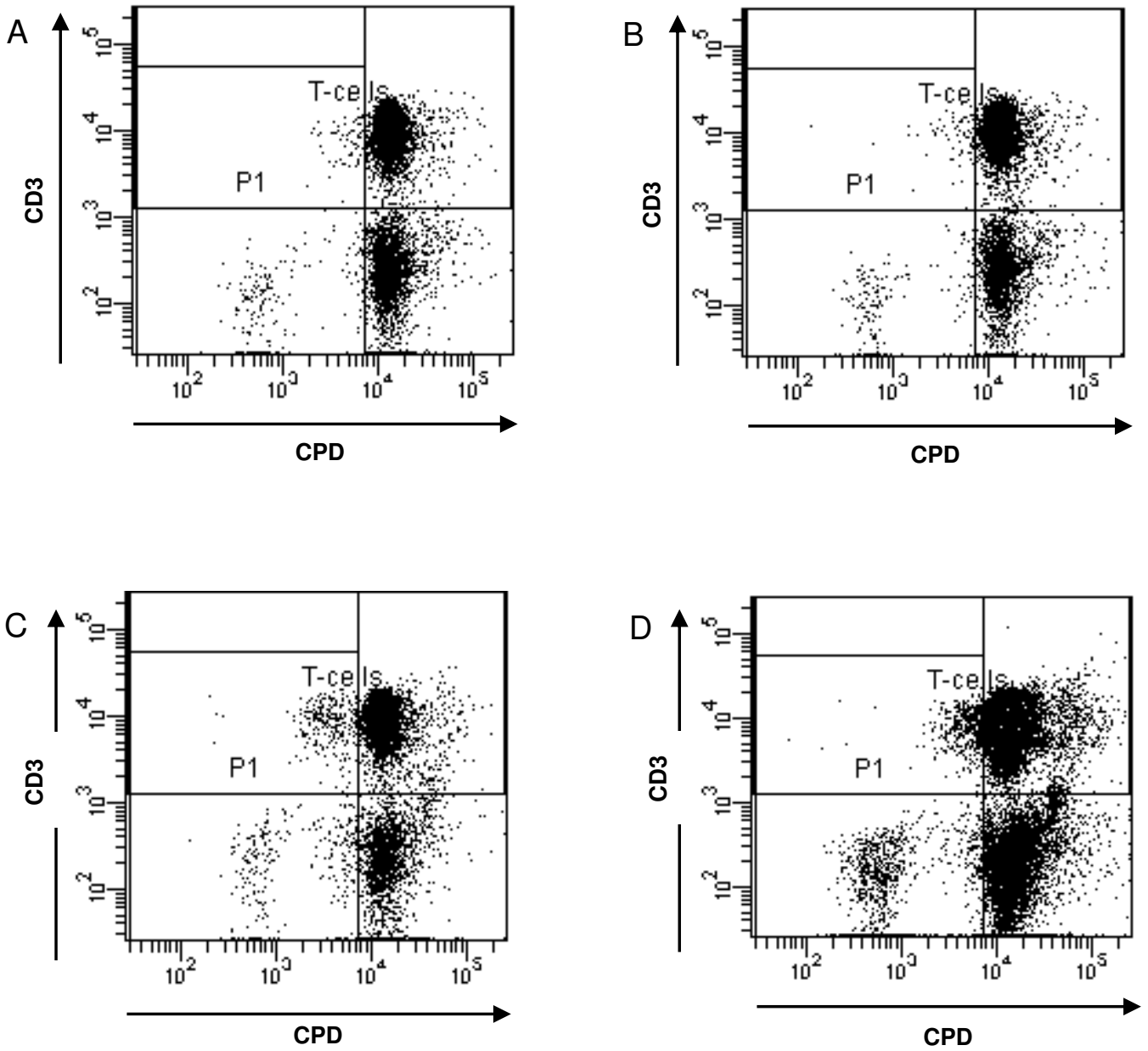

Abbildung A.3: Gating-Strategie in der Durchflusszytometrie zur Beurteilung des Proliferationsverhaltens humaner T-Zellen in einer nur mit CPD behandelten Probe (untreated) (A) sowie nach Zugabe von NMH (Clexane) (B), LPS (C) oder LPS + NMH (Clexane) (D). Durch die Färbung der Zellen mit dem Fluoreszenzfarbstoff CPD kann der mit der Zellteilung einhergehende Fluoreszenzabfall und damit die Proliferationsrate der Zellen ermittelt werden. In der Grafik wird dies durch eine nach links wandernde Zellpopulation (siehe P1) deutlich. 


\section{Literaturverzeichnis}

Alban S: Adverse effects of heparin. In: Lever R, Mulloy B, Page CP (Hrsg.): Heparin: a century of progress (Handb Exp Pharmacol). Springer, Berlin 2012, 211-263

Al-Eidan FAS (2015): Is the incidence trend of heparin-induced thrombocytopenia decreased by the increased use of low-molecular-weight-heparin? Mediterr J Hematol Infect Dis ㄱ, e2015029

Alousi AM, Weisdorf DJ, Logan BR, Bolanos-Meade J, Carter S, Difronzo N, Pasquini M, Goldstein SC, Ho VT, Hayes-Lattin B et al. (2009): Etanercept, mycophenolate, denileukin, or pentostatin plus corticosteroids for acute graft-versus-host disease: a randomized phase 2 trial from the Blood and Marrow Transplant Clinical Trials Network. Blood 114, 511-517

Anasetti C, Martin PJ, Storb R, Appelbaum FR, Beatty PG, Davis J, Doney K, Hill HF, Stewart $P$, Sullivan KM (1992): Treatment of acute graft-versus-host disease with a nonmitogenic anti-CD3 monoclonal antibody. Transplantation $\underline{54}, 844-851$

Anderson BE, McNiff JM, Jain D, Blazar BR, Shlomchik WD, Shlomchik MJ (2005): Distinct roles for donor- and host-derived antigen-presenting cells and costimulatory molecules in murine chronic graft-versus-host disease: requirements depend on target organ. Blood 105, 2227-2234

Ang YS, Mahmud N, White B, Byrne M, Kelly A, Lawler M, Mcdonald GSA, Smith OP, Keeling PWN (2000): Randomized comparison of unfractionated heparin with corticosteroids in severe active inflammatory bowel disease. Aliment Pharmacol Ther $\underline{14}, 1015$ 1022

Attal M, Huguet F, Rubie H, Huynh A, Charlet JP, Payen JL, Voigt JJ, Brousset P, Selves J, Muller C (1992): Prevention of hepatic veno-occlusive disease after bone marrow transplantation by continuous infusion of low-dose heparin: a prospective, randomized trial. Blood 79, 2834-2840

August KJ, Chiang KY, Bostick RM, Flanders WD, Waller EK, Langston A, WorthingtonWhite D, Rowland P, Moore KF, Khoury HJ et al. (2011): Biomarkers of immune activation to screen for severe, acute GVHD. Bone Marrow Transplant $\underline{46}, 601-604$

Bacigalupo A, Ballen K, Rizzo D, Giralt S, Lazarus H, Ho V, Apperley J, Slavin S, Pasquini M, Sandmaier BM et al. (2009): Defining the intensity of conditioning regimens: working definitions. Biol Blood Marrow Transplant 15, 1628-1633

Barrett AJ (1997): Mechanisms of the graft-versus-leukemia reaction. Stem Cells $\underline{15}$, 248-258

Bendstrup KE, Jensen JI (2000): Inhaled heparin is effective in exacerbations of asthma. Respir Med 94, 174-175

Benekli M, Hahn T, Williams BT, Cooper M, Roy HN, Wallace P, Stewart C, Bambach B, Jr PLM (2006): Muromonab-CD3 (Orthoclone OKT3 ${ }^{\circledR}$ ), methylprednisolone and cyclosporine for acute graft-versus-host disease prophylaxis in allogeneic bone marrow transplantation. Bone Marrow Transplant $\underline{38}, 365$

Bensinger WI, Clift RA, Anasetti C, Appelbaum FA, Demirer T, Rowley S, Sandmaier BM, Torok-Storb B, Storb R, Buckner CD (1996): Transplantation of allogeneic peripheral blood stem cells mobilized by recombinant human granulocyte colony stimulating factor. Stem Cells $\underline{14}, 90-105$ 
Bensinger WI, Martin PJ, Storer B, Clift R, Forman SJ, Negrin R, Kashyap A, Flowers ME, Lilleby K, Chauncey TR et al. (2001): Transplantation of bone marrow as compared with peripheral-blood cells from HLA-identical relatives in patients with hematologic cancers. N Engl J Med 344, 175-181

Bertz H, Afting M, Kreisel W, Duffner U, Greinwald R, Finke J (1999): Feasibility and response to budesonide as topical corticosteroid therapy for acute intestinal GVHD. Bone Marrow Transplant 24, 1185-1189

Bittencourt H, Lopes M, de Macedo AV, Teixeira ER, Gomes GGS, Ferreira GG, Amaral L, Soares P, Vieira M, Dusse LM (2009): A retrospective comparison of allogeneic peripheral blood stem cell versus bone marrow transplantation. Hematol Oncol Stem Cell Ther $\underline{2}$, 272-277

Bloom S, Kiilerich S, Lassen MR, Forbes A, Leiper K, Langholz E, Irvine EJ, O'Morain C, Lowson D, Orm S (2004): Low molecular weight heparin (tinzaparin) vs. placebo in the treatment of mild to moderately active ulcerative colitis. Aliment Pharmacol Ther $\underline{19}$, 871-878

Bolaños-Meade J, Logan BR, Alousi AM, Antin JH, Barowski K, Carter SL, Hexner EO, Horowitz MM, Levine JE, MacMillan ML et al. (2013): A multi-center, randomized, double blind, phase III clinical trial comparing steroids/placebo vs. steroids/mycophenolate mofetil as initial therapy for acute graft-versus-host disease. Blood and Marrow Transplant Clinical Trials Network Study 0802. Biol Blood Marrow Transplant 19, S137

Bolwell B, Sobecks R, Pohlman B, Andresen S, Rybicki L, Kuczkowski E, Kalaycio M (2004): A prospective randomized trial comparing cyclosporine and short course methotrexate with cyclosporine and mycophenolate mofetil for GVHD prophylaxis in myeloablative allogeneic bone marrow transplantation. Bone Marrow Transplant $\underline{34}, 621-625$

Bradley MB, Cairo MS (2005): Cord blood immunology and stem cell transplantation. Hum Immunol $\underline{66}$, 431-446

Brinkman RR, Gasparetto M, Lee SJJ, Ribickas AJ, Perkins J, Janssen W, Smiley R, Smith C (2007): High-content flow cytometry and temporal data analysis for defining a cellular signature of graft-versus-host disease. Biol. Blood Marrow Transplant. 13, 691700

Budde H, Kolb S, Salinas Tejedor L, Wulf G, Reichardt HM, Riggert J, Legler TJ (2014): Modified extracorporeal photopheresis with cells from a healthy donor for acute graftversus-host disease in a mouse model. PLoS One $\underline{9}$, e105896

Budde H, Thieringer L, Riggert J, Legler TJ (2015): Anti-inflammatory effects of heparin: do they influence murine acute GVHD? Jacobs J Hemato 2, 023

Cahn JY, Klein JP, Lee SJ, Milpied N, Blaise D, Antin JH, Leblond V, Ifrah N, Jouet JP, Loberiza $\mathrm{F}$ et al. (2005): Prospective evaluation of 2 acute graft-versus-host (GVHD) grading systems: a joint Societe Francaise de Greffe de Moelle et Therapie Cellulaire (SFGM-TC), Dana Farber Cancer Institute (DFCl), and International Bone Marrow Transplant Registry (IBMTR) prospective study. Blood 106, 1495-1500

Celasco G, Papa A, Jones R, Moro L, Bozzella R, Surace MM, Naccari GC, Gasbarrini G (2010): Clinical trial: oral colon-release parnaparin sodium tablets (CB-01-05 MMX) for active left-sided ulcerative colitis. Aliment Pharmacol Ther $\underline{31}$, 375-386

Chande N, McDonald JW, Macdonald JK, Wang JJ (2010): Unfractionated or lowmolecular weight heparin for induction of remission in ulcerative colitis. Cochrane Database Syst Rev 2010, CD006774 
Choay J, Petitou M, Lormeau JC, Sinay P, Casu B, Gatti G (1983): Structure-activity relationship in heparin: a synthetic pentasaccharide with high affinity for antithrombin III and eliciting high anti-factor Xa activity. Biochem Biophys Res Commun 116, 492-499

Coghill JM, Sarantopoulos S, Moran TP, Murphy WJ, Blazar BR, Serody JS (2011): Effector CD4+ T cells, the cytokines they generate, and GVHD: something old and something new. Blood 117, 3268-3276

Constant S, Schweitzer N, West J, Ranney P, Bottomly K (1995): B lymphocytes can be competent antigen-presenting cells for priming CD4+ T cells to protein antigens in vivo. $\mathrm{J}$ Immunol 155, 3734-3741

Costantino G, Ceriani E, Rusconi AM, Podda GM, Montano N, Duca P, Cattaneo M, Casazza $G$ (2012): Bleeding risk during treatment of acute thrombotic events with subcutaneous LMWH compared to intravenous unfractionated heparin; a systematic review. PLoS One $\underline{7}$, e44553

Croft M, Joseph SB, Miner KT (1997): Partial activation of naive CD4 T cells and tolerance induction in response to peptide presented by resting B cells. J Immunol $\underline{159}$, 3257-3265

Cutler C, Giri S, Jeyapalan S, Paniagua D, Viswanathan A, Antin JH (2001): Acute and chronic graft-versus-host disease after allogeneic peripheral-blood stem-cell and bone marrow transplantation: a meta-analysis. J Clin Oncol 19, 3685-3691

Dal Pozzo A, Acquasaliente M, Geron MR, Andriuoli G (1989): New heparin complexes active by intestinal absorption: I-multiple ion pairs with basic organic compounds. Thromb Res $\underline{56}, 119-124$

de Bièvre MA, Vrij AA, Schoon EJ, Dijkstra G, de Jong AE; Oberndorff-Klein Woolthuis $\mathrm{AH}$, Hemker HC, Stockbrügger RW (2007): Randomized, placebo-controlled trial of low molecular weight heparin in active ulcerative colitis. Inflamm Bowel Dis $\underline{13}, 753-758$

Dolowitz DA, Dougherty TF (1960): The use of heparin as an anti-inflammatory agent. Laryngoscope $\underline{70}$, 873-884

Dumont N, Aubin E, Proulx DP, Lemieux R, Bazin R (2009): Increased secretion of hyperimmune antibodies following lipopolysaccharide stimulation of CD40-activated human B cells in vitro. Immunology $\underline{126}$, 588-595

Eapen M, Logan BR, Appelbaum FR, Antin JH, Anasetti C, Couriel DR, Chen J, Maziarz RT, McCarthy PL, Nakamura R et al. (2015): Long-term survival after transplantation of unrelated donor peripheral blood or bone marrow hematopoietic cells for hematologic malignancy. Biol Blood Marrow Transplant 21, 55-59

Evans RC, Wong VS, Morris AI, Rhodes JM (1997): Treatment of corticosteroid-resistant ulcerative colitis with heparin: a report of 16 cases. Aliment Pharmacol Ther $\underline{11}$, 10371040

Ferrara JLM, Reddy P (2006): Pathophysiology of graft-versus-host disease. Semin Hematol $\underline{43}, 3-10$

Ferrara JLM, Levine JE, Reddy P, Holler E (2009): Graft-versus-host disease. Lancet $\underline{373}, 1550-1561$

Filipovich AH, Weisdorf D, Pavletic S, Socie G, Wingard JR, Lee SJ, Martin P, Chien J, Przepiorka D, Couriel D et al. (2005): National Institutes of Health consensus development project on criteria for clinical trials in chronic graft-versus-host disease: I. diagnosis and staging working group report. Biol Blood Marrow Transplant 11, 945-956 
Finke J, Bethge WA, Schmoor C, Ottinger HD, Stelljes M, Zander AR, Volin L, Ruutu T, Heim DA, Schwerdtfeger R et al. (2009): Standard graft-versus-host disease prophylaxis with or without anti-T-cell globulin in haematopoietic cell transplantation from matched unrelated donors: a randomised, open-label, multicentre phase 3 trial. Lancet Oncol $\underline{10}$, 855-864

Flowers MED, Pepe MS, Longton G, Doney KC, Monroe D, Witherspoon RP, Sullivan KM, Storb R (1990): Previous donor pregnancy as a risk factor for acute graft-versushost disease in patients with aplastic anaemia treated by allogeneic marrow transplantation. Br J Haematol 74, 492-496

Flowers MED, Inamoto Y, Carpenter PA, Lee SJ, Kiem HP, Petersdorf EW, Pereira SE, Nash RA, Mielcarek M, Fero ML et al. (2011): Comparative analysis of risk factors for acute graft-versus-host disease and for chronic graft-versus-host disease according to National Institutes of Health consensus criteria. Blood 117, 3214-3219

Folwaczny C, Wiebecke B, Loeschke K (1999): Unfractioned heparin in the therapy of patients with highly active inflammatory bowel disease. Am J Gastroenterol 94, 15511555

Fu L, Li G, Yang B, Onishi A, Li L, Sun P, Zhang F, Linhardt RJ (2013): Structural characterization of pharmaceutical heparins prepared from different animal tissues. J Pharm Sci $\underline{102}, 1447-1457$

Gaffney PR, Doyle CT, Gaffney A, Hogan J, Hayes DP, Annis P (1995): Paradoxical response to heparin in 10 patients with ulcerative colitis. Am J Gastroenterol $\underline{90}, 220$ 223

Gale RP, Bortin MM, Bekkum DW, Biggs JC, Dicke KA, Gluckman E, Good RA, Hoffmann RG, Kay HEM, Kersey JH et al. (1987): Risk factors for acute graft-versus-host disease. Br J Haematol 67, 397-406

Garcia DA, Baglin TP, Weitz JI, Samama MM (2012): Parenteral anticoagulants: antithrombotic therapy and prevention of thrombosis, 9th ed: American College of Chest Physicians Evidence-Based Clinical Practice Guidelines. Chest 141, e24S-43S

Gatti RA, Meuwissen HJ, Allen HD, Hong R, Good RA (1968): Immunological reconstitution of sex-linked lymphopenic immunological deficiency. Lancet 292, 1366-1369

GE Healthcare (2007): Ficoll-Paque PLUS. https://cdn.cytivali-

fesciences.com/dmm3bwsv3/AssetStream.aspx?mediaformatid=10061\&destinationid=10016\&assetid=12637; abgerufen am 24.07.2020

Ginhoux F, Jung S (2014): Monocytes and macrophages: developmental pathways and tissue homeostasis. Nat Rev Immunol 14, 392-404

Giralt S, Estey E, Albitar M, van Besien K, Rondón G, Anderlini P, O'Brien S, Khouri I, Gajewski J, MehraRakesh et al. (1997): Engraftment of allogeneic hematopoietic progenitor cells with purine analog-containing chemotherapy: harnessing graft-versus-leukemia without myeloablative therapy. Blood 89, 4531-4536

Glucksberg H, Storb R, Fefer A, Buckner CD, Neiman PE, Clift RA, Lerner KG, Thomas ED (1974): Clinical manifestations of graft-versus-host disease in human recipients of marrow from HLA-matched sibling donors. Transplantation 18, 295-304

Graubert TA, DiPersio JF, Russell JH, Ley TJ (1997): Perforin/granzyme-dependent and independent mechanisms are both important for the development of graft-versus-host disease after murine bone marrow transplantation. J Clin Invest $\underline{100}$, 904-911 
Gray E: Standardisation of unfractionated and low-molecular-weight heparin. In: Lever R, Mulloy B, Page CP (Hrsg.): Heparin: A century of progress (Handb Exp Pharmacol). Springer, Berlin 2012, 65-76

Hänsel R, Sticher O (Hrsg.): Pharmakognosie Phytopharmazie. 7. Auflage; Springer, Berlin 2006

Hatzimichael E, Tuthill M (2010): Hematopoietic stem cell transplantation. Stem Cells Cloning $\underline{3}, 105-117$

Hill GR, Crawford JM, Cooke KR, Brinson YS, Pan L, Ferrara JL (1997): Total body irradiation and acute graft-versus-host disease: the role of gastrointestinal damage and

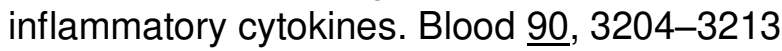

Hill GR, Ferrara JL (2000): The primacy of the gastrointestinal tract as a target organ of acute graft-versus-host disease: rationale for the use of cytokine shields in allogeneic bone marrow transplantation. Blood $\underline{95}, 2754-2759$

Hirsh J, Levine MN (1992): Low molecular weight heparin. Blood $\underline{79}$, 1-17

Hirsh J, Warkentin TE, Shaughnessy SG, Anand SS, Halperin JL, Raschke R, Granger C, Ohman EM, Dalen JE (2001a): Heparin and low-molecular-weight heparin mechanisms of action, pharmacokinetics, dosing, monitoring, efficacy, and safety. Chest $\underline{119}$, 64S-94S

Hirsh J, Anand SS, Halperin JL, Fuster V (2001b): Guide to anticoagulant therapy: Heparin: A statement for healthcare professionals from the American Heart Association. Circulation 103, 2994-3018

Hochart H, Jenkins PV, Smith OP, White B (2006): Low-molecular weight and unfractionated heparins induce a downregulation of inflammation: decreased levels of proinflammatory cytokines and nuclear factor-kappaB in LPS-stimulated human monocytes. $\mathrm{Br} \mathrm{J}$ Haematol $\underline{133}, 62-67$

Hockenbery DM, Cruickshank S, Rodell TC, Gooley T, Schuening F, Rowley S, David D, Brunvand M, Berryman B, Abhyankar S et al. (2007): A randomized, placebo-controlled trial of oral beclomethasone dipropionate as a prednisone-sparing therapy for gastrointestinal graft-versus-host disease. Blood 109, 4557-4563

Holowiecki J (2008): Indications for hematopoietic stem cell transplantation. Pol Arch Med Wewn 118, 658-663

Horowitz MM, Gale RP, Sondel PM, Goldman JM, Kersey J, Kolb HJ, Rimm AA, Ringden O, Rozman C, Speck B (1990): Graft-versus-leukemia reactions after bone marrow transplantation. Blood $\underline{75}, 555-562$

Horrow JC (1985): Protamine: a review of its toxicity. Anesth Analg $\underline{64}$, 348-361

Huang JN, Tsai MC, Fang SL, Chang MDT, Wu YR, Tsai JJ, Fu LS, Lin HK, Chen YJ, Li TW (2014): Low-molecular-weight heparin and unfractionated heparin decrease Th-1, 2, and 17 expressions. PLoS One $\underline{9}$, e109996

Ibrahim RB, Abidi MH, Cronin SM, Lum LG, Al-Kadhimi Z, Ratanatharathorn V, Uberti JP (2009): Nonabsorbable corticosteroids use in the treatment of gastrointestinal graftversus-host disease. Biol Blood Marrow Transplant 15, 395-405

Iori AP, Torelli GF, de Propris MS, Milano F, Pupella S, Gozzer M, Mancini F, Milani ML, Intoppa S, Cerretti R et al. (2008): B-cell concentration in the apheretic product predicts acute graft-versus-host disease and treatment-related mortality of allogeneic peripheral blood stem cell transplantation. Transplantation $\underline{85}, 386-390$ 
Jagasia M, Arora M, Flowers MED, Chao NJ, McCarthy PL, Cutler CS, Urbano-Ispizua A, Pavletic SZ, Haagenson MD, Zhang MJ et al. (2012): Risk factors for acute GVHD and survival after hematopoietic cell transplantation. Blood 119, 296-307

Jiang LB, Ma YF, Feng X, Zhang M (2015): Can heparin therapy reduce 28-day mortality in adult severe sepsis patients? Crit Care $\underline{19}, 66$

Jin JF, Zhu LI, Chen M, Xu HM, Wang HF, Feng XQ, Zhu XP, Zhou Q (2015): The optimal choice of medication administration route regarding intravenous, intramuscular, and subcutaneous injection. Patient Prefer Adherence $\underline{9}$, 923-942

Kanda J, Lopez RD, Rizzieri DA (2011): Alemtuzumab for the prevention and treatment of graft-versus-host disease. Int J Hematol 93, 586-593

Koenig A, Norgard-Sumnicht K, Linhardt R, Varki A (1998): Differential interactions of heparin and heparan sulfate glycosaminoglycans with the selectins. Implications for the use of unfractionated and low molecular weight heparins as therapeutic agents. J Clin Invest 101, 877-889

Korbling M, Dorken B, Ho AD, Pezzutto A, Hunstein W, Fliedner TM (1986): Autologous transplantation of blood-derived hemopoietic stem cells after myeloablative therapy in a patient with Burkitt's lymphoma. Blood $\underline{67}, 529-532$

Korbling M, Holle R, Haas R, Knauf W, Dorken B, Ho AD, Kuse R, Pralle H, Fliedner TM, Hunstein W (1990): Autologous blood stem-cell transplantation in patients with advanced Hodgkin's disease and prior radiation to the pelvic site. J Clin Oncol $\underline{8}, 978-985$

Larosa DF, Orange JS (2008): 1. Lymphocytes. J Allergy Clin Immunol 121, S364-369

Li B, Yan New J, Hian Yap E, Lu J, Ha Chan S, Hu H (2001): Blocking L-selectin and a4integrin changes donor cell homing pattern and ameliorates murine acute graft versus host disease. Eur J Immunol $\underline{31}, 617-624$

Lu SX, Palomba ML, Na IK, Terwey TH, Alpdogan O, Bautista JL, Smith M, Suh D, King CG, Rao UK et al. (2010a): P-selectin regulates leukocyte trafficking and experimental graft-versus-host-disease after allogeneic bone marrow transplantation. Biol Blood Marrow Transplant 16, S307-S308

Lu SX, Holland AM, Na IK, Terwey TH, Alpdogan O, Bautista JL, Smith OM, Suh D, King C, Kochman A et al. (2010b): Absence of P-selectin in recipients of allogeneic bone marrow transplantation ameliorates experimental graft-versus-host disease. J Immunol $\underline{185}, 1912-1919$

Luckheeram RV, Zhou R, Verma AD, Xia B (2012): CD4+T cells: Differentiation and functions. Clin Dev Immunol 2012, 925135

Ludwig RJ, Boehme B, Podda M, Henschler R, Jager E, Tandi C, Boehncke WH, Zollner TM, Kaufmann R, Gille J (2004): Endothelial P-selectin as a target of heparin action in experimental melanoma lung metastasis. Cancer Res $\underline{64}, 2743-2750$

MacMillan ML, Weisdorf DJ, Wagner JE, DeFor TE, Burns LJ, Ramsay NKC, Davies SM, Blazar BR (2002): Response of 443 patients to steroids as primary therapy for acute graft-versus-host disease: comparison of grading systems. Biol Blood Marrow Transplant $\underline{8}, 387-394$

Maeda Y, Levy RB, Reddy P, Liu C, Clouthier SG, Teshima T, Ferrara JLM (2005): Both perforin and Fas ligand are required for the regulation of alloreactive CD8+ T cells during acute graft-versus-host disease. Blood $\underline{105}$, 2023-2027 
Martin PJ, Hansen JA, Anasetti C, Zutter M, Durnam D, Storb R, Thomas ED (1988): Treatment of acute graft-versus-host disease with anti-CD3 monoclonal antibodies. Am J Kidney Dis 11, 149-152

Martin PJ, Schoch G, Fisher L, Byers V, Anasetti C, Appelbaum FR, Beatty PG, Doney K, McDonald GB, Sanders JE (1990): A retrospective analysis of therapy for acute graftversus-host disease: initial treatment. Blood $\underline{76}, 1464-1472$

Martin PJ, Inamoto Y, Flowers MED, Carpenter PA (2012a): Secondary treatment of acute graft-versus-host disease: a critical review. Biol Blood Marrow Transplant 18, 982988

Martin PJ, Rizzo JD, Wingard JR, Ballen K, Curtin PT, Cutler C, Litzow MR, Nieto Y, Savani BN, Schriber JR et al. (2012b): First- and second-line systemic treatment of acute graft-versus-host disease: recommendations of the American Society of Blood and Marrow Transplantation. Biol. Blood Marrow Transplant. 18, 1150-1163

Matsuda S, Koyasu S (2000): Mechanisms of action of cyclosporine. Immunopharmacology $\underline{47}, 119-125$

Mattern T, Thanhäuser A, Reiling N, Toellner KM, Duchrow M, Kusumoto S, Rietschel ET, Ernst M, Brade H, Flad HD (1994): Endotoxin and lipid A stimulate proliferation of human T cells in the presence of autologous monocytes. J Immunol $\underline{153}, 2996-3004$

Mattern T, Flad HD, Brade L, Rietschel ET, Ulmer AJ (1998): Stimulation of human T lymphocytes by LPS is MHC unrestricted, but strongly dependent on B7 interactions. $\mathrm{J}$ Immunol 160, 3412-3418

Michonneau D, Peffault de Latour R, Porcher R, Robin M, Benbunan M, Rocha V, Ribaud P, Ferry C, Devergie A, Vanneaux V et al. (2009): Influence of bone marrow graft B lymphocyte subsets on outcome after HLA-identical sibling transplants. $\mathrm{Br} \mathrm{J}$ Haematol $\underline{145}, 107-114$

Miltenyi S, Müller W, Weichel W, Radbruch A (1990): High gradient magnetic cell separation with MACS. Cytometry $\underline{11}, 231-238$

Moghadam-Kia S, Werth VP (2010): Prevention and treatment of systemic glucocorticoid side effects. Int J Dermatol $\underline{49}$, 239-248

Naparstek E, Slavin S, Weiss L, Sidi H, Ohana M, Reich S, Vlodavsky I, Cohen IR, Naparstek $Y$ (1993): Low-dose heparin inhibits acute graft versus host disease in mice. Bone Marrow Transplant 12, 185-189

Nash RA, Antin JH, Karanes C, Fay JW, Avalos BR, Yeager AM, Przepiorka D, Davies S, Petersen FB, Bartels $P$ et al. (2000): Phase 3 study comparing methotrexate and tacrolimus with methotrexate and cyclosporine for prophylaxis of acute graft-versus-host disease after marrow transplantation from unrelated donors. Blood 96, 2062-2068

Nelson RM, Cecconi O, Roberts WG, Aruffo A, Linhardt RJ, Bevilacqua MP (1993): Heparin oligosaccharides bind L- and P-selectin and inhibit acute inflammation. Blood $\underline{82}$, 3253-3258

Niederwieser D, Maris M, Shizuru JA, Petersdorf E, Hegenbart U, Sandmaier BM, Maloney DG, Storer B, Lange T, Chauncey T et al. (2003): Low-dose total body irradiation (TBI) and fludarabine followed by hematopoietic cell transplantation (HCT) from HLAmatched or mismatched unrelated donors and postgrafting immunosuppression with cyclosporine and mycophenolate mofetil (MMF) can induce durable complete chimerism and sustained remissions in patients with hematological diseases. Blood 101, 16201629 
Onkopedia (2020): Graft-versus-Host Erkrankung, akut. Onkopedia Leitlinie der Deutschen Arbeitsgemeinschaft für Knochenmark- und Blutstammzelltransplantation e.V. https://www.onkopedia.com/de/onkopedia/guidelines/graft-versus-host-erkrankungakut/@@guideline/html/index.html; abgerufen am 06.04.2020

Page C (2013): Heparin and related drugs: beyond anticoagulant activity. ISRN Pharmacol 2013, 910743

Panés J, Esteve M, Cabré E, Hinojosa J, Andreu M, Sans M, Fernandez-Bañares F, Feu F, Gassull MA, Piqué JM (2000): Comparison of heparin and steroids in the treatment of moderate and severe ulcerative colitis. Gastroenterology $\underline{119}$, 903-908

Papert S: New approaches to improve extracorporeal photopheresis for the treatment of graft-versus-host disease. Biol. Diss. Göttingen 2016

Passweg JR, Baldomero H, Bader P, Bonini C, Cesaro S, Dreger P, Duarte RF, Dufour C, Kuball J, Farge-Bancel D et al. (2016): Hematopoietic stem cell transplantation in Europe 2014: more than 40000 transplants annually. Bone Marrow Transplant $\underline{51}$, 786792

Pavletic SZ, Fowler DH (2012): Are we making progress in GVHD prophylaxis and treatment? Hematology Am Soc Hematol Educ Program 2012, 251-264

Penas PF, Fernandez-Herrera J, Garcia-Diez A (2004): Dermatologic treatment of cutaneous graft versus host disease. Am J Clin Dermatol $\underline{5}$, 403-416

Pidala J, Tomblyn M, Nishihori T, Ayala E, Field T, Fernandez H, Perez L, Locke F, Alsina M, Ochoa JL et al. (2011): ATG prevents severe acute graft-versus-host disease in mismatched unrelated donor hematopoietic cell transplantation. Biol Blood Marrow Transplant 17, 1237-1244

Rao NV, Argyle B, Xu X, Reynolds PR, Walenga JM, Prechel M, Prestwich GD, MacArthur RB, Walters BB, Hoidal JR et al. (2010): Low anticoagulant heparin targets multiple sites of inflammation, suppresses heparin-induced thrombocytopenia, and inhibits interaction of RAGE with its ligands. Am J Physiol Cell Physiol 299, C97-110

Ratiopharm GmbH (2017): Fachinformation Heparin-Natrium-5000-ratiopharm® (Ampullen/Fertigspritzen). https://www.fachinfo.de/suche/fi/009608; abgerufen am 15.07.2020

Ruutu T, van Biezen A, Hertenstein B, Henseler A, Garderet L, Passweg J, Mohty M, Sureda A, Niederwieser D, Gratwohl A et al. (2012): Prophylaxis and treatment of GVHD after allogeneic haematopoietic SCT: a survey of centre strategies by the European Group for Blood and Marrow Transplantation. Bone Marrow Transplant 47, 1459-1464

Ruutu T, Gratwohl A, de Witte T, Afanasyev B, Apperley J, Bacigalupo A, Dazzi F, Dreger P, Duarte R, Finke J et al. (2014): Prophylaxis and treatment of GVHD: EBMT-ELN working group recommendations for a standardized practice. Bone Marrow Transplant $\underline{49}$, 168-173

Sanofi-Aventis Deutschland GmbH (2015): Fachinformation Clexane 60 mg/80 mg/100 mg Fertigspritzen Sanofi. https://mein.sanofi.de/produkte/Clexane/Downloads?id=4faf1244-1dcf-4675-ad93-78d916d97c10; abgerufen am 09.07.2017

Schacke H, Docke WD, Asadullah K (2002): Mechanisms involved in the side effects of glucocorticoids. Pharmacol Ther $\underline{96}, 23-43$

Schroeder MA, DiPersio JF (2011): Mouse models of graft-versus-host disease: advances and limitations. Dis Model Mech 4 , 318-333 
Schultz KR, Paquet J, Bader S, HayGlass KT (1995): Requirement for B cells in T cell priming to minor histocompatibility antigens and development of graft-versus-host disease. Bone Marrow Transplant 16, 289-295

Seeds EAM, Horne AP, Tyrrell DJ, Page CP (1995): The effect of inhaled heparin and related glycosaminoglycans on allergen-induced eosinophil infiltration in guinea-pigs. Pulm Pharmacol $\underline{8}$, 97-105

Shen J, Ran ZH, Tong JL, Xiao SD (2007): Meta-analysis: the utility and safety of heparin in the treatment of active ulcerative colitis. Aliment Pharmacol Ther $\underline{26}, 653-663$

Shimabukuro-Vornhagen A, Hallek MJ, Storb RF, von Bergwelt-Baildon MS (2009): The role of B cells in the pathogenesis of graft-versus-host disease. Blood 114, 4919-4927

Shizuru JA, Negrin RS, Weissman IL (2005): Hematopoietic stem and progenitor cells: clinical and preclinical regeneration of the hematolymphoid system. Annu Rev Med $\underline{56}$, 509-538

Shlomchik WD, Couzens MS, Tang CB, McNiff J, Robert ME, Liu J, Shlomchik MJ, Emerson SG (1999): Prevention of graft versus host disease by inactivation of host antigenpresenting cells. Science $\underline{285}, 412-415$

Shlomchik WD (2007): Graft-versus-host disease. Nat Rev Immunol 푸 340-352

Simonis D, Christ K, Alban S, Bendas G (2007): Affinity and kinetics of different heparins binding to P- and L-selectin. Semin Thromb Hemost $\underline{33}$, 534-539

Socie G, Schmoor C, Bethge WA, Ottinger HD, Stelljes M, Zander AR, Volin L, Ruutu T, Heim DA, Schwerdtfeger R et al. (2011): Chronic graft-versus-host disease: long-term results from a randomized trial on graft-versus-host disease prophylaxis with or without anti-T-cell globulin ATG-Fresenius. Blood 117, 6375-6382

Sorror ML, Sandmaier BM, Storer BE, Franke GN, Laport GG, Chauncey TR, Agura E, Maziarz RT, Langston A, Hari $P$ et al. (2011): Long-term outcomes among older patients following nonmyeloablative conditioning and allogeneic hematopoietic cell transplantation for advanced hematologic malignancies. JAMA $\underline{306}, 1874-1883$

Sprent J, Schaefer M, Korngold R (1990): Role of T cell subsets in lethal graft-versushost disease (GVHD) directed to class I versus class II H-2 differences. II. Protective effects of L3T4+ cells in anti-class II GVHD. J Immuno. 144, 2946-2954

Springer TA (1994): Traffic signals for lymphocyte recirculation and leukocyte emigration: The multistep paradigm. Cell $\underline{76}, 301-314$

Stevenson JL, Choi SH, Varki A (2005): Differential metastasis inhibition by clinically relevant levels of heparins: correlation with selectin inhibition, not antithrombotic activity. Clin Cancer Res 11, 7003-7011

Storb R, Deeg HJ, Whitehead J, Appelbaum F, Beatty P, Bensinger W, Buckner CD, Clift R, Doney K, Farewell V (1986): Methotrexate and cyclosporine compared with cyclosporine alone for prophylaxis of acute graft versus host disease after marrow transplantation for leukemia. N Engl J Med 314, 729-735

Storb R, Deeg HJ, Fisher L, Appelbaum F, Buckner CD, Bensinger W, Clift R, Doney K, Irle C, McGuffin R (1988): Cyclosporine v methotrexate for graft-v-host disease prevention in patients given marrow grafts for leukemia: long-term follow-up of three controlled trials. Blood $\underline{71}, 293-298$ 
Sullivan KM, Deeg HJ, Sanders J, Klosterman A, Amos D, Shulman H, Sale G, Martin P, Witherspoon R, Appelbaum F (1986): Hyperacute graft-v-host disease in patients not given immunosuppression after allogeneic marrow transplantation. Blood $\underline{67}, 1172-1175$

Teshima T, Ordemann R, Reddy P, Gagin S, Liu C, Cooke KR, Ferrara JLM (2002): Acute graft-versus-host disease does not require alloantigen expression on host epithelium. Nat Med $\underline{8}, 575-581$

Thermo Fisher Scientific (2017): Technical Data Sheet: Cell Proliferation Dye eFluor ${ }^{\mathrm{TM}}$ 450. https://www.thermofisher.com/document-connect/documentconnect.html?url=https\%3A\%2F\%2Fassets.thermofisher.com\%2FTFS-Assets\%2FLSG\%2Fmanuals\%2F65-0842.pdf\&title=VGVjaG5pY2FsIERhdGEgU2hIZXQ6IENIbGwgUHJvbGImZXJhdGIvbiBEeWUgZUZsdW9yJnRyYWRIOyAONTA=; abgerufen am 1.4.2020

Tischner D, Theiss J, Karabinskaya A, van den Brandt J, Reichardt SD, Karow U, Herold MJ, Lühder F, Utermöhlen O, Reichardt HM (2011): Acid sphingomyelinase is required for protection of effector memory $T$ cells against glucocorticoid-induced cell death. J Immunol $\underline{187}, 4509-4516$

Tough DF, Sun S, Sprent J (1997): T cell stimulation in vivo by lipopolysaccharide (LPS). J Exp Med 185, 2089-2094

Truitt RL, Atasoylu AA (1991): Contribution of CD4+ and CD8+ T cells to graft-versushost disease and graft-versus-leukemia reactivity after transplantation of MHC-compatible bone marrow. Bone Marrow Transplant $\underline{8}, 51-58$

Ulmer AJ, Flad HD, Rietschel T, Mattern T (2000): Induction of proliferation and cytokine production in human T lymphocytes by lipopolysaccharide (LPS). Toxicology 152, 3745

van Belle K, Herman J, Boon L, Waer M, Sprangers B, Louat T (2016): Comparative in vitro immune stimulation analysis of primary human $B$ cells and $B$ cell lines. J Immunol Res $\underline{2016}, 5281823$

van Lint MT, Uderzo C, Locasciulli A, Majolino I, Scime R, Locatelli F, Giorgiani G, Arcese W, lori AP, Falda M et al. (1998): Early treatment of acute graft-versus-host disease with high- or low-dose 6-methylprednisolone: a multicenter randomized trial from the Italian Group for Bone Marrow Transplantation. Blood 92, 2288-2293

Vaure C, Liu Y (2014): A comparative review of toll-like receptor 4 expression and functionality in different animal species. Front Immunol $\underline{5}, 316$

Walenga JM, Petitou M, Lormeau JC, Samama M, Fareed J, Choay J (1987): Antithrombotic activity of a synthetic heparin pentasaccharide in a rabbit stasis thrombosis model using different thrombogenic challenges. Thromb Res $\underline{46}, 187-198$

Wang C, Chi C, Guo L, Wang X, Guo L, Sun J, Sun B, Liu S, Chang X, Li E (2014): Heparin therapy reduces 28 -day mortality in adult severe sepsis patients: a systematic review and meta-analysis. Crit Care $\underline{18}, 563$

Wang J, Zhan P, Ouyang J, Chen B, Zhou R, Yang Y (2010): Unrelated donor umbilical cord blood transplantation versus unrelated donor bone marrow transplantation in adult and pediatric patients: a meta-analysis. Leuk Res $\underline{34}, 1018-1022$

Wang XF, Li AM, Li J, Lin SY, Chen CD, Zhou YL, Wang X, Chen Cl, Liu SD, Chen Y (2013): Low molecular weight heparin relieves experimental colitis in mice by downregulating IL-1beta and inhibiting syndecan-1 shedding in the intestinal mucosa. PLoS One $\underline{8}, \mathrm{e} 66397$ 
Wardrop D, Keeling D (2008): The story of the discovery of heparin and warfarin. $\mathrm{Br} \mathrm{J}$ Haematol $\underline{141}, 757-763$

Weitz JI (1997): Low-molecular-weight heparins. N Engl J Med 337, 688-698

Westin JR, Saliba RM, de Lima M, Alousi A, Hosing C, Qazilbash MH, Khouri IF, Shpall EJ, Anderlini P, Rondon G et al. (2011): Steroid-refractory acute GVHD: predictors and outcomes. Adv Hematol 2011, 601953

Wolff D, Ayuk F, Elmaagacli A, Bertz H, Lawitschka A, Schleuning M, Meyer RG, Gerbitz A, Hilgendorf I, Hildebrandt GC et al. (2013): Current practice in diagnosis and treatment of acute graft-versus-host disease: results from a survey among German-Austrian-Swiss hematopoietic stem cell transplant centers. Biol Blood Marrow Transplant $\underline{19}$, 767-776

Wood RM, Bick MW (1959): A comparison of the influence of parenteral trypsin, cortisone, and heparin on acute inflammation. AMA Arch Ophthalmol 62, 112-116

Xu H, Liew LN, Kuo IC, Huang CH, Goh DLM, Chua KY (2008): The modulatory effects of lipopolysaccharide-stimulated $B$ cells on differential T-cell polarization. Immunology $\underline{125}, 218-228$

Xun CQ, Thompson JS, Jennings CD, Brown SA, Widmer MB (1994): Effect of total body irradiation, busulfan-cyclophosphamide, or cyclophosphamide conditioning on inflammatory cytokine release and development of acute and chronic graft-versus-host disease in H-2-incompatible transplanted SCID mice. Blood 83, 2360-2367

Young $E$ (2008): The anti-inflammatory effects of heparin and related compounds. Thromb Res $\underline{122}, 743-752$

Zarychanski R, Abou-Setta AM, Kanji S, Turgeon AF, Kumar A, Houston DS, Rimmer E, Houston BL, Mclntyre L, Fox-Robichaud AE et al. (2015): The efficacy and safety of heparin in patients with sepsis: a systematic review and metaanalysis. Crit Care Med $\underline{43}$, 511-518

Zezos P, Papaioannou G, Nikolaidis N, Patsiaoura K, Papageorgiou A, Vassiliadis T, Giouleme O, Evgenidis N (2006): Low-molecular-weight heparin (enoxaparin) as adjuvant therapy in the treatment of active ulcerative colitis: a randomized, controlled, comparative study. Aliment Pharmacol Ther $\underline{23}$, 1443-1453

Zubler RH, Werner-Favre C, Wen L, Sekita K, Straub C (1987): Theoretical and practical aspects of B-cell activation: murine and human systems. Immunol Rev $\underline{99}$, 281-299 


\section{Danksagung}

Für die freundliche Unterstüzung und hilfsbereite sowie konstruktive Betreuung dieser Arbeit danke ich Herrn Prof. Dr. med. Tobias Legler.

Sehr dankbar bin ich Herrn Dr. rer. nat. Holger Budde für die intensive Betreuung meiner Dissertation. Sein Ideenreichtum und seine zahlreichen Anregungen für die Versuchsgestaltung haben mir die Durchführung und das Schreiben dieser Arbeit wesentlich erleichtert.

Herzlich möchte ich mich auch bei Susanne Papert und Marie-Sophie Sorns für die Unterstützung bei allen experimentellen Arbeiten und die schöne Zeit im Labor bedanken. 